\title{
Implementation of shared decision making in breast cancer care
}

Citation for published version (APA):

Savelberg - Pasmans, W. J. P. G. (2019). Implementation of shared decision making in breast cancer care: towards placing the next pieces of the puzzle. [Doctoral Thesis, Maastricht University]. Gildeprint Drukkerijen. https://doi.org/10.26481/dis.20190606wsp

Document status and date:

Published: 01/01/2019

DOI:

10.26481/dis.20190606wsp

Document Version:

Publisher's PDF, also known as Version of record

\section{Please check the document version of this publication:}

- A submitted manuscript is the version of the article upon submission and before peer-review. There can be important differences between the submitted version and the official published version of record.

People interested in the research are advised to contact the author for the final version of the publication, or visit the DOI to the publisher's website.

- The final author version and the galley proof are versions of the publication after peer review.

- The final published version features the final layout of the paper including the volume, issue and page numbers.

Link to publication

\footnotetext{
General rights rights.

- You may freely distribute the URL identifying the publication in the public portal. please follow below link for the End User Agreement:

www.umlib.nl/taverne-license

Take down policy

If you believe that this document breaches copyright please contact us at:

repository@maastrichtuniversity.nl

providing details and we will investigate your claim.
}

Copyright and moral rights for the publications made accessible in the public portal are retained by the authors and/or other copyright owners and it is a condition of accessing publications that users recognise and abide by the legal requirements associated with these

- Users may download and print one copy of any publication from the public portal for the purpose of private study or research.

- You may not further distribute the material or use it for any profit-making activity or commercial gain

If the publication is distributed under the terms of Article $25 \mathrm{fa}$ of the Dutch Copyright Act, indicated by the "Taverne" license above, 
Implementation of shared decision making in breast cancer care; towards placing the next pieces of the puzzle

Wilma Savelberg-Pasmans 
The research in this thesis was conducted at the School for Public Health and Primary Care: CAPHRI, department Family Practice at Maastricht University. CAPHRI participates in the Netherlands School of Primary Care Research (CaRe), acknowledged by the Royal Dutch Academy of Science (KNAW). CAPHRI was classified as 'excellent' by the external evaluation committee of leading international experts that reviewed CAPHRI in December 2010.

The studies in this thesis were supported by grants from Pink Ribbon grant number 2012.PS23.C152: 'A pre-implementation and post-implementation study on shared decision-making in the surgical treatment of women with earlystage breast cancer', and Alpe d'Huzes KWF, grant number MAC2014-7024: 'The challenge of implementing Shared Decision Making to personalize choices for loco regional treatment and its follow-up of breast cancer patients'.

\section{COLOFON}

Cover design and lay out: Clim Sorée

Production: Gildeprint drukkerijen www.gildeprint.nl

(C) Copyright: Wilma Savelberg-Pasmans, Maastricht 2019 ISBN:

9789463236102 


\title{
Implementation of shared decision making in breast cancer care; towards placing the next pieces of the puzzle
}

\author{
Proefschrift
}

Ter verkrijging van de graad van doctor aan de Universiteit Maastricht, op gezag van Rector Magnificus, Prof. dr. Rianne M. Letschert, volgens het besluit van het College van Decanen, in het openbaar te verdedigen op donderdag 6 juni 2019, om 16.00 uur.

Door

Wilma Johanna Petra Gerarda Savelberg-Pasmans 


\section{Promotores}

Prof. dr. T. van der Weijden

Prof. dr. L. Boersma

\section{Co-promotor}

Dr. M. Smidt

\section{Beoordelingscommissie}

Prof. dr. B. Kremer (voorzitter)

Prof. dr. G. Bos

Prof. dr. H. Vermeulen (RadboudUMC) Dr. S. Engelen

Dr. A. Jie (Zuijderland MC) 


\section{Index}

Chapter 1

9

General introduction

Chapter 2

Developing a patient decision aid for the treatment of women with early stage breast cancer: the struggle between simplicity and complexity.

\section{Chapter 3}

Protocol for a pre-post implementation study on shared decision making in the surgical treatment of women with early stage breast cancer.

\section{Chapter 4}

Integrating a patient decision aid in a clinical pathway; a process evaluation among breast cancer care teams with a favourable attitude towards shared decision making.

\section{Chapter 5}

There is progress in sharing decisions with patients, although the second half of the shared decision making process needs attention.

\section{Chapter 6}

Does lack of deeper understanding explain the suboptimal performance on crucial parts of shared decision making?

\section{Chapter 7}

General discussion

Summary

Valorisation 


\section{General introduction}

Hanna was diagnosed with early stage breast cancer at the age of 46 years. Fortunately, the tumor was small, no metastases were found and she could easily be treated with breast conserving therapy. However, she chose for a mastectomy. When she was asked for her motive for this preference she explained: "10 years ago my mother was diagnosed with breast cancer. She chose for a breast conserving therapy. Everything seemed to work out well. However, 6 years later she died as a result of breast cancer. I know, this was a case of 'bad luck'. But for me, this was definitely the reason to choose a mastectomy. If I would have chosen breast conserving therapy, I would have been afraid, every day of my life, that the breast cancer would return, just like in my mother's situation."

Mary was diagnosed with breast cancer just before she turned 52 years of age. Her appearance was of a beautiful women, in tasteful clothing that brought out her figure very well. She told the nurse how devastated she had been as she received the bad news. She said: "I don't consider myself as vain, but I like the way I look and the thought of losing one of my breasts, gives me nightmares. In addition, I love to swim, I pictured myself in a bathing suit with a loose prosthesis. I would never have gone swimming again. I know, a reconstruction could have been the solution, but such an extensive surgery with a long recovery process, was not an option for me, as I am self-employed. I could not have spared the time. So, I almost shouted out "yes" to the breast conserving treatment, even before my surgeon ended her explanation. Now, I am so glad I have chosen this treatment". 


\section{Introduction}

Safe and appropriate medical procedures were long time seen as the only way forward in reaching high level quality of care. In the recent years however, scientific studies have shown that providing good quality care does not only mean offering patients appropriate treatment, based on the latest scientific evidence. Autonomy of patient, one of the basics of patient centred care, has become increasingly important (1). Over the past decades, there has been a clear change in the way we view the roles of patients and clinicians in making a treatment decision. The clinician is no longer regarded as just being the expert who knows best and decides which treatment is most appropriate for this patient. The relationship between the clinician and the patient has slowly but indisputably grown to a level in which there is room for a dialogue with input from both participants, each with their own expertise (2). Patients expect to be well informed, as well as professionals are obligated to inform them about pros and cons of a treatment $(3,4)$. The Dutch Law on the medical treatment agreement (WGBO) is clear on this: "For medical treatment, a doctor needs the patient's informed permission. That is why a doctor must inform patients explicitly in order to make a good choice (5). Patients also want to be more involved in medical decision making (6). Meanwhile, because of advances in medical science, the number of treatment options being available expanded rapidly, resulting in medical decision making getting more complicated (7). Different, more or less equal, treatment options for one medical condition, each with its own risks and benefits increasingly co-exist, indicating that patients' preferences may determine the decision (8).

\section{Preference sensitive decision in breast cancer}

In 2010 almost 100.000 people in the Netherlands were newly diagnosed with cancer. Overall lung cancer and colon cancer are the most common cancers for both sexes. Breast cancer is the most common cancer type for women (9). Each year, one out of eight women is facing the diagnosis breast cancer, of which a considerable amount are diagnosed with early stage breast cancer (stage I or II) (9). In the recent years, the structure in cancer care has improved due to guidelines and clinical pathways, but decision making remains complex. This complexity contributes to the fact that there is no best treatment for every patient, since the trade-off between advantages and disadvantages of different treatments can vary per patient (10).

Women diagnosed with early stage breast cancer can be given the choice between a breast conserving therapy, almost always including radiotherapy $(\mathrm{BCT})$, or a mastectomy, mostly without radiotherapy. 
The two treatment options have shown to be equally effective in terms of survival and recurrence, indicating that this is a preference sensitive decision (11).

Preferences may vary substantially between individuals and are often related to level of fear and anxiety, patient's age, family history, perceived survival odds, body image values, attitudes towards radiotherapy, the (perceived) preference of the surgeon, the patient professional communication, and the involvement in decision-making process (12-14).

\section{Shared decision making}

Shared decision making (SDM) is increasingly seen as a promising model to involve patients in medical decision making. If executed well, the autonomy of the patient is respected and patient involvement in treatment decisions promoted (15). SDM has been defined as: "an approach where clinicians and patients share the best available evidence when faced with the task of making decisions, and where patients are supported to consider options, to achieve informed preferences" (15). To achieve SDM, Elwyn distinguished three steps in the model of SDM that is described at the start of this thesis: 1 ) the clinician explains to the patient that there are different options available and a choice has to be made (choice talk), 2) the clinician provides extensive information about the different treatment options, including pros and cons (option talk) and 3) the clinician supports the patient to consider preferences and to weigh the treatment options and to decide which option is the best (decision talk) (16) (Figure 1).

Figure 1 Model for Shared Decision Making (16)

\section{Deliberation}

Initial

Preference

Informed Preference

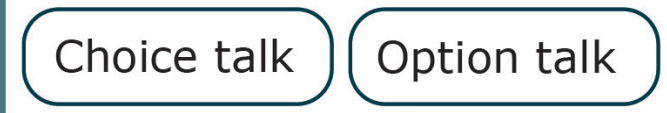

Decision talk

\section{Decision support}


To support SDM, there is a growing interest in using patient decision aids (PtDAs). A PtDA is a tool that provides information about the disease, the possible treatment options, the pros and cons of each option, and includes value elicitation statements. PtDAs do not replace clinician consultations nor are they designed to choose one option above another. Instead, they are designed to provide neutrally framed information in order to guide patients and to prepare them to make a well informed, value based decision (17). Using a PtDA in communication between surgeons and women with breast cancer was shown to have a positive effect on communication, to increase the knowledge of patients about the options and improve realistic perception of outcome and their satisfaction with the decision $(6,18)$. Studies on the use of a PtDA in the SDM process showed a variable effect on the length of the consultation $(6,19)$.

PtDAs need to be developed thoroughly and carefully, to guarantee validity and reliability, to ensure clinicians' agreement with and willingness to use them $(17,20)$. To enhance the quality of PtDAs, a group of international researchers and clinicians, formed the International Patient Decision Aid Standards collaborations (IPDAS) and set up a scientific based framework including criteria with regard to the development and implementation of PtDAs. According to the IPDAS PtDAs must be developed and tested in collaboration with all the stakeholders, patients as well as professionals, to upfront address barriers for implementation $(20,21)$.

\section{Implementation of SDM}

There is a constant flow of new results from scientific research which contributes to the quality, efficiency or effectiveness in health care. It is well known that it takes time before research results or new insights, that relate to improvements in patient care, reach clinical practice. Furthermore, healthcare professionals need to adopt these findings into practice in order to change outcomes $(22,23)$.

Implementation is the process of introducing innovations of proven values, with the aim to accomplish a sustainable change. Implementation of innovations and quality improvements in health care is difficult. As the workload is high, caregivers have their hands full handling daily routines and there is no obvious motivation or time to change these routines. To achieve change, it is important to consider complexity of usual care and the large number of factors that can hinder or facilitate change $(24,25)$. Even if a change is accomplished this does not mean this will sustain. 
Often professionals will revert to previous behaviour as soon as the project is finished (26). It is obvious that usually one single action to implement does not do the trick, instead there is a need for multifaceted implementation strategies, tailored to barriers, facilitators, organisational aspects, and target groups (25). Moreover, effective implementation of innovation benefits from a systematic and carefully planned process (27).

Despite an increasing interest for the adoption of SDM including the use of a PtDA, and despite the robust evidence that SDM improves relevant patient outcomes such as satisfaction with the decision made, implementation into clinical practice has proven to be difficult, slow and to face many challenges (28). Implementation of SDM is suffering from negative attitudes towards SDM in general or towards the content of PtDAs, lack of knowledge and self-efficacy in clinicians, as well as fear that it is too time consuming (28-32). Awareness, experiences, willingness to adopt SDM may vary between team members, thus complicating the implementation.

The field of SDM is increasing fast, still, there are many gaps. Although barriers to further implement SDM concerning clinicians and patients are reasonably known, we lack appropriate insight in barriers concerning organizational and contextual aspects (33). Strategies that are used to implement SDM mostly seem to focus on the development of PtDAs and training of clinicians $(34,35)$. Trying to implement a PtDA without a thorough consideration of the clinical pathway and the guarantee that this fits in the clinical workflow, is difficult and will not facilitate integration of it as usual care (36).

In the Netherlands this was illustrated for example, with the first PtDA for breast cancer, developed in 2001. Although the PtDA showed positive results with regard to the quality of the decision-making process, the patient satisfaction, the doctor-patient relationship and the health outcome, it has never been implemented in daily practice. In 2009 another PtDA, that was developed was published on the Dutch governmental patient portal (www.kiesbeter.nl) (37). The PtDA was freely available for both patients and professionals from this portal, but -again- not implemented in daily practice. Patients, nor professionals were aware of the existence of the PtDA, let alone use it. This proved that simply making available a PtDA without any relationship with care models or self-management models does not leads to implementation (38). 


\section{Aim and research questions}

Though there seems to have grown a certain level of motivation among professionals to implement SDM in breast cancer care in the Netherlands, implementation is still difficult and more or less fragmented. We aimed to initiate a dialogue about the value of SDM to increase patient centeredness and contribute to quality of care in breast cancer in hospitals. To do so we wanted to gain more knowledge on how to implement SDM. At that time the breast cancer team in the Maastricht University Medical Centre (MUMC+) intended to develop, pilot test and implement a PtDA with regard to the surgical decision for patients with early stage breast cancer, in collaboration with researchers, clinicians and patients as best practice.

The format and the content of the PtDA had to be acceptable and useful for breast cancer teams in other hospitals in the Netherlands. This inspired us to develop an implementation strategy, which led to the aim of this thesis: to develop, pilot test and improve comprehensive and tailored strategies to implement SDM, customized for each participating hospital. These implementation strategies include:

1. explanation on how to apply the steps in the SDM process,

2. procedures and supporting tools to enhance the performance of SDM in clinical practice,

3. an advice on were and how to record related SDM actions at an individual patient level

The research questions were:

- How to develop, improve and alpha test a PtDA for surgical treatment of early stage breast cancer and how to ensure that usability, comprehensibility and acceptability of the tool itself meets the standards and requirements of professionals and patients?

- What is the uptake of the SDM implementation strategies in breast cancer care by professionals and the perceived uptake and use of a PtDA by breast cancer patients?

- What are the experiences of patients with regard to the SDM process in breast cancer and the usefulness of the PtDA?

- What are the experiences and perceived barriers and facilitators of professionals with regard to the SDM process in breast cancer care? 


\section{Outline of this thesis}

Chapter 2 describes in detail the development of the prototype and iterative alpha test of a PtDA, a time consuming and challenging process which we performed together with patients, patient advocates and professionals, and the industrial designers of Zorgkeuzelab. The meticulous development and testing of the PtDA had to ensure that usability, comprehensibility and acceptability of the tool itself met de standards and requirements of professionals and patients.

A description of the research protocol for a pilot study is given in chapter 3. The protocol for a pre- and post-implementation study focuses on the optimising the strategies to implement the PtDA in clinical practice. The multi-facetted strategy was customized to the needs of each breast cancer team, without disturbing daily practice.

Chapter 4 describes how we used the optimised multi-facetted implementation strategy to expose patients to the PtDA. Subsequently patients participated in structured interviews to study their subjective experiences with the strategies on offering the PtDA and encouraging them to use it. We also added an objective view with regard to the actual uptake of the implementation strategies by professionals, by conducting an audit of patient files.

We present the experiences of patients with regard the SDM process during the study in chapter $\mathbf{5}$. We describe the extent to which patients have experienced the steps of the SDM process and their perceived usefulness the PtDA.

In chapter 6 we give an overview of our findings with respect to attitudes of professionals on SDM in general and the use of a PtDA, and their opinion on the implementation strategies. We interviewed professionals to gain insight in their knowledge and subjective indicated performance of SDM.

In the general discussion in chapter $\mathbf{7}$, results are summarised and findings are discussed in view of current literature, implications for practice and future research. 


\section{References}

1. Fowler F, Levin C, Sepucha K. Informing And Involving Patients To Improve The Quality Of Medical Decisions. Health Affairs. 2011;30(4):699-706.

2. Charles C, Whelan T, Gafni A. What do we mean by partnership in making decisions about treatment? BMJ (Clinical research ed). 1999;319(7212):780-2.

3. Charles C, Gafni A, Whelan T. Shared decision-making in the medical encounter: What does it mean? (or it takes at least two to tango). Social Science \& Medicine. 1997;44(5):681-92.

4. Coulter A. Patient information and shared decision-making in cancer care. British Journal Of Cancer. 2003;89:S15.

5. Rijksoverheid. Wet op de Geneeskundige Behandeling (WGBO) https://www.rijksoverheid.nl/onderwerpen/rechten-van-patient-enprivacy/rechten-bij-een-medische-behandeling/informatie-arts-voor-medische-behandeling1994 [

6. Stacey D, Bennett CL, Barry MJ, Col NF, Eden KB, Holmes-Rovner M, Llewellyn-Thomas H, Lyddiatt A, Legare F, Thomson, R. Decision aids for people facing health treatment or screening decisions. The Cochrane database of systematic reviews. 2011(10):Cd001431.

7. Mulley AG, Trimble C, Elwyn G. Stop the silent misdiagnosis: patients' preferences matter. BMJ: British Medical Journal. 2012;345.

8. Elwyn G, Edwards A, Kinnersley P, Grol R. Shared decision making and the concept of equipoise: the competences of involving patients in healthcare choices. The British Journal of General Practice. $2000 ; 50(460): 892-9$.

9. IKNL. Cijfers over kanker [webpage]. https://www.cijfersoverkanker. $\mathrm{nl} /$ selecties/incidentie_borst/img568b9b027142c: IKNL; 2010 [

10. Stacey D, Samant R, Bennett C.IDecision Making in Oncology: A Review of Patient Decision Aids to Support Patient Participation. CA: A Cancer Journal for Clinicians. 2008;58(5):293-304.

11. Fisher B, Anderson S, Bryant J, Margolese RG, Deutsch M, Fisher ER, Jeong J-H, Wolmark N. Twenty-Year Follow-up of a Randomized Trial Comparing Total Mastectomy, Lumpectomy, and Lumpectomy plus Irradiation for the Treatment of Invasive Breast Cancer. New England Journal of Medicine. 2002;347(16):1233-41.

12. Abdul-Razzak KK, Ajlony MJ, Khoursheed AM, Obeidat BA. Vitamin D deficiency among healthy infants and toddlers: a prospective study from Irbid, Jordan. Pediatr Int. 2011;53(6):839-45.

13. Caldon LJM, Collins KA, Wilde DJ, Ahmedzai SH, Noble TW, Stotter A, Sibbering DM, Holt S. Reed MWR. Why do hospital mastectomy rates vary? Differences in the decision-making experiences of women with breast cancer.British Journal of Cancer. 2011;104(10):1551-7. 
14. Hershman DL, Buono D, Jacobson JS, McBride RB, Tsai WY, Joseph KA, Neugut AI. Surgeon characteristics and use of breast conservation surgery in women with early stage breast cancer. Annals of surgery. 2009;249(5):10.1097/SLA.0b013e3181a38f6f.

15. Elwyn G, Laitner S, Coulter A, Walker E, Watson P, Thomson R. Implementing shared decision making in the NHS. BMJ (Clinical research ed). 2010;341.

16. Elwyn G, Frosch D, Thomson R, Joseph-Williams N, Lloyd A, Kinnersley P, Cording E,Tomson DD, Rollnick S, Edwards A, Barry M. Shared Decision Making: A Model for Clinical Practice. Journal of general internal medicine. 2012;27(10):1361-7.

17. Volk RJ, Llewellyn-Thomas H, Stacey D, Elwyn G. Ten years of the International Patient Decision Aid Standards Collaboration: evolution of the core dimensions for assessing the quality of patient decision aids. BMC medical informatics and decision making. 2013;13(2):S1.

18. Sivell S, Edwards A, Manstead ASR, Reed MWR, Caldon L, Collins $\mathrm{K}$, Clements A, Elwyn G. Increasing readiness to decide and strengthening behavioral intentions: Evaluating the impact of a web-based patient decision aid for breast cancer treatment options (BresDex: www.bresdex.com). Patient education and counseling. 2012;88(2):209-17.

19. Whelan T, Levine M, Willan A, Gafni A, Sanders K, Mirsky D, Chambers S. O'Brien MA, Reid S, Dubois S. Mastectomy or lumpectomy? Effect of a decision aid on knowledge and treatment decision making for breast cancer surgery: a randomized trial. Jama. 2004;292(4):435-41.

20. Coulter A, Stilwell D, Kryworuchko J, Mullen PD, Ng CJ, van der Weijden T. A systematic development process for patient decision aids. BMC medical informatics and decision making. 2013;13(Suppl 2):S2-S.

21. Evans R, Elwyn G, Edwards A, Watson E, Austoker J, Grol R. Toward a Model for Field-Testing Patient Decision-Support Technologies: A Qualitative Field-Testing Study. Journal of Medical Internet Research. 2007;9(3):e21.

22. Eccles MP, Mittman BS. Welcome to Implementation Science. Implementation Science. 2006;1(1):1.

23. Dixon-Woods M, Amalberti R, Goodman S, Bergman B, Glasziou P. Problems and promises of innovation: why healthcare needs to rethink its love/hate relationship with the new. BMJ Quality \&amp; Safety. 2011;20(Suppl 1):i47-i51.

24. Baker R, Camosso-Stefinovic J, Gillies C, Shaw EJ, Cheater F, Flottorp $\mathrm{S}$, Robertson N. Tailored interventions to overcome identified barriers to change: effects on professional practice and health care outcomes. The Cochrane database of systematic reviews. 2010(3):Cd005470. 
25. Grol $R$, Wensing $M$. Implementation of change in healthcare: a complex problem. In: Grol R, Eccles M, Wensing M, Davis D, editors. Improving patientcare: the implementation of change in health care: Wiley-Blackwell; 2013. p. 3-17.

26. Grol R, Wensing M. Effective implementation of change in healthcare: a systematic approach. In: Grol R, Eccles M, Wensing M, Davis D, editors. Improving Patient Care: The Implementation of Change in Health Care: Wiley-Blackwell; 2013. p. $40-64$

27. Grol R, Wensing M, Bosch M, Hulscher M, Eccles M. Theories on implementation of change in healthcare. In: Grol R, Eccles M, Wensing M, Davis $D$, editors. Improving Patient Care; The implementation of of Change in Health care2013.

28. Elwyn G, Scholl I, Tietbohl C, Mann M, Edwards AG, Clay C, Legare F, van der Weijden T. Lewis, CL, Wexler RM, Frosch DL. "Many miles to go ...": a systematic review of the implementation of patient decision support interventions into routine clinical practice. BMC medical informatics and decision making. 2013;13 Suppl 2:S14.

29. Légaré F, Ratté S, Gravel K, Graham ID. Barriers and facilitators to implementing shared decision-making in clinical practice: Update of a systematic review of health professionals' perceptions. Patient education and counseling. 2008;73(3):526-35.

30. Barry MJ, Edgman-Levitan S. Shared Decision Making; The Pinnacle of Patient-Centered Care. New England Journal of Medicine. 2012;366(9):780-1.

31. Floer B, Schnee M, Böcken J, Streich W, Kunstmann W, Isfort J, Butzlaff Ml. "Shared Decision Making". Medizinische Klinik. 2004;99(8):435-40.

32. Sandra F, S. YT, E. UE, Karen S. What does it take to have sustained use of decision aids? A programme evaluation for the Breast Cancer Initiative. Health Expectations. 2011;14(s1):85-95.

33. Légaré F, Witteman HO. Shared Decision Making: Examining Key Elements And Barriers To Adoption Into Routine Clinical Practice. Health Affairs. 2013;32(2):276-84.

34. Charles C, Gafni A, Whelan T. Self-reported use of shared decisionmaking among breast cancer specialists and perceived barriers and facilitators to implementing this approach. Health Expectations. $2004 ; 7(4): 338-48$.

35. Vodermaier A, Caspari C, Koehm J, Kahlert S, Ditsch N, Untch M. Contextual factors in shared decision making: a randomised controlled trial in women with a strong suspicion of breast cancer. British Journal Of Cancer. 2009;100:590.

36. Elwijn G. Implementing shared decision making in the NHS. BMJ: British Medical Journal. 2010;341:971-3. 
37. Molenaar S, Sprangers MA, Rutgers EJ, Luiten EJ, Mulder J, Bossuyt $\mathrm{PM}$, van Everdingen JJ, Oosterveld $\mathrm{P}$, de Haes $\mathrm{HCl}$. Decision support for patients with early-stage breast cancer: effects of an interactive breast cancer CDROM on treatment decision, satisfaction, and quality of life. Journal of clinical oncology : official journal of the American Society of Clinical Oncology. 2001;19(6):1676-87.

38. Obeidat R, Finnell DS, Lally RM. Decision aids for surgical treatment of early stage breast cancer: A narrative review of the literature.

Patient education and counseling. 2011;85(3):e311-e21. 
Developing a patient decision aid for the treatment of women with early stage breast cancer: the struggle between simplicity and complexity.

Wilma Savelberg

Trudy van der Weijden

Liesbeth Boersma

Marjolein Smidt

Christa Willekens

Albine Moser,

BMC Medical Informatics and Decision Making

BMC series - open, 2017 17:112 


\section{Abstract}

\section{Background}

A patient decision aid (PtDA) can support shared decision making (SDM) in preference-sensitive care, with more than one clinically applicable treatment option. The development of a patient decision aid is a complex process, involving several steps, including designing and testing the prototype with all stakeholders, so-called alpha testing.

\section{Objective}

Developing and alpha testing a patient decision aid for primary treatment of early stage breast cancer, ensuring that the tool is considered relevant, valid and feasible by patients and professionals.

\section{Methods}

Our qualitative descriptive study applied methods include faceto-face think-aloud interviews, a focus group and semi-structured telephone interviews. The study population consisted of breast cancer patients facing the choice between breast conserving therapy with or without preceding neo-adjuvant chemotherapy and mastectomy, and professionals involved in breast cancer care in dedicated multidisciplinary breast cancer teams.

\section{Results}

A patient decision aid was developed and improved based on four iterative test rounds, taking nearly two years, involving 26 patients and 26 professionals. The development was an extensive process, which took double the expected time and resources. The main topics of concern were the complexity of the decision and conflicting views of professionals and patients regarding side-effects, the amount of information and how to present this information.

\section{Conclusion}

While the research group opted for simplicity in the interest of implementation, the clinicians objected that the complexity of the decision could not be ignored. The final version of the patient decision aid appeared to be well-appreciated by professionals and patients, although the proof of its acceptability will be in its use in real life practice (beta testing). 


\section{Introduction}

Women with early stage breast cancer can often choose between two options with comparable outcomes; breast-conserving therapy $(B C T)$, including radiation therapy, or mastectomy, with or without radiation therapy (1). Some patients are offered neo-adjuvant systemic treatment to enable or facilitate BCT. As there is more than one clinically valid treatment option, shared decision making (SDM) is becoming increasingly important. SDM has been defined as 'an approach where clinicians and patients share the best available evidence when faced with the task of making decisions, and where patients are supported to consider options, to achieve informed preferences' (2).

A Patient Decision Aid (PtDA) can support the SDM process $(3,4)$. It provides information about the disease, the possible treatment options, the pros and cons of each option, and sometimes value elicitation statements. It is increasingly recognized that using a PtDA in the communication between surgeons and women facing early stage breast cancer increases women's knowledge about the options and their satisfaction with the decision, and reduce decision regret $(4,5)$.

Developing a PtDA is a difficult, time-consuming and complex process, which requires the involvement of many different professionals as well as patients (3). It needs to be done carefully, with a fully documented development process to ensure the validity and reliability of the decision aid. PtDAs can have significant impact on choices patients make.

Poor quality PtDAs may cause harm to patients $(3,6,7)$. In addition, clinicians who disagree with the content of the PtDA are unlikely to use it or encourage their patients to do so (3) and will thus hamper clinical implementation. Coulter et al. (3) described quality criteria for the development of PtDAs, one of which is alpha testing, that is, testing the prototype in an iterative process among people directly involved in the development process (8) (figure 1). It involves patients who have faced the decision in question in the past, and clinicians working for the target population (9). 
Figure 1 Model development process for decision aids (adapted from Coulters Model)
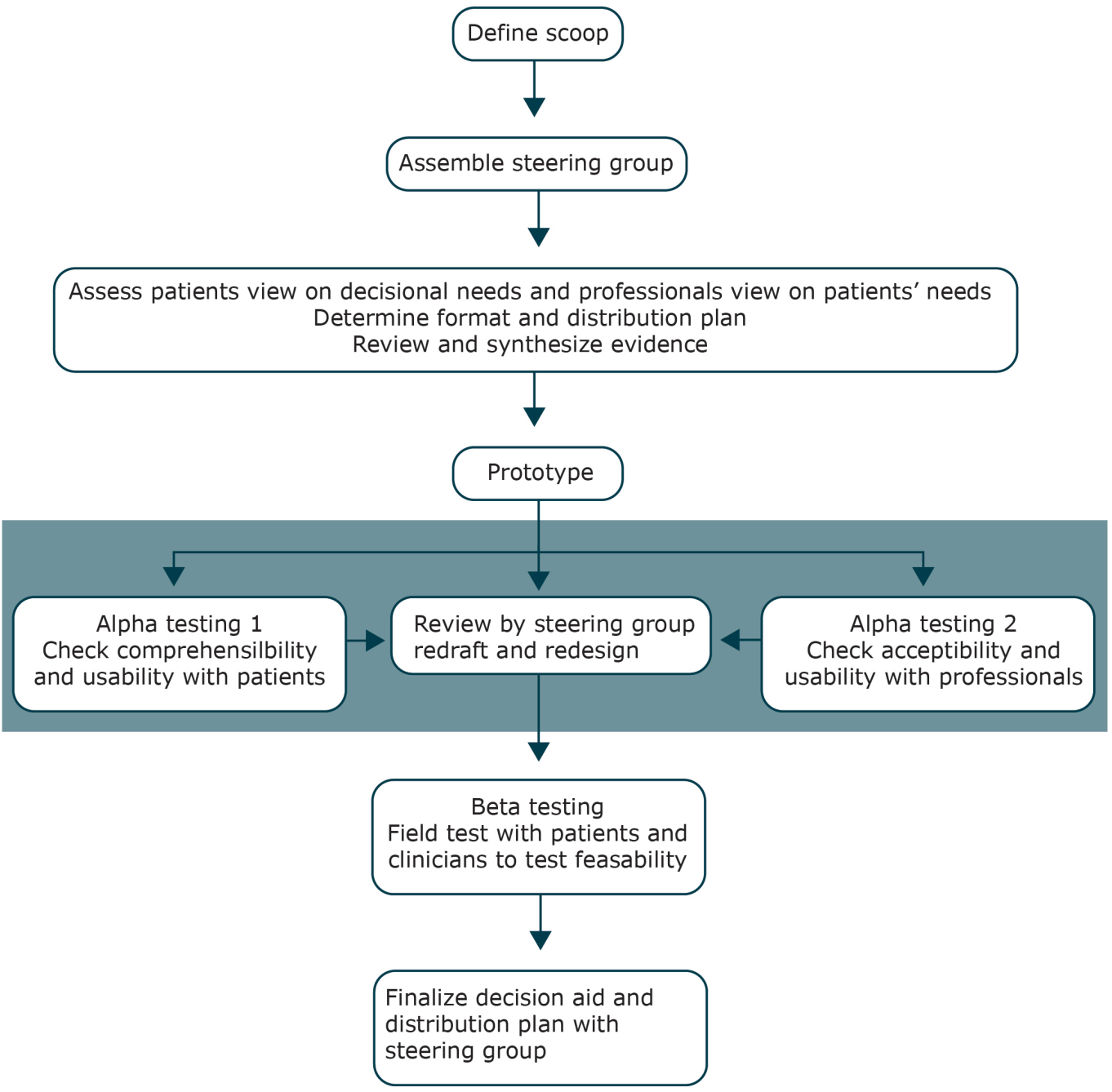

We are aware of 11 PtDAs described in the literature to support women with early stage breast cancer in deciding between breast removal and breast conserving treatment (10-20). Alpha testing has not been reported for any of these PtDAs. In the beta testing phase, the usability of three PtDAs was tested among patients, and acceptability of two PtDAs was tested among professionals $(5,10,12,14,17)$. We wanted to ensure that we developed a PtDA that, professionals want to use, and patients appreciate, and that helps them to fully understand the options to make a decision. We chose to conduct an extensive alpha test as this seemed the optimal phase for both patients and professionals to influence the functionality and content of the PtDA, and to pave the way for clinical implementation. 
We believe that patient participation in the alpha testing phase is closest to co-creation. The potential impact of an alpha test seems higher than testing when the PtDA is in the beta testing phase, as there will only be room for minor adjustments in this last phase.

Alpha testing addresses usability, comprehensibility, and acceptability aspects. Usability is defined as 'the extent to which a product is used by a specific group to achieve certain goals effectively, efficiently and satisfactorily in a particular context (21). Recommendations for usability testing include running many small tests with no more than 5 users per test round (22). Comprehensibility has been defined as 'the way the information is understandable' and was especially tested among patients (23). Acceptability, tested only among the professionals, has been defined as 'adequate to satisfy a need, requirement or standard' and refers to ratings regarding the comprehensibility of components of a decision aid, its length, the amount of information, balanced presentation of information about options, and overall suitability for decision making (24).

In the Netherlands, the first PtDA for this topic was developed in 2001(15). Although it showed positive results regarding the quality of the decision-making process, patient satisfaction, doctor-patient relationship, and health outcome, it has not been implemented in the daily practice of surgeons. In 2009, another PtDA, developed along with the clinical practice guideline on surgical treatment of early stage breast cancer, was published on the Dutch government's patient portal (www. kiesbeter.nl). Although it was freely available for both patients and professionals from this portal, this PtDA was not implemented in daily practice either. Most professionals and patients were not even aware of its existence. For sake of implementation we opted for simplicity and developed a prototype PtDA with brief, easy to read and compact information, like an option grid to be used by clinicians during clinical encounters (25).

The information was based on the existing but out-dated PtDA provided on the government's patient portal (15), as well as the Dutch clinical guidelines (Oncoline) on breast cancer, additional literature and expert opinion. Our prototype was developed in a power point like presentation by the research team, following the checklist of the International Patient Decision Aids Standards (7).

We hypothesized that alpha testing with patients and professionals would help ensure the validity and reliability of the development process and thus would stimulate future ownership and systematic implementation of the PtDA. 
In this paper we outline in detail the process of developing the prototypes of the PtDA together with patients, patient advocates and professionals, as an illustrative example. The aim of this study was to develop, alpha test and improve a patient decision aid for surgical treatment of early stage breast cancer and ensure that usability, comprehensibility and acceptability of the tool itself met the standards and requirements of professionals and patients.

\section{Methods}

\section{Design}

We conducted a qualitative descriptive study to alpha-test and iteratively improved a PtDA. The iterative and participatory approach involved patients, patient advocates and health professionals from all clinical disciplines (surgeons, radiotherapists, oncologists) within breast cancer care.

\section{Setting}

The first prototype was developed by a research team, consisting of a general surgeon, an implementation scientist, a clinical epidemiologist, a researcher on patient-centered care and a medical student together with members of the dedicated breast cancer team of Maastricht University Medical Centre (MUMC+, Maastricht, The Netherlands), which treats about 250 newly diagnosed breast cancer patients a year. Professionals from various Dutch hospitals and the national network of breast cancer teams were invited to take part in the alpha testing.

\section{Participants of the alpha testing procedure}

\section{Patients}

The patients were recruited via staff of the MUMC+ breast cancer team, and the Dutch Breast Cancer Association (BVN).

Inclusion criteria to participate in the alpha testing were: patients diagnosed with early stage breast cancer, understanding Dutch, who had already undergone surgical treatment. We assumed these patients were less sensitive to experience stress and anxiety by being exposed to a draft PtDA, compared to patients who had yet to start treatment. They were included using purposive sampling to reach sufficient diversity in terms of educational level and breast cancer experience. (Table 1). All participants provided a written consent for their participation.

Recruitment for the first usability and comprehensibility round yielded nine breast cancer patients diagnosed and treated approximately one year prior to participation, recruited via MUMC+ professionals. 
The patients were drawn from the consultations, visiting the out clinic in their follow up phase.

Recruitment for the second round yielded six patients, recruited by BVN among their members. We placed a call on their website, indicating the inclusion criteria.

In the third round, four women diagnosed with breast cancer within one year prior to participation were again recruited through professionals from the MUMC+ Oncology Centre.

Finally, recruitment for the fourth round yielded six more patients via the BVN, through a message on their website.

Table 1: Characteristics of patients participating in the interviews, reported for each of the 4 test rounds.

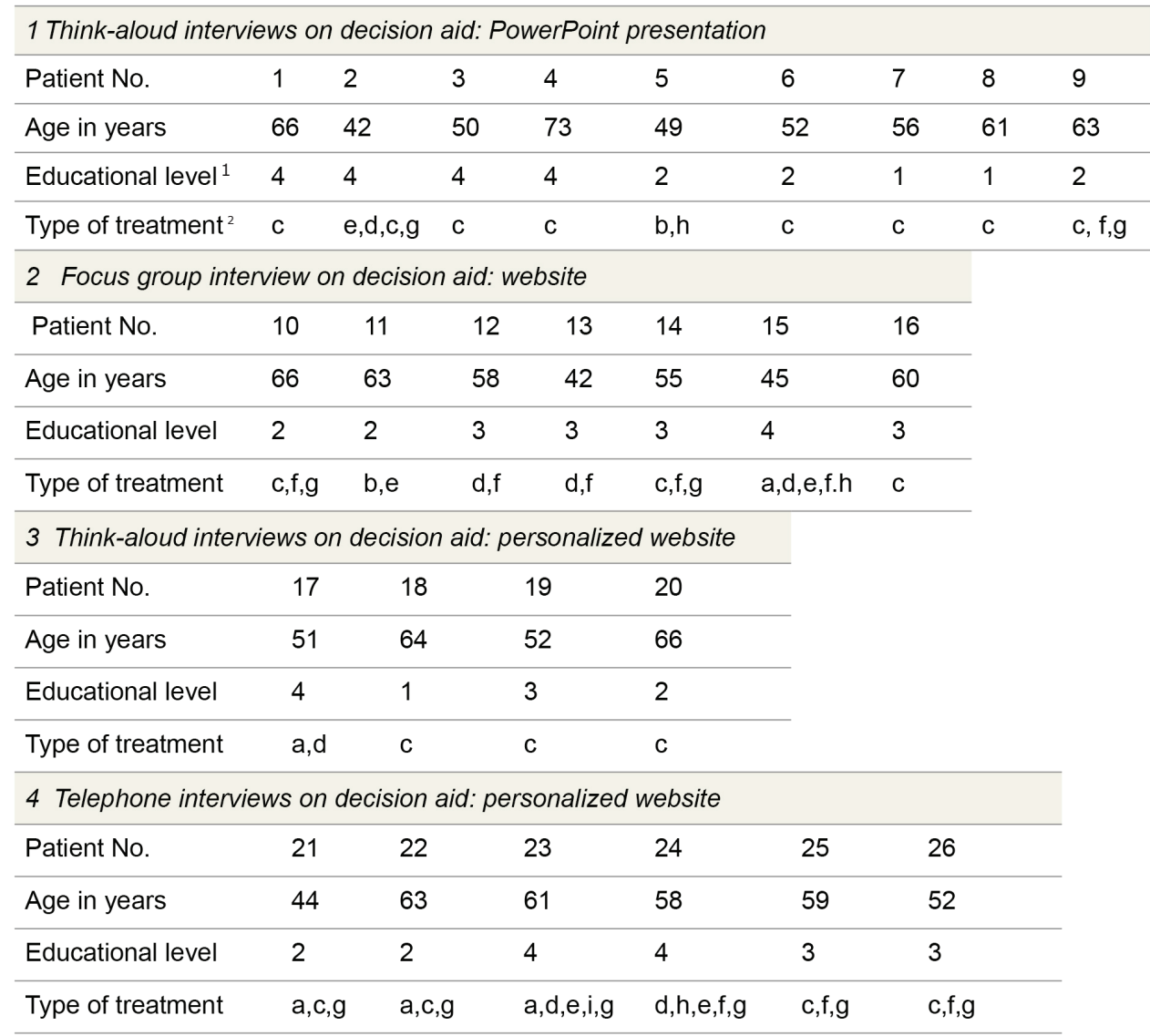

${ }^{1} 1$ : lower level education; 2: intermediate level education; 3: higher education; 4: university degree

2a: neo-adjuvant chemotherapy; b: breast conserving surgery followed by full mastectomy; c: breast conserving therapy; $d$ : mastectomy; e: radiotherapy; : chemotherapy; g: hormonal therapy; h: reconstruction; i: immunotherapy. 


\section{Professionals}

Health care professionals participating in the alpha testing included oncologic surgeons, radiation oncologists, medical oncologists, and nurses. Twenty-six health care professionals were recruited by members of the development team using purposive sampling to achieve diversity in terms of disciplines and hospitals (Table 2). Professionals involved in the process of developing the PtDA were excluded from the alpha test.

\section{Ethics}

The study was approved by the MUMC+ ethics committee (no.1405-42). Handling of personal data was in accordance with the Dutch Personal Data Protection Act and Medical Research (Human Subjects) Act. All participants provided written informed consent, and all data were processed confidentially and anonymously.

Table 2. Characteristics of professionals participating in the interviews, reported for each of the 4 test rounds.

1 Written comments and cognitive interviews on decision aid: PowerPoint

\begin{tabular}{|c|c|c|c|c|c|c|c|c|c|}
\hline No. of interview & 1 & 2 & 3 & 4 & 5 & 6 & 7 & 8 & 9 \\
\hline Type of professional ${ }^{1}$ & a & a & a & C & c & c & $d$ & e & $f$ \\
\hline Hospital $^{2}$ & MUMC+ & AMC & LUMC & LUMC & MUMC+ & MUMC+ & MC & MUMC+ & MUMC+ \\
\hline \multicolumn{10}{|c|}{2 Consultation on decision aid: website } \\
\hline No. of interview & 10 & 11 & 12 & & & & & & \\
\hline Type of professional & $d$ & a & C & & & & & & \\
\hline Hospital & MC & MUMC+ & MUN & & & & & & \\
\hline
\end{tabular}

3 Think-aloud interviews on decision aid: personalized website

\begin{tabular}{llllll}
\hline No. of interview & 13 & 14 & 15 & 16 & 17 \\
\hline Type of professional & e & a & b & c & d \\
\hline Hospital & MUMC+ & MUMC+ & MUMC+ & MUMC+ & MC
\end{tabular}

\begin{tabular}{|c|c|c|c|c|c|c|c|c|c|}
\hline No. of interview & 18 & 19 & 20 & 21 & 22 & 23 & 24 & 25 & 26 \\
\hline Type of professional & a & a & a & a & a & a & a & a & $g$ \\
\hline Hospital & $\mathrm{JBZ}$ & CZE & TWZ & CWZ & LUMC & AMC & AMC & AM & - \\
\hline
\end{tabular}

${ }^{1}$ a: surgeon oncologist; b: medical oncologist; c: specialized breast care nurse; $d$ : radiation oncologist; e: plastic surgeon; $f$ : health educator; g: staff of Dutch Breast Cancer Association.

2 MUMC+: Maastricht University Medical Centre; AMC: Amsterdam Medical Centre; LUMC: Leiden University Medical Centre; JBZ: Jeroen Bosch Hospital; MC:MAASTRO clinic; CZE: Catherina Hospital Eindhoven; TWZ: Elisabeth-Tweesteden Hospital Tilburg; CWZ: Canisius Wilhelmina Hospitals; AM: Alexander Monro Breast Cancer Clinic. 


\section{Data collection}

Data were collected between September 2012 and June 2015 using different techniques, such as think-aloud interviews, focus group, and telephone questionnaires (Figure 2).

Figure 2 Flowchart cyclic development and alpha testing process

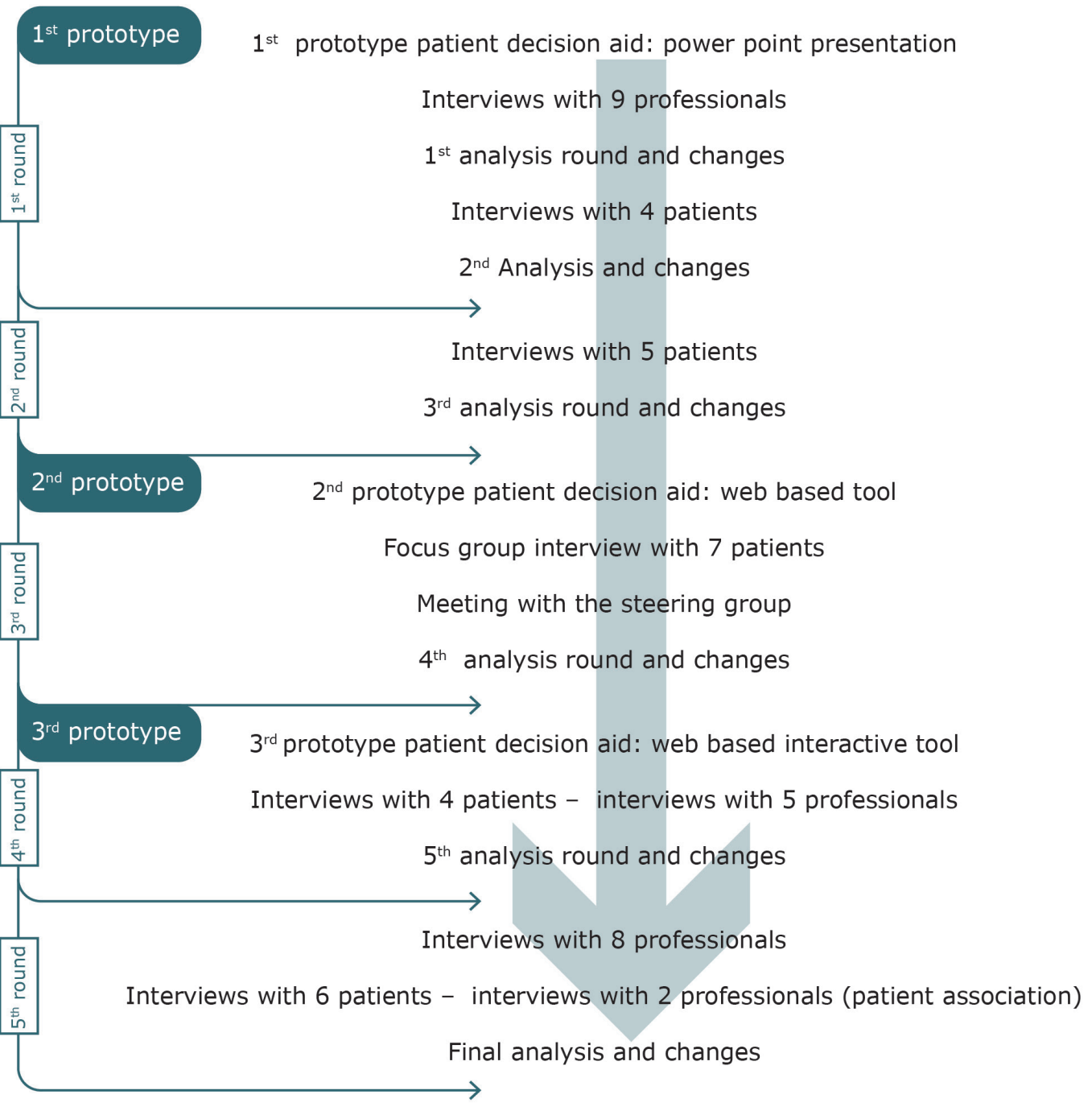

Alpha testing among patients

For the first round, the researcher made individual appointments with participating patients in their home environment or at the hospital. Patients were then shown the PowerPoint prototype. 
A think-aloud method was used: patients were asked to go through the PtDA, and stimulated to immediately express any comments on the PtDA. After the exercise was completed, the researcher asked a few additional questions such as: what is your general impression of the PtDA, and what did you particularly appreciate about the PtDA? The think-aloud interviews were audiotaped and lasted between 30 and 60 minutes.

After a web-based PtDA had been developed, participants received a web address and a login code in the second round. They were asked to go through the website carefully, reading the content and navigating all pages. Two researchers led a two-hour focus group, held at the office of BVN, using a structured interview technique. During the session, participants were asked to give their views on the content, navigation, and layout of the PtDA in an interactive manner (appendix 1). This session was audiotaped.

In the third round, the participants were invited to the MUMC+ Oncology Centre to view the latest web-based, interactive prototype of the PtDA. The patients were asked to give comments while using the improved and personalized PtDA, again using the think-aloud method. The interviews, which lasted between 45 and 60 minutes, were audiotaped.

Finally, in the fourth round, we sent the patients a web address and a login code, and asked them to go through the website at home. After one week we conducted a semi-structured telephone interview. Questions related to general appreciation, what information was relevant, or missing, and how they perceived the navigational qualities of the website. These interviews lasted between 20 to 30 minutes, and were audiotaped.

\section{Alpha testing among professionals}

In the first round, each of the professionals read the PtDA individually, without the researcher being present. Researcher and professional then met and discussed problematic topics while scrolling through the PtDA, with researcher taking notes.

For the second round, we organized a review session with members of the research- and breast cancer team from MUMC+. The aim was to determine whether the current prototype met the basic requirements for further testing. One of the researchers took notes. 
In the third round, the professionals reviewed the PtDA using a thinkaloud method. The interviews were audiotaped.

In the fourth round, professionals of dedicated breast cancer teams, as well as some national experts on breast cancer care, received a login name and a password. They were asked to view the PtDA. After the review, they were interviewed by telephone, while field notes were taken.

\section{Analyses}

Data were analysed using a directed content analysis with three main categories, viz. usability, comprehensibility, and acceptability, as an analytical framework. A coding tree was developed for these three main categories. We then divided the main categories into smaller subcategories derived from the literature (Table 3)(22-24). Later in the analysis process, we also worked inductively, as new subcategories emerged. Analysis took place in an iterative process: interviews and analyses were alternated between each round of modifications and improvements to the successive prototypes of the PtDA.

\section{Results}

\section{Round 1 (September 2012 - December 2013)}

First prototype of the PtDA

The first prototype PtDA was built in the format of a PowerPoint-like presentation to achieve awareness of the two treatment options. It included survival rates, side-effects, all pros and cons of the treatments, pictures of surgical results, and value elicitation statements.

Survival rates and the occurrence of the most important side-effects were given in percentages and presented as graphs. Value clarification consisted of five statements, all with five answering categories (Yes, very; yes, a little; neutral; no, not really; no, not at all). Filling in these questions did not result in a conclusion or summary. Patients could choose to navigate by constantly clicking the forward button or clicking on one of the tabs. Clicking all the buttons in every slide, resulted in lots of duplicate information. 
Table 3. Components of alpha testing.

\begin{tabular}{|c|c|c|c|}
\hline & & Definition & Criteria \\
\hline Patients & $\begin{array}{l}\text { Comprehensibility } \\
(23)\end{array}$ & $\begin{array}{l}\text { The way the } \\
\text { information is } \\
\text { understandable }\end{array}$ & $\begin{array}{l}\text { - The information in this website is described clearly. } \\
\text { - The language used in this website is easy. (simplicity). } \\
\text { - The information in this website is easy to understand. }\end{array}$ \\
\hline $\begin{array}{c}\text { Patients \& } \\
\text { Professionals }\end{array}$ & $\begin{array}{l}\text { Usability } \\
\text { (22) }\end{array}$ & $\begin{array}{l}\text { The extent to which a } \\
\text { product is used by a } \\
\text { specific group to } \\
\text { achieve certain goals } \\
\text { effectively, efficiently, } \\
\text { and satisfactorily in a } \\
\text { particular context }\end{array}$ & 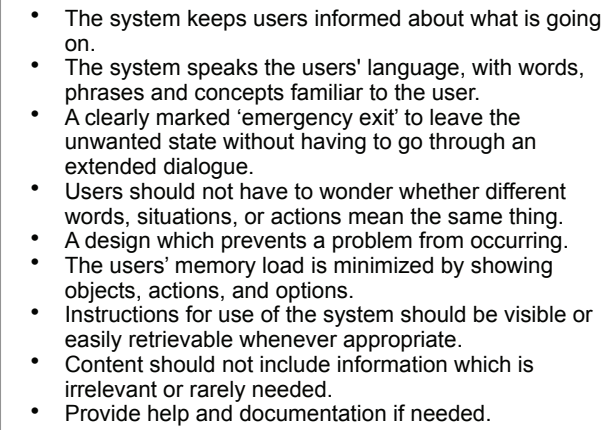 \\
\hline Professionals & $\begin{array}{l}\text { Acceptability } \\
(24)\end{array}$ & $\begin{array}{l}\text { Suitable to meet a } \\
\text { need, a requirement or } \\
\text { standard }\end{array}$ & $\begin{array}{l}\text { - The information is understandable. } \\
\text { - The information is experienced as complete. } \\
\text { - The length of the information is adequate. } \\
\text { - The is a balanced presentation of information. } \\
\text { - The wite is overall suitable. }\end{array}$ \\
\hline
\end{tabular}

Comments and changes

Table 4 shows a short overview of the comments and how they were addressed.

\section{Patients}

Patients' general opinion about the PtDA was positive. It was seen as useful in empowering them to ask the right questions when visiting the clinic. Nevertheless, they mentioned several aspects that could be improved:

1. They felt that the numeric data were unrealistic. In their perception, more patients experience complications than was indicated by the numbers, which were based on research.

2. The position of the value elicitation statements at the start of the PtDA was questioned. They experienced the questions as confusing and did not see the purpose of these questions in the PtDA. Patients wanted to read about the facts and figures first, before being confronted with questions on their values.

3. Patients thought the risk communication was not very clear, especially where narrative terms such as 'rarely' and 'few' were used for complications of radiotherapy.

4. All patients regarded the navigation through the PtDA as difficult. They did not always know where to click and consequently slides were overlooked, resulting in important information being missed. 
'what do these terms mean, "rarely" I mean is that $10 \%$ of the patients, less or more. Reading this, I don't feel well informed. I have to guess, that does not feel right.' (patient 1.3)

\section{Professionals}

The professionals' general opinion towards the PtDA was that they were critical of it. They doubted the ability of patients to be involved in such a difficult decision, in view of additional aspects like chemotherapy and breast reconstruction, which were only touched upon briefly. With regard to acceptability, the professionals were sceptical about implementation. They were unclear about the added value and the time required to use the PtDA. The professionals disagreed about the optimal amount of information, and which information was essential to make the decision. They worried about several aspects:

1. Nurses in particular thought that the evidence-based data, e.g. on complication rates, were invalid. They referred to their experience of rates varying between hospitals.

2. There was also resistance to using numeric probability data. The professionals advocated the use of terms like 'rarely' and 'few' because it would prevent patients from feeling distressed.

3. According to the professionals most patients already have a preference before they are informed about the options. The professionals therefore recommended presenting the value elicitations twice, at the opening and closing of the PtDA. This would make the PtDA more interactive and could help the patient correct possible misperceptions.

'Within the short time I have available for each patient, I don't think I can manage to go through such a decision tool as well.' (Professional 1.2) 
Table 4 Comments on the prototypes per round

\begin{tabular}{|c|c|c|c|}
\hline Round 1 (power point) & Patients & Professionals & Changes \\
\hline General & $\begin{array}{l}\text { Positive attitude, helping } \\
\text { patients to ask the right } \\
\text { questions. } \\
\text { Navigation problems. }\end{array}$ & $\begin{array}{l}\text { Critical, unclear about } \\
\text { the added value and } \\
\text { time required to use it. }\end{array}$ & A web based PtDA was developed. \\
\hline Numeric data & Unrealistic numeric data. & $\begin{array}{l}\text { Nurses thought the } \\
\text { numeric data were } \\
\text { unrealistic. }\end{array}$ & $\begin{array}{l}\text { As numeric data were evidence } \\
\text { based, no changes were made at this } \\
\text { point. }\end{array}$ \\
\hline Value elicitation & $\begin{array}{l}\text { Preferred the value } \\
\text { elicitation at the end of } \\
\text { the PtDA }\end{array}$ & $\begin{array}{l}\text { Preferred the value } \\
\text { elicitation at the } \\
\text { beginning and at the } \\
\text { end of the PtDA. }\end{array}$ & $\begin{array}{l}\text { Value elicitation at the beginning was } \\
\text { removed. }\end{array}$ \\
\hline $\begin{array}{l}\text { Narrative terms in risk } \\
\text { communication }\end{array}$ & $\begin{array}{l}\text { Lacked the use of } \\
\text { narrative terms. }\end{array}$ & $\begin{array}{l}\text { Preferred the use of } \\
\text { narrative terms. }\end{array}$ & Narrative terms were avoided. \\
\hline $\begin{array}{l}\text { Round } 2 \text { (first web } \\
\text { based) }\end{array}$ & Patients & Professionals & Changes \\
\hline General & $\begin{array}{l}\text { Easy to read, simple to } \\
\text { use. }\end{array}$ & No additional value & A new web based PtDA was build. \\
\hline $\begin{array}{l}\text { Data on side effects } \\
\text { and long term } \\
\text { complications }\end{array}$ & $\begin{array}{l}\text { Probability data as well } \\
\text { as level of complaints } \\
\text { were too optimistic }\end{array}$ & & $\begin{array}{l}\text { Probability data were presented in a } \\
\text { different way. }\end{array}$ \\
\hline $\begin{array}{l}\text { Extensiveness of } \\
\text { information }\end{array}$ & $\begin{array}{l}\text { Missed information on: } \\
\text { neo-adjuvant therapy, } \\
\text { hormonal therapy, breast } \\
\text { reconstruction. }\end{array}$ & $\begin{array}{l}\text { Missed information on: } \\
\text { heredity, neo-adjuvant } \\
\text { therapy, breast } \\
\text { reconstruction. }\end{array}$ & All proposed information was added. \\
\hline Value elicitation & $\begin{array}{l}\text { Offered no added value } \\
\text { in this form. }\end{array}$ & $\begin{array}{l}\text { Statement were too } \\
\text { simplistic. }\end{array}$ & $\begin{array}{l}\text { Statements and structure was } \\
\text { changed. }\end{array}$ \\
\hline $\begin{array}{l}\text { Round } 3 \text { (second web } \\
\text { based) }\end{array}$ & Patients & Professionals & Changes \\
\hline General & $\begin{array}{l}\text { Information, figures and } \\
\text { photographs were } \\
\text { comprehensible }\end{array}$ & $\begin{array}{l}\text { Information was } \\
\text { relevant and the PtDA } \\
\text { was seen as useful }\end{array}$ & \\
\hline $\begin{array}{l}\text { Data on side effects } \\
\text { and complications }\end{array}$ & $\begin{array}{l}\text { Questioned description } \\
\text { as well as level of side } \\
\text { effect on radiotherapy }\end{array}$ & $\begin{array}{l}\text { Some questions in their } \\
\text { own discipline }\end{array}$ & Data and rates were rechecked \\
\hline $\begin{array}{l}\text { Round } 4 \text { (Final web } \\
\text { based) }\end{array}$ & Patients & Professionals & Changes \\
\hline General & $\begin{array}{l}\text { Easy accessible, useful, } \\
\text { clear }\end{array}$ & $\begin{array}{l}\text { Concise, compact and } \\
\text { complete }\end{array}$ & \\
\hline $\begin{array}{l}\text { Data on recovery after } \\
\text { breast reconstruction }\end{array}$ & $\begin{array}{l}\text { Information was too } \\
\text { optimistic }\end{array}$ & & $\begin{array}{l}\text { As this information was evidence } \\
\text { based no changes were made. }\end{array}$ \\
\hline
\end{tabular}




\section{Changes to the prototype}

In response to the navigation problems experienced with the PowerPoint prototype, we developed a website. The website consisted of four different sections: general information, information on breast-conserving therapy, information on mastectomy, and a summary of pros and cons of each treatment including value elicitation statements.

Numeric information about complications after radiotherapy was added and presented in an easy-to-read figure.

With regard to the value elicitation, no consensus could be reached among the professionals. In view of the patients' disapproval, the value elicitation statements at the opening of the PtDA was removed while the statements at closing remained.

\section{Round 2 (December 2013 - August 2014)}

Second prototype of the PtDA

The second prototype was built as a website. We used the same content, same amount of pictures and graphs to present risks. At the end of the PtDA a summary of the filled in value clarification statements appeared. Navigation was much more simple, this made this prototype more compact without all the duplicated information.

\section{Comments and changes}

\section{Patients}

Patients participating in this round indicated that the PtDA was attractive, easily readable, with clear language, and simple to use. The following comments were made:

1. They thought that the information on radiation therapy was too concise, with short- and long-term effects insufficiently presented. Probability data were viewed as too optimistic, and in their perception patients experienced more complications than the PtDA suggested.

2. Patients wanted more information on neo-adjuvant therapy and hormonal therapy. In addition they found the information on breast reconstruction incomplete, as breast reconstruction treatments were listed but without any further explanation.

3. They also thought that the statements at the end of the PtDA, which were meant as a value elicitation tool, offered no added value and did not support the decision making process.

'The figures on residual damage of radiation therapy are too low. That's because there's been little research into this. Patients' experience shows that the real figures are much higher.' (Patient 2.2) 


\section{Professionals}

The professionals had the following comments:

1. They thought the PtDA lacked information about heredity, information about neo-adjuvant therapy, and about the possibilities for reconstruction.

2. The statements in the value elicitation did not meet the professionals' standards because the statements did not reflect the complexity of the considerations that the women had to deal with. The professionals argued that the decisions patients had to make were presented too simplistically.

3. They thought that the PtDA did not provide all the information that should be available to enable a sound decision. None of them saw any additional value of the PtDA for the quality of decision making.

'If you're going to implement this decision aid, I'm not going to use it. If I'm to use a decision aid for patients, it will have to add something to the quality of the care I provide, and this decision aid does not do that.' (Professional 2.1)

\section{Changes to the prototype}

Some of the professionals, involved in the development had recently attended a presentation about a PtDA for prostate cancer treatment, developed by a company of industrial designers specializing in the development of PtDAs (Zorgkeuzelab $®$ ). Since the professionals were highly enthusiastic about the companies' approach and did not intend to adopt the current prototype, we decided to build a new website in collaboration with Zorgkeuzelab $₫$. The resulting PtDA included interactive elements to provide tailored information to each patient. The structure was simplified and easier to navigate. Contents were made more reader-friendly, with easy-to-read charts, and the content was expanded to include information on heredity, neo-adjuvant therapy and breast reconstruction. Finally, the considerations in the remaining value elicitation at closing were changed, and based on the comments patients had made during consultations and during our interviews.

\section{Round 3 (August 2014 - February 2015)}

Third prototype of the PtDA

The final structure of the PtDA was established in the third prototype. It is an interactive and personalized website co-designed by a company

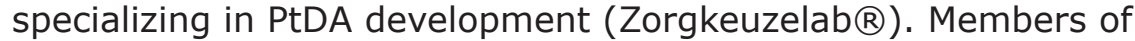
the MUMC+ breast cancer care team provided additional content. A 'prescription pad' was designed for the professionals, enabling them to prescribe a personalized PtDA. Each prescription contains the website address and a unique login code. On each prescription, the professional ticks the pre-printed treatment options that are indicated for the individual patient according to the tumour board. 
Once the patient has logged in, the home page shows a brief explanation of the purpose of the PtDA along with a short video clip explaining shared decision making and the use of the PtDA by a surgeon and a patient. The homepage has two links 'Your diagnosis', and 'Summary'. The first link enables the patient to personalize the patient decision aid, by clicking the different buttons for treatment options just as they are ticked on the prescription. By doing so the patient ensures that she will only meet information on options relevant to her. In addition to this general part, there are three tabs:

Surgical Treatments, Breast Reconstruction and Chemotherapy. The structure of each tab is similar: first 'Information', second 'Value elicitation statements' and finally 'Your preference'. The last two are intended to be completed, printed, and taken along to a visit to a clinician. The value elicitation parts include open text boxes for patients who wish to write about their preference.

\section{Comments and changes}

Patients

Patients indicated that the information as well as the figures and photographs were comprehensible. The following comments were made:

1. Patients questioned the description of side-effects following radiation; they felt that the fatigue was more severe than described. They appreciated the graphs because they made the numerals more transparent.

'I love the way the graphs clarify the numerical information. They look great and are very illustrative.' (Patient 3.1)

\section{Professionals}

In general, the professionals thought the information in the PtDA was relevant. They believed that women would use the PtDA at home to review the information they had already received verbally at the consultation.

The professionals also confirmed that the value elicitation was useful and helpful in making a choice. Still one type of comments remained:

1. The professionals had some questions about facts and figures within their own discipline. For instance: there were some ambiguities concerning re-operation rates after breast-conserving surgery.

'I think it can be very useful for the patient, enabling them to take enough time to look at everything, prior to their visit to the doctor. And be able to look at things again later.' (professional 3.1) 


\section{Changes to the prototype}

Numeric information about re-operations after breast-conserving surgery was added. Medical illustrations of the breast, axilla and upper body were added

\section{Round 4 (March 2015 - June 2015)}

Fourth PtDA

For the fourth version only minor details were altered.

\section{Comments and changes}

\section{Patients}

The patients thought the PtDA would be very useful and was easily accessible. Information was viewed as being understandable and described clearly, and the patients appreciated the medical illustrations. Only one comment was left:

1. The information on breast reconstruction options, regarding the duration of the surgery and the recovery time, emotional stress, social impact and time investment, was perceived as too brief and optimistic.

'What is lacking is some information about the duration, the size, the recovery time after the operation. It's not just a matter of side-effects, but it's also the effort to be invested, the burden.' (Patient 4.2)

\section{Professionals}

The professionals mentioned that the content of the PtDA was concise, compact yet complete and the structure was appealing. They only had some minor textual comments on the percentage of radiotherapy after mastectomy, as recent research had shown that the percentage of women treated with post-mastectomy radiotherapy was higher than indicated in the PtDA.

'What is lacking is that ablation is frequently followed by radiotherapy; after breast amputation patients are often given radiotherapy if there's a positive central node.' (Professional 5.4)

\section{Changes to the prototype}

Information on the impacts, such as the emotional, social and time investments involved in treatments and the side-effects of radiotherapy and breast reconstruction, e.g. by means of personal stories, was not incorporated in the PtDA, Percentages of radiation therapy were discussed among the development team, but in view of the different opinions it was decided not to adjust the percentages for the time being. 


\section{Discussion}

This article outlined the elaborate process of the development and alpha testing of a PtDA in an iterative process for the complex primary treatment decision for women with early stage breast cancer. To establish uptake and improve the effectiveness and usability of PtDAs, patient and other stakeholder involvement is applicable. The iterated process in ongoing data collection and alternating the PtDA has proofed to be a well-chosen way to involve end users and to improve the PtDA (26). In the course of the alpha testing procedure, in this study professionals and patients exerted significant influence on its content, structure and lay-out. Patients had very valuable views, sometimes conflicting among each other but also with professionals, about presentation of relevant risks and values, for which we succeeded to find a common denominator that was still comprehensible for lowereducated patients. We could not comply with all the recommendations of the participants. The research team met with the professional involved in the development after each test round to review all the comments and discuss the impact on the content of the PtDA. If there were uncertainties, literature was reviewed and clinicians in relevant disciplines were asked for input. After thorough considerations the research team and professionals decided whether or not to adjust the content Being engaged in the alpha testing decreased the professionals' resistance towards the idea of using such a PtDA, and increased their sense of ownership, especially after the professional PtDA designers had contributed to the process of development. The consequence of working with the designers was shared ownership of the PtDA, helping to ensure content maintenance and regular updates, but also implying a loss of public accessibility of the PtDA.

It was challenging to reach consensus among the professionals with regard to data on risks and outcomes. They quite often disagreed with the numeric data on probabilities, arguing for instance that complication rates at their hospital differed from the average data reported in the PtDA. This is an interesting thought that resonates with the growing culture of public reporting of specific hospital performance indicators. We wanted to develop a generic PtDA, which can be used across the Netherlands, so the probabilities were based on data from the NABON Breast Cancer Audit (NBCA) and the Netherlands Comprehensive Cancer Organization (IKNL). Where Dutch data were not available, we used the international literature. Professionals involved in the alpha testing argued that the date, viz. re-operation rates, additional radiation rates after mastectomy, diverged from their hospital performance indicators, sometimes showed better results compared to the generic data used in the PtDA. Members of the research team explained that using generic data enable the PtDA being used across the Netherlands. 
If they were not convinced, the professionals involved in the development contacted them again to discuss this issue some more. Being colleagues with the same doubts at the beginning helped to make them understand and in the end, the professionals involved in the alpha test were satisfied with the standardization of risk communication, using exact numbers alternating with ranges. Agreeing with the content of the PtDA is generally viewed as a facilitator for the uptake of the PtDA (3). All the relevant professionals were involved in three of the four test rounds. Assuring that every discipline in the treatment of early stage breast cancer could give an opinion on the content of the PtDA. The sample in the last test round was more homogeneous, due to the fact that at this stage we wanted to be sure, that breast cancer surgeons agreed on the numeric data used.

With regards to the content in terms of risks and benefits, a few points of difference were identified between the professionals and the patients. A continuously recurring disagreement concerned the side-effects of radiotherapy. Although not supported by scientific evidence, patients felt that health problems after radiation, especially in the longer term, were more frequent than indicated in the PtDA. They based their opinion on their own experience and stories from other patients. However, the lack of scientific evidence prevented us from adjusting the facts and figures in the PtDA. Although we could use personal stories to endorse the severity of side effects experienced by patients, but in absence of scientific evidence and after thorough consideration the research team and the involved professionals chose not to do so (27).

Another difference of opinion between patients and professionals was the position of the value elicitation statements within the PtDA. According to the professionals, most patients already have a treatment preference before they are informed about the options. The professionals therefore thought it would be helpful to complete the value elicitation twice, prior to reading the information on risks and benefits and after completing the PtDA. This could help patients correct possible misperceptions. The patients, on the other hand, thought this was confusing. Although, it is obvious that patients require sufficient knowledge of options to realize that certain values are relevant (28). There is not yet clear evidence whether it is more helpful to identify considerations first and then present the options that match these considerations or to present all options prior to the value elicitation. Patients' opinion and the lack of evidence convinced us to present the value elicitation at the end of the PtDA.

During the development process, it became clear that the clinicians who had to adopt the PtDA opposed the short pilot format that the research group initially developed. 
The research group had opted for simplicity (brief and compact) which could be used during consultation to facilitate implementation, while the clinicians objected that the complexity of the decision could not be ignored. The research group finally decided to develop a web-based PtDA instead of the intended 'option grid' format (25).

Option grids are one-page leaflets with a summary table to enable rapid comparison between options, structured by the patients' frequently asked questions. They are designed for use during clinical encounters. The advantage of option grids is that they are less complex to develop, easier to disseminate and less expensive. A web-based PtDA takes time to develop, is expensive and not easy to use during the clinical encounter. However, a PtDA offers more opportunities to provide the comprehensive information required to make complex decisions. Given the complexity of the options for primary treatment of early-stage breast cancer, we realized that a one-page option grid would have been appropriate and sufficient. In addition, our web-based PtDA offers the option of personalizing information. Personalizing the PtDA to the indicated treatment options enables patients to minimize the information overload.

To ensure the quality of qualitative research we assessed its trustworthiness. Trustworthiness criteria are credibility (29). In our study, credibility was ensured by taking sufficient time, viz. two years, to develop the PtDA and gather data about professionals' and patients' requirements regarding usability and acceptability, as well as in-depth data on comprehensibility of the content of the decision aid (prolonged engagement). Participants were invited and encouraged in several rounds to express their thoughts and concerns. A coding list consisting of criteria on acceptability, usability, and comprehensibility was used to categorize the findings, which were then discussed in the research team. We gathered data by means of written comments, think-aloud interviews, focus group discussions, group discussions and telephone interviews and independently analysed by two members of the team, after which interpretations were compared. Different researchers were involved in data collection, and multiple experts on breast cancer, PtDA developers and researchers were involved in the development process. Different sources were used to ensure a wide variety of patient participants, and these were interviewed at different points in their treatment trajectory.

It could be a limitation that the majority of the participants was above 50 years of age. The occurrence of breast cancer in young patients is not very large, so access to this age group is limited. In addition, in young women diagnosed with breast cancer there is often a question of heredity resulting in a treatment limited to mastectomy. 


\section{Conclusion}

We developed a PtDA with end users in four iterative rounds. We focussed on alpha testing involving patient and professionals. Although the final product was much more extensive and complex than had been planned beforehand, we succeeded in building a solid PtDA that was appreciated by patients and professionals alike, including the patient association. The development process we chose was thorough with the involvement of many participants that could contribute to the adaption of the PtDA. The alpha testing has taken time and therefore made the development of a PtDA a prolonged and expensive process. Such a process, however, turned out to be necessary to examine all the thoughts and needs of patients and for the professionals to examine acceptability and gain a sense of ownership, thereby facilitating clinical implementation.

We expect that presenting personalized treatment options in the PtDA will improve the uptake by patients that would enhance patients' knowledge, increase their confidence about the decision and decrease uncertainties about risks. Although many stakeholders were included in the extensive alpha testing procedure, and clinicians in the last test round were impressed by the content and function of the PtDA, there is no guarantee that the PtDA, with generic data, will be adopted by every breast cancer team in the Netherlands. But the fact that in the end all the involved patients, professionals and BVN accepted and appreciated the PtDA could facilitate implementation.

We are currently investigating outcomes and implementation issues in a pilot implementation study (30). 


\section{References}

1. Litiere S, Werutsky G, Fentiman IS, Rutgers E, Christiaens MR, Van Limbergen $\mathrm{E}$, Baaijens $\mathrm{MH}$, Bogaerts J. Bartelink H. Breast conserving therapy versus mastectomy for stage I-II breast cancer: 20 year follow-up of the EORTC 10801 phase 3 randomised trial. The Lancet Oncology. 2012;13(4):412-9.

2. Sivell S, Edwards A, Manstead AS, Reed MW, Caldon L, Collins $\mathrm{K}$, Clements A, Elwyn G. Increasing readiness to decide and strengthening behavioral intentions: evaluating the impact of a web-based patient decision aid for breast cancer treatment options (BresDex: www.bresdex.com). Patient education and counseling. 2012;88(2):209-17.

3. Coulter A, Stilwell D, Kryworuchko J, Mullen PD, Ng CJ, van der Weijden T. A systematic development process for patient decision aids. BMC medical informatics and decision making. 2013;13 Suppl 2:S2.

4. Stacey $D$, Legare $F$, Col NF, Bennett $C L$, Barry MJ, Eden KB, Holmes-Rovner M, Llewellyn-Thomas $H$, Lyddiatt $A$, Legare $F$, Thomson, R. Decision aids for people facing health treatment or screening decisions. Cochrane Database Syst Rev. 2014; 1:CD001431.

5. Whelan T, Levine M, Willan A, Gafni A, Sanders K, Mirsky D, Chambers S. O'Brien MA, Reid S, Dubois S. Effect of a decision aid on knowledge and treatment decision making for breast cancer surgery: a randomized trial. Jama. 2004;292(4):435-41.

6. Sepucha KR, Levin CA, Uzogara EE, Barry MJ, O'Connor AM, Mulley AG. Developing instruments to measure the quality of decisions: early results for a set of symptom-driven decisions. Patient education and counseling. 2008;73(3):504-10.

7. Elwyn G, O'Connor A, Stacey D, Volk R, Edwards A, Coulter A, Thomson R, Barratt A, Barry M, Bernstein S, Butow P, Clarke A, Entwistle $V$, Feldman-Stewart $D$, Holmes-Rovner M, LlewellynThomas H, Moumjid N, Mulley A, Ruland C, Sepucha K, Sykes A, Whelan T. Developing a quality criteria framework for patient decision aids: online international Delphi consensus process. $\mathrm{Bmj}$. 2006;333(7565):417.

8. Evans R, Elwyn G, Edwards A, Watson E, Austoker J, Grol R. Toward a model for field-testing patient decision-support technologies: a qualitative field-testing study. Journal of medical Internet research. 2007;9(3): 221.

9. Elwyn G, Kreuwel I, Durand MA, Sivell S, Joseph-Williams N, Evans R, Edwards E. How to develop web-based decision support interventions for patients: a process map. Patient education and counseling. 2011;82(2):260-5. 
10. Au AH, Lam WW, Chan MC, Or AY, Kwong A, Suen D, Wong AL, Juraskova I, Wong TW, Field RI.. Development and pilot-testing of a Decision Aid for use among Chinese women facing breast cancer surgery. Health expectations : an international journal of public participation in health care and health policy. 2011;14(4):405-16.

11. Harwood R, Douglas C, Clark D. Decision aids for breast and nodal surgery in patients with early breast cancer: development and a pilot study. Asia-Pacific journal of clinical oncology. 2011;7(2):11422.

12. Hollen PJ, Gralla RJ, Jones RA, Thomas CY, Brenin DR, Weiss GR, Schroen A, Petroni GR. A theory-based decision aid for patients with cancer: results of feasibility and acceptability testing of DecisionKEYS for cancer. Supportive care in cancer : official journal of the Multinational Association of Supportive Care in Cancer. 2013;21(3):889-99.

13. Izquierdo F, Gracia J, Guerra M, Blasco JA, Andradas E. Health technology assessment-based development of a Spanish breast cancer patient decision aid. International journal of technology assessment in health care. 2011;27(4):363-8.

14. Jibaja-Weiss ML, Volk RJ, Granch TS, Nefe NE, Spann SJ, Aoki N, Robinson E, Freidman LC, Beck JR. Entertainment education for informed breast cancer treatment decisions in low-literate women: development and initial evaluation of a patient decision aid. Journal of cancer education : the official journal of the American Association for Cancer Education. 2006;21(3):133-9.

15. Molenaar S, Sprangers MA, Rutgers EJ, Luiten EJ, Mulder J, Bossuyt PM, van Everdingen JJ, Oosterveld $\mathrm{P}$, de Haes $\mathrm{HCl}_{\text {, }}$. Decision support for patients with early-stage breast cancer: effects of an interactive breast cancer CDROM on treatment decision, satisfaction, and quality of life. Journal of clinical oncology : official journal of the American Society of Clinical Oncology. 2001;19(6):1676-87.

16. Sawka CA, Goel V, Mahut CA, Taylor GA, Thiel EC, O'Connor AM, Ackerman I, Burt JH, Gort EH. Development of a patient decision aid for choice of surgical treatment for breast cancer. Health expectations : an international journal of public participation in health care and health policy. 1998;1(1):23-36.

17. Sivell S, Marsh W, Edwards A, Manstead AS, Clements A, Elwyn G, BresDex, groupl. Theory-based design and field-testing of an intervention to support women choosing surgery for breast cancer: BresDex. Patient education and counseling. 2012;86(2):179-88.

18. Street RL, Jr., Voigt B, Geyer C, Jr., Manning T, Swanson GP. Increasing patient involvement in choosing treatment for early breast cancer. Cancer. 1995;76(11):2275-85. 
19. Whelan T, Levine M, Gafni A, Sanders K, Willan A, Mirsky D,. Chambers S. O'Brien MA, Reid S, Dubois S. Mastectomy or lumpectomy? Helping women make informed choices. Journal of clinical oncology : official journal of the American Society of Clinical Oncology. 1999;17(6):1727-35.

20. Wong J, D'Alimonte L, Angus J, Paszat L, Metcalfe K, Whelan T, Llewellyn-Thomas H. Warner E, Franssen E, Szumacher E. Development of patients' decision aid for older women with stage I breast cancer considering radiotherapy after lumpectomy. Int J Radiat Oncol Biol Phys. 2012;84(1):30-8.

21. Tiof. Ergonomic requirements for office work with visual display terminals Geneva1998 [ Available from: http://www.usabilitynet. org/tools/r_international.htm\#9241-11.

22. Nielsen J. Usability 101: Introduction to Usability2012.

23. Elling S, Lenz L, de Jong M. Website Evaluation: Questionnaire: Development of a research-based tool for evaluating informational websites. 2007.

24. O'Connor AM, Bennett C, Stacey D, Barry MJ, Col NF, Eden KB, Entwistle V, Fiset V, Holmes-Rovner M, Khangura S, LlewellynThomas H, Rovner DR.. Do patient decision aids meet effectiveness criteria of the international patient decision aid standards collaboration? A systematic review and meta-analysis. Medical decision making : an international journal of the Society for Medical Decision Making. 2007;27(5):554-74.

25. Elwyn G, Lloyd A, Joseph-Williams N, Cording E, Thomson R, Durand MA, Edwards A. Option Grids: shared decision making made easier. Patient education and counseling. 2013;90(2):20712.

26. Witteman HO, Dansokho SC, Colquhoun $H$, Coulter A, Dugas $M$, Fagerlin A, Giguere A, Glouberman S, Haslett L, Hoffman A, Ivers $\mathrm{N}$, Légaré $\mathrm{F}$, Légaré J, Levin $\mathrm{C}$, Lopez $\mathrm{K}$, Montori $\mathrm{V}$, Provencher $\mathrm{T}$, Renaud JS, Sparling K, Stacey D, Vaisson G, Volk RJ, Witteman $\mathrm{W}$, User-centered design and the development of patient decision aids: protocol for a systematic review. Systematic reviews. 2015;4:11.

27. Bekker HL. The loss of reason in patient decision aid research: do checklists affect the validity of informed choice interventions? Patient education and counseling. 2010;78.

28. Fagerlin A, Pignone M, Abhyankar P, Col N, Feldman-Stewart D, Gavaruzzi T, Kryworuchko J, Levin CA, Pieterse AH, Reyna V, Stiggelbout A, Scherer LD, Wills C, Witteman HO. Clarifying values: an updated review. BMC medical informatics and decision making. 2013;13 Suppl 2:S8. 
29. Lincoln YS, Guba EG. But is it rigorous? Trustworthiness and authenticity in naturalistic evaluation. New Directions for Program Evaluation. 1986;1986(30):73-84.

30. Savelberg W, Moser A, Smidt M, Boersma L, Haekens C, Weijden T. Protocol for a pre-implementation and post-implementation study on shared decision-making in the surgical treatment of women with early-stage breast cancer. BMJ Open. 2015;5(3):e007698. 


\section{Appendix 1 Interview guide focus group}

What was your first impression with regard to the PtDA?

Content of the PtDA:

- What did you think about het content of the PtDA?

- Which information did you find the most relevant?

- Which information did you find the least relevant?

- What did you think about the content of the value elicitation?

- What are the improvements we have to make concerning the content?

- Which information did you miss?

- Are there any subjects you would like to add to the PtDA?

Navigation:

- How did you experience the navigation of the website?

- How fast could you find all required information?

- Which information was hard to find?

- Which information was easy to find?

Amount of information:

- What was your impression of the amount of information per page?

General:

- Do you have any suggestion on how to improve the navigation?

- Do you have any suggestions on how to improve the content?

- Do you have any other suggestions to improve the website overall? 
Protocol for a pre-post implementation study on shared decision making in the surgical treatment of women with early stage breast cancer.

Wilma Savelberg

Albine Moser

Marjolein Smidt

Liesbeth Boersma,

Christel Haekens

Trudy van der Weijden

BMJ Open 2015;5:e007698. doi: 10.1136/bmjopen -2015007698 


\section{Abstract}

\section{Introduction}

The majority of patients diagnosed with early stage breast cancer are in a position to choose between having a mastectomy or lumpectomy with radiation therapy (breast conserving therapy). Since the long-term survival rates for mastectomy and for breast conserving therapy are comparable, patients' informed preferences are important for decision making. Although most clinicians believe they do involve patients in the decision-making process, the information that women with breast cancer receive regarding the surgical options is often rather subjective, and does not invite patients to express their preferences. Shared decision making (SDM) is meant to help patients clarify their preferences, resulting in greater satisfaction with their final choice. Patient decision aids can be supportive in SDM. We present the protocol of a study to beta test a patient decision aid and optimise strategies for the implementation of SDM regarding the treatment of early-stage breast cancer in the actual clinical setting.

\section{Methods and Analysis}

This paper concerns a pre-post implementation study, lasting from October 2014 to June 2015. The intervention consists of implementing SDM using a patient decision aid. The intervention will be evaluated using qualitative and quantitative measures, acquired prior to, during and after the implementation. Outcome measures are knowledge about treatment, perceived SDM and decisional conflict. We will also conduct face-to-face interviews with a sample of patients and their care providers, to assess their experiences with the implementation of SDM and the patient decision aid.

\section{Ethics and Dissemination}

This protocol was approved by the Maastricht University Medical Centre ethics committee. The findings will be disseminated through peerreviewed journal articles and presentations at national conferences. Findings will be used to finalise a multi-faceted implementation strategy to test the implementation of SDM and a patient decision aid in terms of cost-effectiveness, in a multicentre cluster RCT. 


\section{Introduction}

Several studies have revealed that mastectomy and breast conserving surgery with radiation therapy are comparable in terms of local control and long-term survival (1). In addition, some studies found no difference in quality of life between patients treated with breast conserving treatment or mastectomy, while other studies reported higher quality of life after breast-conserving treatment compared with mastectomy (2). Many patients with early-stage breast cancer face the dilemma of choosing between these two options when considering breast surgery. Deciding between these two can be regarded as being influenced by patient preferences.

Evidence is growing that patient preferences may vary substantially between individuals (3). In addition to survival, important factors in the decision-making process are the patient's age, family history and preference for reconstruction and quality of life. At the time of diagnosis, patients with breast cancer have their own values, concerns and knowledge, which can influence their treatment preferences (2).

There is also increasing evidence that most patients want to be involved in treatment decisions (4). For many patients, greater involvement in cancer treatment decisions can improve their knowledge about treatment benefits, enhance their satisfaction with the decision and improve their quality of life $(5,6)$. It is important to present the information to patients as neutrally as possible and to involve them in the decision, in order to achieve a tailor-made, personalised treatment plan. Shared decision making (SDM) is regarded as a promising model to achieve such patient involvement. SDM has been defined as: 'an approach where clinicians and patients share the best available evidence when faced with the task of making decisions, and where patients are supported to consider options, to achieve informed preferences" (7).

Nevertheless, there is a problem with the implementation of SDM in clinical practice. Physicians typically feel they do not have the time, or lack the skills, to offer a complete and balanced presentation of the pros and cons of suitable medical options (8). One measure to support SDM would be to use a patient decision aid, (9-11) which provides information facilitating discussion and deliberation about treatment options. There is strong evidence that these aids are effective in achieving informed preferences and decisions that are more in line with patient preferences (4). The distribution and use of patient decision aids is also associated with increased knowledge about options and decreased decisional conflict (10). 
We feel that integrating a patient decision aid in the daily workflow at the clinic is the first move towards implementing more uniform and objective SDM in an actual oncology setting. In the USA and the UK, patient decision aids have been implemented as part of a usual care program in breast cancer centres. Both programs consist of various decision aid materials, including videos and booklets. In addition, both programs provide tools involving question listing, audio recording and note taking services by trained associates, who are either premedical interns or professional counsellors $(6,12,13)$. Although these are excellent initiatives, one should be cautious about merely copying these approaches, as implementation should take political, cultural and economic conditions into consideration $(14,15)$.

The challenge is to feasibly embed SDM and the patient decision aid in the clinical practice workflow. It is well-known that the implementation of new methods in clinical practice can be difficult, as clinicians have busy schedules filled with daily routines and there is often no obvious motivation nor time to change them (16). Implementation strategies which do not focus on the problems that health professionals experience are less effective in accomplishing change (1).

One single intervention is probably insufficient to achieve successful implementation of SDM using patient decision aids in clinical practice, so a systematic approach and careful planning of implementation activities is needed (15). Achieving successful implementation requires devoting attention to the process of developing the patient decision aid, its scientific basis, its format and its content. The Implementation of Change Model describes the involvement of different target groups in the 'development, testing and execution of an implementation' (15). 


\section{Objectives and research questions}

The objective of this project is to pilot-test and optimise strategies for the implementation of SDM for patients with early-stage breast cancer in an actual clinical setting.

Our hypothesis is that a multi-facetted strategy would enable us to implement SDM in such a way that it meets the needs and demands of both professionals and patients, without disrupting daily practice.

Primary research questions to support the development of the implementation strategy are:

1. What are the perceived barriers and facilitators, needs and preferences of patients and the professionals of the breast cancer team with regard to:

- the integration of the patient decision aid in patient care, making it acceptable for integration in the clinical workflow;

- the model of SDM, i.e. how, when and by whom it should be integrated in the clinical pathway;

- coaching of the professionals or instructions for SDM.

Secondary research questions to support the design of a large-scale study to evaluate the final implementation strategy are:

2. What is the impact of the implementation of the patient decision aid on the process of SDM, on the patients' knowledge, and on decisional conflict?

$2 b$. To what extent does the decision aid produce changes in the intended (i.e. preferences) and final treatment decisions by doctors and patients? 


\section{Method}

\section{General design}

The design of the study is a pre-post implementation to beta test the patient decision aid and develop related implementation strategies in the clinic, involving quantitative and qualitative methods. For the sake of readability, the methods are described below in the sequence in which they are carried out, starting with the quantitative data collection (which is not in line with the above sequence of the research questions).

In the pre-implementation period ( 3 months), data are collected from early breast cancer patients $(\mathrm{N}=40)$ receiving care as usual. During the implementation period ( 5 months) data are collected from women $(\mathrm{N}=40)$ taking part in the process of SDM using the patient decision aid. This study will last from 1 October 2014 to 1 June 2015.

\section{Setting}

Data collection takes place in four Dutch hospitals in the western, central and southern parts of the Netherlands.

\section{Participants}

\section{Patients}

Each hospital will include 10 patients with newly diagnosed early breast cancer (stage I or II) who are eligible for breast conserving therapy or mastectomy as their primary therapy during the pre-intervention period. During the intervention period, each hospital will again include 10 patients (mother sample) with newly diagnosed early breast cancer (stage I or II) who are eligible for breast conserving therapy or mastectomy as their primary therapy. From this sample, four patients of each hospital will be included to take part in the qualitative study during the post-intervention period (Table 1).

Table 1 Recruitment of patients

\begin{tabular}{|c|c|c|c|c|c|c|}
\hline & \multicolumn{2}{|c|}{ Pre-intervention } & \multicolumn{2}{|c|}{ Intervention } & \multicolumn{2}{|c|}{ Post-intervention } \\
\hline & \multicolumn{2}{|c|}{ Quantitative data collection } & \multicolumn{2}{|c|}{ Quantitative data collection } & \multicolumn{2}{|c|}{ Qualitative data collection } \\
\hline & Hospital & $\begin{array}{l}\text { Number of } \\
\text { patients }\end{array}$ & Hospital & $\begin{array}{l}\text { Number of } \\
\text { patients }\end{array}$ & Hospital & $\begin{array}{l}\text { Number of } \\
\text { Interviews }\end{array}$ \\
\hline Patients & $\begin{array}{l}\text { H. } 1 \\
\text { H. } 2 \\
\text { H. } 3 \\
\text { H. } 4\end{array}$ & $\begin{array}{l}10 \\
10 \\
10 \\
10\end{array}$ & $\begin{array}{l}\text { H. } 1 \\
\text { H. } 2 \\
\text { H. } 3 \\
\text { H. } 4\end{array}$ & $\begin{array}{l}10 \\
10 \\
10 \\
10\end{array}$ & $\begin{array}{l}\text { H. } 1 \\
\text { H. } 2 \\
\text { H. } 3 \\
\text { H. } 4\end{array}$ & $\begin{array}{l}4 \text { out of the } 10 \\
4 \text { out of the } 10 \\
4 \text { out of the } 10 \\
4 \text { out of the } 10\end{array}$ \\
\hline Professionals & & & & & $\begin{array}{l}\mathrm{H} 1 \\
\mathrm{H} 2 \\
\mathrm{H} 3 \\
\mathrm{H} 4\end{array}$ & $\begin{array}{l}\text { All participating } \\
\text { professionals, but at least } 1 \\
\text { surgeon and nurse per } \\
\text { hospital }\end{array}$ \\
\hline
\end{tabular}




\section{Inclusion criteria}

The study will include patients diagnosed with stage I or II breast cancer, provided the two treatment options, mastectomy or breast conserving surgery with radiotherapy, are applicable. Eligible patient should be able to speak and understand Dutch.

Eligible patients will be identified at the multidisciplinary meetings of the breast cancer oncology team. The surgeon or nurse revealing the cancer diagnosis to the patients will inform them about this study. They will also provide the patients with an information letter to inform them about the aim and procedure of the study and the importance of their participation: the letter includes an informed consent form.

Handling of personal data will be in accordance with the Dutch Personal Data Protection Act and Medical Research (Human Subjects) Act). The study has been approved by the Maastricht University Medical Centre (MUMC) ethics committee.

\section{Professionals}

In each hospital, all breast surgeons, radiation oncologists, nurse practitioners and nurses taking part in the education and decisionmaking process will be invited to participate in the intervention.

\section{Intervention}

The intervention consists of instruments and activities to implement SDM, including the patient decision aid, in the clinic.

A draft patient decision aid has been developed by a research team from MUMC and the Amsterdam Academic Medical Centre (AMC), based on existing patient decision aids (www.kiesbeter.nl), the Dutch clinical practice guideline on breast cancer, additional literature and expert opinion. This draft was alpha tested in a first trial round for professionals and patients. The decision aid is an expected to be easy-to-use website, which is made available to patients included in the study through a link and a password. It offers an explanation of the surgical options, as well as a brief overview of considerations that could be relevant to women regarding their own values, preferences and concerns and enables patients to navigate through the decision aid. Comprehensive information is presented about mastectomy and breast-conserving surgery, including numerical information about survival and recurrence rates, pros and cons of both treatments and side-effects.

The verbal information is supported by pictures and graphs. Finally, 
the information is summarised in a factsheet. The decision aid further includes a number of questions to help women identify their values (17). To make the information more accessible during the consultation, we have developed an additional options grid, in the form of a one-page table summarising the treatment options, which can also be used at home.

The patient decision aid will be made available to clinicians in February 2015. Participating clinicians need to learn to use the patient decision aid correctly. To achieve this, they will be instructed regarding SDM and its favourable effects. The instructions include a compact e-learning component with role-modelling and suggestions for integrating the patient decision aid in the clinical pathway and for task delegation. This will be provided in a tailored manner, with a certain degree of local adaptation allowed for each hospital and department.

\section{Data collection and analysis}

Quantitative data (see below) will be collected from 10 patients of each hospital during the pre-implementation period (1 November 2014 - 1 February 2015) and from 10 patients of each hospital during the intervention period (1 February 2015 - 1 May 2015), using consecutive sampling of patients who fill in the questionnaires. In addition, 4 of the 10 patients included during the intervention period will be recruited by surgeons and nurses for collection of qualitative data ( see below) from 1 May 2015 to 1 June 2015, that is, after the intervention. These patients will be selected using convenience sampling.

The results from both study groups will be compared by descriptive statistical procedures to identify differences between the two groups.

\section{Quantitative data}

Variables and instruments

A variety of instruments will be used to assess different outcome measures (table 2):

- Patients' knowledge about breast cancer and treatment options will be assessed using an adapted breast cancer information test (18). This scale includes knowledge-type questions about early stage breast cancer treatment. Questions are answered using true or false.

- Decisional conflict will be assessed using the Decisional Conflict Scale (DCS)(19). This 16-item scale captures factors associated with decisional conflict or uncertainty. The DCS has three subscales: decisional uncertainty, factors that contribute to uncertainty, and perceived effective decision. Each of these items is scored on a fivepoint Likert scale from 1 (strongly agree) to 5 (strongly disagree). 
- The process of SDM will be assessed by the perceptions of patients and clinicians, using the SDM Q9 instrument.(20) The Dutch version of the SDM Q9 has recently been validated. The instrument has a dyadic approach and consists of nine statements, which can be rated on a six-point scale from 0 (completely disagree) to 5 (completely agree). Summing all items leads to a raw total score between 0 and 45.

- The process of SDM will also be assessed by an independent observer from audio recordings of the consultations. The audio tapes will be rated with the Observer OPTION (Observing patient involvement) scale 12 item by two researchers (21). The Observer OPTION scale 12 item consists of a set of competences, including problem definition, explaining legitimate choices, portraying options and communication risk, and conducting the decision process. The instrument aims to measure to what extent the patient is involved in the decision about the treatment, and consists of 12 items. The measurement level is ordinal with scores of 0 to 4 .

- An audit will be conducted on the actual decision taken.

- The time that participants spend reading the patient decision aid will be recorded.

- The time spent by the professionals on consultation will be determined from the audio recordings.

\section{Qualitative data}

Variables and instruments

Information on the patient decision aid will be obtained from patients by means of semi-structured interviews which will be conducted during the post-intervention period (22). An interview guide will be prepared for the patient interviews. The questions will focus on the content, presentation and navigation (user-friendliness) and the perceived usefulness of the patient decision aid (utility), and on the patients' experiences with the SDM process.

Qualitative data from the clinicians will be obtained through focus group or face-to-face discussions to evaluate the SDM and the use of the decision aid, during the post-intervention period. A question route (23) will be defined moving from general to more specific issues, focusing on their perceptions and experiences of applying SDM and the patient decision aid, as well as general appreciation and the intention to recommend the patient decision aid to colleagues. We will also discuss barriers and facilitators (positive features, changes needed, relevance, timing of use). 
The interviews with patients and the discussions with the clinicians will be audiotaped and transcribed verbatim. Both data sets will be analysed using the constant comparison method (24).

Table 2: Outcome measures

\begin{tabular}{|c|c|c|c|c|c|}
\hline & Pre-intervention period & & Intervention period & & Post-intervention period \\
\hline & Nov 2014 - Jan 2015 & $\begin{array}{l}\text { Feb } \\
2015\end{array}$ & Feb - May 2015 & $\begin{array}{l}\text { June } \\
2015\end{array}$ & May-June 2015 \\
\hline & $\begin{array}{l}\text { Quantitative collection } \\
\text { among patients }\end{array}$ & & $\begin{array}{l}\text { Quantitative collection } \\
\text { among patients }\end{array}$ & & $\begin{array}{l}\text { Qualitative collection among patients } \\
\text { and professionals }\end{array}$ \\
\hline \multicolumn{6}{|l|}{ Measures } \\
\hline Time to read the patient decision aid & & & $\mathrm{x}$ & & \\
\hline $\begin{array}{l}\text { Knowledge about breast cancer and } \\
\text { treatment (breast cancer information } \\
\text { test) }\end{array}$ & $x$ & & $x$ & & \\
\hline Decisional Conflict Scale (DCS) & & $x$ & & $x$ & \\
\hline $\begin{array}{l}\text { Perceived shared decision making } \\
\text { (SDM-Q9) }\end{array}$ & $x$ & & $x$ & & \\
\hline $\begin{array}{l}\text { Process of shared decision making } \\
\text { objectivized (OPTION) }\end{array}$ & $x$ & & $x$ & & \\
\hline Consultation time & $x$ & & $x$ & & \\
\hline Experiences & & & & & $\mathrm{X}$ \\
\hline Perceptions of feasibility & & & & & $x$ \\
\hline Usability & & & & & $x$ \\
\hline Utility & & & & & $x$ \\
\hline Satisfaction & & & & & $x$ \\
\hline
\end{tabular}

\section{Discussion}

\section{Design}

The design combines the strengths of quantitative and qualitative research (25). The qualitative data obtained, which are based on human experience, will be examined in detail and in depth. The data will be used to assess the usability of the patient decision aid and the barriers and facilitators for the implementation of the decision aid in a small group, including both professionals and patients. We aim to evaluate the feasibility of the measurement instruments and the potential effect of the implementation strategies (instructions and patient decision aid) on the performance and experience of SDM compared to a historical control group, to enable a power calculation for a large multicentre RCT.

\section{Sample size}

Limitations of the sampling process: in view of the available time, the size of the target group and the nature of the intervention, it is not possible to conduct a random sampling. During the course of the study, all patients with early stage breast cancer in the participating hospitals will be invited to participate, until we reach the number of 10 participants for each hospital. Thus, over a certain period, the entire accessible population will be studied (26). Inviting all members of the accessible population reduces the risk of bias. 
According to Johanson (27), a number of 30 to 40 patients is recommended for a pilot study whose purpose is a preliminary survey. The sample size in this study meets these recommendations.

Sample size for qualitative data collection in qualitative studies tends to be small. The number of participants needed depends on the point where data saturation is reached. Data saturation is expected to occur after 12 participants have been interviewed, provided these patients are not verbally vulnerable.(25) Since little is known about SDM and the use of patient decision aids in the clinical setting with respect to this data, this study will include 20 patients who are exposed to the intervention. We thus expect that data saturation will occur, and that the process will yield rich and in-depth findings.

\section{Implementation of the intervention}

Achieving success requires a systematic approach and careful planning of the implementation strategy. Joseph-Williams (2013) argues that barriers could be overcome by behavioural changes at the level of the patient, clinicians/healthcare team and the organisation in daily care. In this study we primarily focus on the clinicians/healthcare team and the organisation, since interventions are successfully implemented when barriers regarding these factors are overcome $(1,28)$.

Worldwide training programs on SDM vary greatly in what they offer and how they present it. In addition, evidence of their effectiveness is inconclusive (29). We have opted for e-learning because the purpose in this study is to examine the support and assistance required to develop suitable educational programmes in an RCT. E-learning might be a promising strategy to support the implementation of SDM and patient decision aids in actual clinical settings.

\section{Measures}

The SDMQ9 is a recently developed instrument measuring the perceptions of the stakeholders of the SDM process (30). We decided to use this instrument because of the dyadic approach in SDM. Both doctors and patients are acknowledged and seen as equally involved in the consultation and decision making. A study concerning the use of the Dyadic OPTION scale supports this dyadic approach (31). 
The process of SDM will be analysed in this study by means of the OPTION scale. This scale has been validated and is based on the phases of SDM. In her review, Stacey found two studies using the OPTION scale to evaluate the interaction between patient and professional. More recently, the Observer OPTION5 item was introduced as an instrument focussing on essential aspects of SDM, providing shorter measurements. Despite its promising results, it needs more empirical work (32) to explore its scientific value. To our knowledge, there are few studies combining all of these measurements to gain extensive insights into the process of SDM and the implementation of a patient decision aid.

We originally intended to measure decisional conflict immediately after the completion of surgical treatment. But based on recommendations of the professionals, whose experience is that satisfaction or regret does not occur until later in the process, we decided to measure decisional conflict three months after the surgical treatment.

In conclusion, this study seeks to examine the main obstacles and success factors for the implementation of SDM using a patient decision aid, and to determine the most favourable way to integrate this in the clinical pathway. In addition, we will investigate the impact of this implementation on several outcome variables. These will be used as a basis to design a multi-faceted complex implementation strategy, with the intention of testing the implementation of SDM and a patient decision aid in a multicentre cluster RCT. 


\section{References}

1. Baker R, Camosso-Stefinovic J, Gillies C, Shaw EJ, Cheater F, Flottorp S, Robertson N. Tailored interventions to overcome identified barriers to change: effects on professional practice and health care outcomes. Cochrane Database Syst Rev2010. p. CD005470.

2. Fisher B, Anderson S, Bryant J, Margolese R, Deutsch M, Fisher E, Jeong J-H, Wolmark N.Twenty-year follow-up of a randomized trial comparing total mastectomy, lumpectomy, and lumpectomy plus irradiation for the treatment of invasive breast cancer. N Engl J Med. $2002 ; 347(16): 1233-41$.

3. Obeidat R, Finnell DS, Lally RM. Decision aids for surgical treatment of early stage breast cancer: a narrative review of the literature. Patient education and counseling. 2011;85(3):e311-21.

4. Stacey $D$, Bennett $C L$, Barry MJ, Col NF, Eden KB, Holmes-Rovner M, Llewellyn-Thomas H, Lyddiatt A, Legare F, Thomson, R. Decision aids for people facing health treatment or screening decisions. Cochrane Database Syst Rev. 2011(10):CD001431.

5. Livaudais JC, Franco R, Fei K, Bickell NA. Breast cancer treatment decision-making: are we asking too much of patients? Journal of general internal medicine. 2013;28(5):630-6.

6. Belkora JK, Loth MK, Volz S, Rugo HS. Implementing decision and communication aids to facilitate patient-centered care in breast cancer: a case study. Patient Educ Couns. 2009;77(3):360-8.

7. Elwyn G, Frosch D, Thomson R, Joseph-Williams N, Lloyd A, Kinnersley P, Cording E,Tomson DD, Rollnick S, Edwards A, Barry M.. Shared decision making: a model for clinical practice. J Gen Intern Med. 2012;27(10):1361-7.

8. Fowler FJ, Jr., Levin CA, Sepucha KR. Informing and involving patients to improve the quality of medical decisions. Health Aff (Millwood). 2011;30(4):699-706.

9. Stacey D, Kryworuchko J, Bennett C, Murray MA, Mullan S, Legare F. Decision coaching to prepare patients for making health decisions: a systematic review of decision coaching in trials of patient decision AIDS. Med Decis Making. 2012;32(3):E22-33.

10. Belkora JK, Volz S, Teng AE, Moore DH, Loth MK, Sepucha KR. Impact of decision aids in a sustained implementation at a breast care center. Patient Educ Couns. 2012;86(2):195-204.

11. Waljee JF, Rogers MA, Alderman AK. Decision aids and breast cancer: do they influence choice for surgery and knowledge of treatment options? J Clin Oncol. 2007;25(9):1067-73.

12. Belkora JK, Teng A, Volz S, Loth MK, Esserman LJ. Expanding the reach of decision and communication aids in a breast care center: a quality improvement study. Patient Educ Couns. 2011;83(2):234-9. 
13. Pass M, Belkora J, Moore D, Volz S, Sepucha K. Patient and observer ratings of physician shared decision making behaviors in breast cancer consultations. Patient Educ Couns. 2012;88(1):93-9.

14. Lloyd A, Joseph-Williams N, Edwards A, Rix A, Elwyn G. Patchy 'coherence': using normalization process theory to evaluate a multifaceted shared decision making implementation program (MAGIC). Implement Sci. 2013;8(1):102.

15. Grol R, Wensing M, Eccles M, Davis D. Improving patient care: The implementation of change in health care: John Wiley and Sons; 2013.

16. Elwyn G, Laitner S, Coulter A, Walker E, Watson P, Thomson R. Implementing shared decision making in the NHS. BMJ. 2010;341:c5146.

17. Fagerline $A$, Pignone $M$, Abhyanka $P$, Col N, Feldman-Stewart D, Gavaruzzi T, Kryworuchko J, Levin CA, Pieterse AH, Reyna V, Stiggelbout A, Scherer LD, Wills C, Witteman HO, Clarifying values: an updated review. Medical informatics an decision making $2013 ; 13(2)$.

18. Sawka CA, Goel V, Mahut CA, Taylor GA, Thiel EC, O'Connor AM, Ackerman I, Burt JH, Gort EH. Development of a patient decision aid for choice of surgical treatment for breast cancer. Health Expect. $1998 ; 1(1): 23-36$.

19. Stalmeier PF, Roosmalen MS, Verhoef LC, Hoekstra-Weebers JE, Oosterwijk JC, Moog U, Hoogerbrugge N, van Daal W. The decision evaluation scales. Patient Educ Couns. 2005;57(3):286-93.

20. Kriston L, Scholl I, Holzel L, Simon D, Loh A, Harter M. The 9-item Shared Decision Making Questionnaire (SDM-Q-9). Development and psychometric properties in a primary care sample. Patient Educ Couns. 2010;80(1):94-9.

21. Elwyn G, Edwards A, Wensing M, Hood K, Atwell C, Grol R. Shared decision making: developing the OPTION scale for measuring patient involvement. Qual Saf Health Care. 2003;12(2):93-9.

22. Kvale S, Brinkmann S. Interviews. Learning the craft of qualitative research interviewing. London: Sage; 2009.

23. Krueger R, Casey M. Focusgroups. A practical guide for applied research. 4 ed. Thousand Oaks, CA: Saga.

24. Corbin J, Strauss A. Basics of qualitative research. 3 ed. Thousand Oaks CA Saga; 2006.

25. O'Connor A, Llewellyn-Thomas H, Stacey D. IPDAS Collaboration Background Document. 2005.

26. Polit D, Beck C. Nursing reasearch; Generating and assessing Evidence fot Nursing Practice. 9 ed: Wolters kluwer Healt; 2012.

27. Johanson G, GP B. Initial Scale Development: Sample Size for Pilot Studies. Educational and psychological measures. 2010;70(3):394400. 
28. Joseph-Williams N, Elwyn G, Edwards A. Knowledge is not power for patients: a systematic review and thematic synthesis of patientreported barriers and facilitators to shared decision making. Patient Educ Couns. 2013.

29. Legare F, Politi MC, Drolet R, Desroches S, Stacey D, Bekker H, Sdm-Cpd Team. Training health professionals in shared decisionmaking: an international environmental scan. Patient Educ Couns. 2012;88(2):159-69.

30. Scholl I, Kriston L, Dirmaier J, Harter M. Comparing the nine-item Shared Decision-Making Questionnaire to the OPTION Scale - an attempt to establish convergent validity. Health Expect. 2012.

31. Melbourne E, Roberts S, Durand MA, Newcombe R, Legare F, Elwyn G. Dyadic OPTION: Measuring perceptions of shared decision-making in practice. Patient Educ Couns. 2011;83(1):55-7.

32. Elwyn G, Lloyd A, Joseph-Williams N, Cording E, Thomson R, Durand MA, Edwards A. Option Grids: shared decision making made easier. Patient Educ Couns. 2013;90(2):207-12. 
Integrating a patient decision aid in a clinical pathway; a process evaluation among breast cancer care teams with a favourable attitude towards shared decision making.

Wilma Savelberg

Liesbeth Boersma

Marjolein Smidt

Trudy van der Weijden

Submitted European journal of cancer care. 


\section{Abstract}

\section{Objective}

Although, patient decision aids (PtDA) have been shown to improve shared decision making (SDM), the integration in clinical care pathways seems to remain limited.

This study investigated implementation challenges by assessing: 1) the uptake of strategies to implement a PtDA by professionals; 2) the uptake of the PtDA by patients; 3 ) desirable outcomes such as, concordance between preference and actual treatment and patients' perceptions on involvement.

\section{Methods}

We performed a prospective process evaluation among four breast cancer care teams that had been exposed to a multifaceted implementation strategy. Data were gathered by auditing patient files and by telephone interviews with patients. We used descriptive statistics and explored predictors of the uptake of the PtDA.

\section{Results}

The full implementation strategy was followed for $14 \%$ of the included patients $(\mathrm{N}=84)$. In over half of the patients $(58 \%)$ tumour boards advised more than one option. Nearly all patients (92\%) reported to have received the PtDA while $67 \%$ had actually used it. The most important factor influencing the use, was the clinician promoting it when delivering the PtDA (OR $9.9595 \%$ CI 3.03-37.72). For $90 \%$ of the patients, concordance was found between stated preference and final treatment. Non-concordance could partly be explained because 5 patients incorrectly received a PtDA.

\section{Discussion and conclusion}

Although the full implementation strategy was followed in a minority of the patients, a satisfactory delivery of the PtDA and concordance was achieved. Redesign of the care pathway and personal instruction on the use of PtDAs seem crucial. Clinicians should be aware that overuse of PtDAs may raise false expectations, and that using a PtDA is not a purpose, but an instrument to support SDM. 


\section{Introduction}

For most women diagnosed with early stage breast cancer (stage I or II) both breast conserving therapy (BCT) or a mastectomy are equally effective in terms of survival (1), indicating that the patient's preference should probably dominate the decision. Preferences, or so-called decisional attributes, that are often mentioned by patients are related to the level of fear and anxiety, perceived survival odds, body image values, attitudes toward radiotherapy, the preference or perceived preference of the surgeon, the communication between patient and professional, and the patient's involvement in the decision-making process $(2,3)$.

Several studies have shown that involving patients in the decision making process improves their knowledge of treatment risks and benefits, and their satisfaction with the final decision (4). Patient decision aids (PtDA) improve the process of patients' involvement in the decision making process, as well as outcomes such as more accurate risk perceptions among patients, and decisions being more consistent with the patients' values (5). There is also increasing evidence that most patients want to participate actively in treatment decisions (6).

Although support for the large-scale adoption of shared decision making (SDM) is growing, actual implementation is slow and faces many challenges (7). Implementation of SDM is suffering from lack of knowledge and self-efficacy among clinicians $(8,9)$. Negative attitudes of clinicians toward SDM in general, or toward the content of PtDAs are also frequently cited as barriers $(10,11)$. Assuming that PtDAs are an essential tool in supporting the SDM process, we developed a PtDA based on the IPDAS criteria between 2013 and 2015, as part of the implementation of SDM in breast cancer care (12). As part of the development the PtDA was pilot-tested by patients and professionals in four Dutch hospitals which had shown a particular interest in the PtDA, as well as by patient advocates of the Dutch breast cancer association (12). During the pilot period we encountered various challenges such as embedding the PtDA in the clinical pathway, enabling its timely presentation to patients without causing delays to the start of treatment, motivating professionals to actually deliver the PtDA, and dividing the decision-making process over more than one consultation. Not all patients used the PtDA, which was due to lack of motivation, not being clearly instructed, distraction by intense emotions, or otherwise feeling resistance. Meaning that a combination of implementation strategies, not only focussing on the clinician but also on the process and organisation of breast cancer care, could lead to a successful implementation of the PtDA. The local problems we found are in line with comparable studies from the UK, France and Canada (13-16). 
Giving the barriers we encountered in our development study and in the literature on breast cancer care, we developed implementation strategies, some of which were customized for each hospital, and subsequently used these to implement the PtDA in breast cancer care. The main aim of the current implementation study was to further investigate implementation challenges of the PtDA thus improving the process of SDM. We did so by assessing 1 . the uptake of the PtDA implementation strategies in breast cancer care by professionals, 2 . the uptake of the PtDA as perceived by patients, and 3 . desirable outcomes such as concordance between their stated preferences and the actual decisions made about treatment, and the patients' perceptions of being involved in decision making.

\section{Method}

\section{General Design}

We designed an observational study, a prospective process evaluation of the above-described strategies to implement the PtDA in regional hospitals. Quantitative data were collected by auditing patient files and by interviewing patients by telephone using a structured questionnaire. To describe the our findings we used SQUIRE 2.0 guidelines for reporting quality improvement study (17).

The study took place from May 2016 to June 2017, with four hospitals being included on starting dates at their own convenience, and a maximum duration of intervention and data collection of 8 months per hospital.

\section{Participants}

The breast cancer team of MUMC+ is part of a regional oncology network (OncoZON) consisting of nine breast cancer teams in the south of the Netherlands. In the early months of 2016, all teams were invited to implement SDM using the implementation strategy, and six teams agreed to do so. Four of these teams also agreed to participate in the process evaluation. To get access to the PtDA, the teams had to consent to pay a fixed fee to the company hosting the PtDA. Each hospital was asked to consecutively include 30 patients with newly diagnosed breast cancer, stage I or II, who were eligible for breast conserving therapy or mastectomy and who had been offered the PtDA, according to the professionals. Eligible patients should be able to speak and understand Dutch and were identified at the tumour board meetings. The clinician presenting and explaining the cancer diagnosis and treatment options to the patient, who also handed over the login code for the PtDA, informed the eligible patient about the present study. 
The clinician provided written information about the aim and procedure of the study. If the patient gave permission to be approached, the researcher (W.S.) phoned the patient within two weeks after the consultation with the clinician.

\section{Ethical considerations}

The MUMC+ ethics committee (No. 16-4-083) declared that this study does not fall under the scope of the Medical Research Involving Human Subjects Act. Handling of personal data was in accordance with the Dutch Personal Data Protection Act and Medical Research (Human Subjects) Act.

\section{Intervention}

The intervention consisted of offering patients the personalized PtDA, and offering professionals a set of strategies to enhance the performance of SDM in clinical practice, tailored to the specific needs and workflow of each hospital. The preferred procedure for presenting and using the PtDA was described as follows:

- The personal login code is printed on a paper prescription pad, which is available on the clinician's desk in the consultation room. Each sheet contains a drawing of the breasts to help the clinician indicate the size and location of the tumour, as well as the various treatment choices to remind the professional about presenting the PtDA, and a unique personal login code.

- The clinician hands out the prescription pad sheet with the personal login code to 'prescribe' the PtDA. The clinician personalizes the sheet by ticking the treatment options that are relevant for the patient additional to breast conserving treatment or mastectomy, viz. adjuvant or neo-adjuvant chemotherapy, and/or reconstructive surgery during or after the curative surgery. (See Appendix 1)

- The web-based PtDA can be read at home, where the patient logs in. After first reading the general information, the patient is invited to tick the options that had been marked on the prescription pad sheet, so only the treatment options that are available to the individual patient are shown on the screen. Thus, each patient can personalize the PtDA to prevent overload of information.

- The PtDA includes a 4-minute video, aimed at both patients and professionals, in which a clinician and a patient talk about the importance of SDM and how the PtDA can be used to support this process. The purpose is to raise awareness of the team character of the SDM process and the positive impact of SDM.

The PtDA presents comprehensive information about all the possible options. The information includes numerical information about survival and recurrences rates, pros and cons of treatments and side effects. The numerical information is presented in graphical population diagrams. 
For each treatment option, patient values are elicited by inviting the patient to indicate the importance of certain issues on visual analogue scales. The patient can illustrate values and issues with open-text wordings or narratives. To conclude, the patient can print a one-page sheet summarizing her personal value scores and open-text wordings, to take this along to the next consultation.

The strategy to implement the preferred procedure for presenting and using the PtDA consisted of the following ingredients:

- A hospital-specific standardized procedure to discuss the treatment options and decide whether there is an indication for using the PtDA in the multidisciplinary tumour board meetings and to systematically record the options and the indication in the patient's file.

- An explanation on how to apply the steps in the SDM process.

- A tailored advice for the breast cancer team about the timing of the delivery of the PtDA to the patient (by whom, how) to ensure smooth integration in the clinical pathway.

- An advice to record the treatment options discussed with the patient and the delivery of the PtDA in the patient file.

- An explanation on how to motivate patients in using the PtDA.

In close consultation with each participating hospital, the implementation strategy was tailored to the hospital. The company hosting the PtDA and the first author both acted as the change agents.

\section{Endpoints and data collection}

To assess the uptake of the set of implementation strategies by professionals, we collected data on the recording of treatment options and the indication for and delivery of the PtDA, from the tumour board reports as well as from the patient files, using a standardized data extraction sheet (Appendix 2). The reports of the multidisciplinary tumour board were systematically audited for the suggested treatment plan or options and whether an indication for the PtDA had been recorded. The patient files were further audited for records of the presentation of the PtDA and the final treatment decision.

To assess the uptake of the PtDA as perceived by patients, to assess concordance between preferred and actual treatment, and to assess the perception of the SDM process, patients were interviewed by telephone using a structured questionnaire. This questionnaire consisted of 4 sections.

1) A section consisting of three items assessing co-variables including age in years and educational level (7 categories).

2) A Section consisting of 13 items assessing the patient's perceptions of the process of presentation, promotion and actual uptake of the PtDA, with answer options yes, no, I don't know; and the patient's satisfaction with the use of the PtDA, on a 10-point Likert scale. 
3) A section assessing the patient's preference for the type of surgical treatment, on a 7-point scale (anchors: I definitely do / do not intend to choose to have a BCT/ mastectomy) (18).

4) A section assessing the patient's experience of SDM, measured by the Dutch version of the CollaboRATE instrument (19-21), including three questions with a 10-point anchored scale $(0=$ no effort was made, $9=$ every effort was made). (Appendix 3 )

To assess concordance between preferred and actual treatment, we also collected data on actual treatment from the patient files.

\section{Data analysis}

The data were analysed using descriptive statistics in the Statistical Package for Social Sciences, version 11. For each variable we calculated proportions, means and standard deviations for the total sample and for each individual hospital. In case of skewed data, we calculated medians and interquartile ranges. With regard to the CollaboRATE instrument, we calculated the average and top score (21). To calculate the top score we coded each encounter as ' 1 ' if the response to all three items was 9, or ' $O$ ' if the response to any of the three items was less than 9 . We then calculated the percentage of all encounters that were coded as ' 1 '. This is the CollaboRATE Top Score.

We hypothesized that systematically recording the delivery of the PtDA to the patient (by whom, how) in the patient file, as well as personal instructions on the importance and use of the PtDA, would result in a better uptake of the PtDA by patients. To test this hypotheses, we built a multivariate backward logistic regression model for the uptake of the PtDA (logged in yes or no) as a dependent variable and the following independent variables: age, educational level, recording of the delivery of the PtDA in the patient file, and whether the patient clearly remembered if the clinician who delivered the PtDA had promoted its use.

We also hypothesized that stating whether the PtDA was indicated by the multidisciplinary tumour board and recording the delivery of the PtDA would result in a higher score on the CollaboRATE instrument. To test this hypothesis we built a multivariate backward logistic regression model of the perceived process of SDM (i.e., top score or no top score for all three questions of CollaboRATE) as the dependent variable and the following independent variables: age, educational level, setting the indication for the PtDA by the multidisciplinary tumour board and recording the delivery of the PtDA. 


\section{Results}

\section{Study population}

A total of 86 patients were initially included, 84 of whom consented to participate. One patient did not want to participate on second thoughts, and another patient could not be reached in time. The teams did not manage to include the preferred number of 30 patients per hospital, due to lack of time, perceived overload of research tasks in breast cancer care and organizational issues. Table 1 summarizes the demographic and clinical characteristics of the included patients. The average age of the participants was 61 years and one third of them (30\%) reported a low educational level.

Table 1 Patient demographic and clinical characteristics

\begin{tabular}{|c|c|c|c|c|c|}
\hline $\begin{array}{l}\text { Demographic } \\
\text { characteristics }\end{array}$ & $\begin{array}{l}\text { Total } \\
\mathrm{N}=84\end{array}$ & $\begin{array}{l}\text { Hosp. } 1 \\
\mathrm{~N}=31\end{array}$ & $\begin{array}{l}\text { Hosp. } 2 \\
\mathrm{~N}=25\end{array}$ & $\begin{array}{l}\text { Hosp. } 3 \\
N=18\end{array}$ & $\begin{array}{l}\text { Hosp. } 4 \\
\mathrm{~N}=10\end{array}$ \\
\hline $\begin{array}{l}\text { Age (years) mean, } \\
\text { standard deviation } \\
\text { (SD) }\end{array}$ & $61.1(9.9)$ & $60.2(10.8)$ & $61.8(9.9)$ & $61.6(10)$ & $61.2(6.6)$ \\
\hline \multicolumn{6}{|l|}{ Education level } \\
\hline $\begin{array}{l}\text { - Low level of } \\
\text { education }\end{array}$ & $25(29 \%)$ & $8(25 \%)$ & $8(32 \%)$ & 7 (37\%) & $2(20 \%)$ \\
\hline $\begin{array}{l}\text { Intermediate } \\
\text { to higher level } \\
\text { of education }\end{array}$ & $59(69 \%)$ & $23(72 \%)$ & $16(64 \%)$ & $12(63 \%)$ & $8(80 \%)$ \\
\hline - $\quad$ Missing & $2(2 \%)$ & $1(2 \%)$ & $1(4 \%)$ & 0 & 0 \\
\hline \multicolumn{6}{|l|}{ Treatment plan } \\
\hline $\begin{array}{l}\text { No. of patients with } \\
\text { one option }\end{array}$ & $35(42 \%)$ & $5(16 \%)$ & $6(24 \%)$ & $14(78 \%)$ & $10(100 \%)$ \\
\hline $\begin{array}{l}\text { No. of patients with } \\
\text { >one options }\end{array}$ & 49 (58\%) & $26(84 \%)$ & $1976 \%)$ & $19(76 \%)$ & 0 \\
\hline
\end{tabular}




\section{Topic 1: Uptake of the strategies to implement the PtDA in breast cancer care by the professionals.}

For $14 \%$ (12) of the patients the recommended implementation strategy (i.e. the 5 steps mentioned below) was followed completely. Based on our audit of the patient files, the most frequently missed step was setting the indication for the PtDA by the tumour board.

1. For $49(58 \%)$ patients the tumour board report recommended two treatment options. The indication for the PtDA was reported in 30 (34\%) of the tumour board reports.

2. With regard to the reports in the patient files, we found more than one treatment option recorded in 51 (59\%) patient files, while delivery of the PtDA was recorded in $68(79 \%)$ patient files (Table 2 ).

3 . The majority of patients $(93 \%)$ clearly remembered that the clinician had explained to them that there was more than one treatment option available, while $88 \%$ of the patients remembered that the clinician had made it clear that a decision between options had to be made. (Table 3)

4. Most patients (93\%) remembered that they had received a prescription pad sheet with a login code, while 67 (80\%) patients reported that the clinician had personalized the PtDA by ticking the boxes of the applicable treatment options on the prescription pad.

5. Two-thirds of the patients $(n=58,69 \%)$ clearly remembered the clinician explaining the importance of using the PtDA and/or receiving instructions on how to use it.

Table 2. Uptake of the SDM implementation strategies in breast cancer care by professionals, according to the tumour board report or patient files

\begin{tabular}{|c|c|c|c|c|c|}
\hline & $\begin{array}{l}\text { Total } \\
(\mathrm{N}=84)\end{array}$ & $\begin{array}{l}\text { Hosp. } 1 \\
(\mathrm{~N}=31)\end{array}$ & $\begin{array}{l}\text { Hosp. } 2 \\
(\mathrm{~N}=25)\end{array}$ & $\begin{array}{l}\text { Hosp. } 3 \\
(\mathrm{~N}=18)\end{array}$ & $\begin{array}{l}\text { Hosp. } 4 \\
(\mathrm{~N}=10)\end{array}$ \\
\hline $\begin{array}{l}\text { Indication for PtDA recorded in } \\
\text { the tumour board report }\end{array}$ & $30(34 \%)$ & $18(58 \%)$ & $10(42 \%)$ & $2(11 \%)$ & 0 \\
\hline $\begin{array}{l}\text { Recording of treatment options } \\
\text { in the patient file }\end{array}$ & $51(59 \%)$ & $24(77 \%)$ & 21 (88\%) & $6(33 \%)$ & 0 \\
\hline $\begin{array}{l}\text { Records of discussions on } \\
\text { treatment options between } \\
\text { clinicians and patients }\end{array}$ & $33(39 \%)$ & $20(65 \%)$ & $7(29 \%)$ & $1(6 \%)$ & $5(50 \%)$ \\
\hline $\begin{array}{l}\text { Recording the delivery of the } \\
\text { PtDA in the patient file }\end{array}$ & $68(79 \%)$ & $29(94 \%)$ & $21(88 \%)$ & $12(67 \%)$ & $6(60 \%)$ \\
\hline \multicolumn{6}{|l|}{ Final surgical treatment } \\
\hline BCT & $63(75 \%)$ & $18(58 \%)$ & $19(79 \%)$ & $16(89 \%)$ & $9(90 \%)$ \\
\hline Mastectomy & $20(24 \%)$ & $13(42 \%)$ & $5(17 \%)$ & $2(11 \%)$ & $1(10 \%)$ \\
\hline Missing & $1(1 \%)$ & & $1(4 \%)$ & & \\
\hline
\end{tabular}


Table 3. Results of the structured telephone interviews

\begin{tabular}{|c|c|c|c|c|c|c|}
\hline Variable & & $\begin{array}{l}\text { Total } \\
\mathrm{N}=84\end{array}$ & $\begin{array}{l}\text { Hosp. } 1 \\
\mathrm{~N}=31\end{array}$ & $\begin{array}{l}\text { Hosp. } 2 \\
\mathrm{~N}=25\end{array}$ & $\begin{array}{l}\text { Hosp. } 3 \\
\mathrm{~N}=18\end{array}$ & $\begin{array}{l}\text { Hosp. } 4 \\
\mathrm{~N}=10\end{array}$ \\
\hline \multirow{3}{*}{$\begin{array}{l}\text { Did your doctor tell you there } \\
\text { were different options for treating } \\
\text { your breast cancer? }\end{array}$} & Yes & $77(93 \%)$ & $29(94 \%)$ & $23(96 \%)$ & $15(83 \%)$ & $10(100 \%)$ \\
\hline & No & $4(5 \%)$ & $2(6 \%)$ & $1(4 \%)$ & $1(6 \%)$ & \\
\hline & $?$ & $2(2 \%)$ & & & $2(11 \%)$ & \\
\hline \multirow{3}{*}{$\begin{array}{l}\text { Did your doctor make it clear that } \\
\text { a decision needed to be made? }\end{array}$} & Yes & $73(88 \%)$ & $28(90 \%)$ & $20(83 \%)$ & $15(83 \%)$ & $10(100 \%)$ \\
\hline & No & $5(6 \%)$ & $3(10 \%)$ & $1(4 \%)$ & $1(6 \%)$ & \\
\hline & $?$ & $5(6 \%)$ & & $3(13 \%)$ & $2(11 \%)$ & \\
\hline \multirow{3}{*}{$\begin{array}{l}\text { Patient received a prescription } \\
\text { pad sheet }\end{array}$} & Yes & 77 (92\%) & $27(87 \%)$ & $21(88 \%)$ & $18(100 \%)$ & $10(100 \%)$ \\
\hline & No & $2(2 \%)$ & & $2(8 \%)$ & & \\
\hline & $?$ & $5(6 \%)$ & $4(13 \%)$ & $1(4 \%)$ & & \\
\hline \multirow{3}{*}{$\begin{array}{l}\text { The clinician personalized the } \\
\text { PtDA }\end{array}$} & Yes & $67(80 \%)$ & $21(66 \%)$ & $18(76 \%)$ & $17(94 \%)$ & $10(100 \%)$ \\
\hline & No & $3(4 \%)$ & & $2(8 \%)$ & $1(6 \%)$ & \\
\hline & $?$ & $14(16 \%)$ & $10(34 \%)$ & $4(16 \%)$ & & \\
\hline \multirow{3}{*}{$\begin{array}{l}\text { The clinician explained the } \\
\text { importance and/or gave } \\
\text { instructions on using the PtDA }\end{array}$} & Yes & $59(69 \%)$ & $20(64 \%)$ & $15(58 \%)$ & $13(72 \%)$ & $10(100 \%)$ \\
\hline & No & $4(5 \%)$ & $2(6 \%)$ & $1(4 \%)$ & $1(6 \%)$ & \\
\hline & $?$ & $21(26 \%)$ & $9(30 \%)$ & $9(38 \%)$ & $4(22 \%)$ & \\
\hline \multirow[t]{2}{*}{ Patient logged in to PtDA } & Yes & $56(67 \%)$ & $14(45 \%)$ & $17(71 \%)$ & $15(83 \%)$ & $9(90 \%)$ \\
\hline & No & $28(33 \%)$ & $17(55 \%)$ & $7(29 \%)$ & $3(17 \%)$ & $1(10 \%)$ \\
\hline \multirow[t]{4}{*}{ Treatment preference } & BST & $56(67 \%)$ & $19(61 \%)$ & $15(63 \%)$ & $15(83 \%)$ & $6(60 \%)$ \\
\hline & Mast. & $20(24 \%)$ & $9(30 \%)$ & $7(29 \%)$ & $1(6 \%)$ & $3(30 \%)$ \\
\hline & $?$ & $8(9 \%)$ & $3(9 \%)$ & $2(8 \%)$ & $2(11 \%)$ & $1(10 \%)$ \\
\hline & & $\begin{array}{l}\text { Total } \\
\mathrm{N}=56\end{array}$ & $\begin{array}{l}\text { Hosp. } 1 \\
\mathrm{~N}=14\end{array}$ & $\begin{array}{l}\text { Hosp. } 2 \\
\mathrm{~N}=17\end{array}$ & $\begin{array}{l}\text { Hosp. } 3 \\
\mathrm{~N}=15\end{array}$ & $\begin{array}{l}\text { Hosp. } 4 \\
\mathrm{~N}=9\end{array}$ \\
\hline \multirow[t]{3}{*}{ Patient personalized the PtDA } & Yes & $49(88 \%)$ & $13(92 \%)$ & $14(82 \%)$ & $12(80 \%)$ & $9(100 \%)$ \\
\hline & No & $3(5 \%)$ & $1(8 \%)$ & $1(6 \%)$ & $1(7 \%)$ & \\
\hline & $?$ & $4(7 \%)$ & & $2(12 \%)$ & $2(13 \%)$ & \\
\hline \multirow{3}{*}{$\begin{array}{l}\text { Patient read the value elicitation } \\
\text { statements }\end{array}$} & Yes & $50(90 \%)$ & $13(92 \%)$ & $15(88 \%)$ & $13(87 \%)$ & $8(89 \%)$ \\
\hline & No & $5(9 \%)$ & $1(8 \%)$ & $1(6 \%)$ & $2(13 \%)$ & $1(11 \%)$ \\
\hline & $?$ & $1(1 \%)$ & & $1(6 \%)$ & & \\
\hline \multirow{3}{*}{$\begin{array}{l}\text { Patient found the value elicitation } \\
\text { statements useful }\end{array}$} & Yes & $42(77 \%)$ & $10(71 \%)$ & $13(76 \%)$ & $13(87 \%)$ & $6(67 \%)$ \\
\hline & No & $4(7 \%)$ & $1(8 \%)$ & $2(6 \%)$ & & $1(11 \%)$ \\
\hline & $?$ & $9(16 \%)$ & $3(21 \%)$ & $2(6 \%)$ & $2(13 \%)$ & $2(22 \%)$ \\
\hline \multirow[t]{3}{*}{$\begin{array}{l}\text { Patient took a printed summary to } \\
\text { the next consultation }\end{array}$} & $\begin{array}{l}\text { Yes } \\
\text { No } \\
?\end{array}$ & $25(45 \%)$ & $9(64 \%)$ & $8(47 \%)$ & $3(20 \%)$ & $4(45 \%)$ \\
\hline & No & $28(50 \%)$ & $5(36 \%)$ & $8(47 \%)$ & $12(80 \%)$ & $3(33 \%)$ \\
\hline & $?$ & $3(5 \%)$ & & $1(6 \%)$ & & $2(22 \%)$ \\
\hline \multirow{3}{*}{$\begin{array}{l}\text { The clinician discussed the } \\
\text { summary with the patient }\end{array}$} & Yes & $13(24 \%)$ & $2(14 \%)$ & 5 (29\%) & $4(27 \%)$ & $1(11 \%)$ \\
\hline & No & $42(75 \%)$ & $12(86 \%)$ & 11 (65\%) & $11(73 \%)$ & $8(89 \%)$ \\
\hline & ? & $1(1 \%)$ & & $1(6 \%)$ & & \\
\hline
\end{tabular}




\begin{tabular}{|l|l|l|l|l|l|}
\hline $\begin{array}{l}\text { Score for satisfaction } \\
\text { With PtDA Mean (SD) }\end{array}$ & $7.9(1)$ & $8.2(9,9)$ & $7.9(1)$ & $7.9(1)$ & $7.6(.7)$ \\
\hline $\begin{array}{l}\text { Score for recommending PtDA to other patients } \\
\text { Mean (SD) }\end{array}$ & $8.1(.9)$ & $8.3(.8)$ & $8(1.2)$ & $8.3(.7)$ & $7.8(.4)$ \\
\hline CollaboRATE & $\mathrm{N}=80$ & $\mathrm{~N}=29$ & $\mathrm{~N}=23$ & $\mathrm{~N}=18$ & $\mathrm{~N}=10$ \\
\hline $\begin{array}{l}\text { How much effort was made to help you } \\
\text { understand your health issues? Mean, (SD) }\end{array}$ & $8.3(.8)$ & $8(1.1)$ & $8.5(.6)$ & $8.4(.6)$ & $8.2(.4)$ \\
\hline $\begin{array}{l}\text { How much effort was made to listen to the things } \\
\text { that matter most to you about your health issues? } \\
\text { Mean, (SD) }\end{array}$ & $8.2(.9)$ & $7.9(1.1)$ & $8.3(.7)$ & $8.3(.7)$ & $8.2(.4)$ \\
\hline $\begin{array}{l}\text { How much effort was made to include what } \\
\text { matters most to you in choosing what to do next? } \\
\text { Mean, (SD) }\end{array}$ & $7.9(1)$ & $7.5(1.8)$ & $7.7(1.3)$ & $8.2(.7)$ & $8.1(.3)$ \\
\hline $\begin{array}{l}\text { CollaboRATE total. Mean (SD) } \\
\text { CollaboRATE top score }\end{array}$ & $8.1(.8)$ & $7.9(1)$ & $8.3(.7)$ & $8.3(.6)$ & $8.2(.3)$ \\
\hline
\end{tabular}

\section{Topic 2: the uptake of the PtDA as perceived by patients}

The average duration of the telephone interview was 8.4 (SD 2.6) minutes. Duration varied from 4 minutes with patients who had not used the PtDA to about 16 minutes for patients who had. Two-thirds $(n=56$, $67 \%$ ) of the patients had actually logged on to the PtDA, see table 3. Various reasons for not logging in were mentioned: nine patients indicated they had received too much information, six patients indicated they had no computer or computer skills, four patients had forgotten about the PtDA, three patients had already come to decide about their treatment and consequently felt no need to use the PtDA, six patients gave other individual reasons.

Of the 56 patients that logged in to the PtDA, $80 \%$ had personalized it and $90 \%$ had read the value clarification statements; $77 \%$ had used them and found them helpful. About half of the patients (45\%) had printed out the summary of the value clarification tool and taken it along to the next consultation, $24 \%$ of the patients reported having discussed the summary with their clinician. Patients gave a score of 7.9 (SD 1.0) on a scale of 0-10 for satisfaction with the use of the PtDA.

The multivariate backward logistic regression model showed that clearly remembering the clinician promoting the use of the PtDA was positively related to using the PtDA (OR 9.95; 95\%CI 3.03-37.72) (Table 4), whereas older age was negatively related (OR $0.9195 \%$ CI $0.85-0.97$ ). Whether delivering the PtDA had been recorded in the patient file was not significantly related to the use of the PtDA (OR 5.22; $95 \%$ CI 0.89 27.91) 
Table 4. Influence of demographic characteristics and the implementation strategies on the odds that patients use the PtDA and the patients' experience with the process of shared decision making.

\begin{tabular}{|l|l|l|l|l|l|}
\hline \multicolumn{2}{|l|}{ Login in to the PtDA } & \multicolumn{4}{l|}{ Score on CollaboRATE } \\
\hline \multicolumn{4}{|l|}{ Dependent: } & \multicolumn{2}{l|}{ Dependent: } \\
\hline \multicolumn{2}{|l|}{ Independent variables that remain in the } & \multicolumn{2}{l|}{ Independent variables that remain in the } \\
\hline Independent & Beta (SE) & Adjusted OR & Independent & Beta (SE) & Adjusted OR \\
\hline Intercept & $5.446(2.17)$ & & Intercept & $-1.53(.81)$ & \\
\hline Age in years & $-0.100(0.34)$ & $0.91(0.85-0.97)$ & Recording of & $1.2(82)$ & $3.3(.67-16.33)$ \\
\hline Recalling & $2.298(0.61)$ & $9.95(3.03-$ & Logging in & $-.86(.55)$ & $.42(.15-1.25)$ \\
\hline$R^{2}=29.98$ & & $R^{2}=10$ & & \\
\hline
\end{tabular}

Adjusted odds ratio (OR) and 95\% confidence intervals (CI) N=84 patients

Topic 3: The proportion of patients for whom there was concordance between their stated preference and the actual decision about their treatment during the intervention period, and the patients' perceptions of the process of SDM.

There was concordance between stated preference and the actual decision made for $60(72 \%)$ patients, while $8(10 \%)$ patients had no preference. For $15(17 \%)$ patients, the actual decisions made about their treatment differed from the previously stated preferences during the interview (Table 5). For four patients, no clear reason for the lack of concordance was found. Eight patients had preferred a BCT, whereas the actual surgical treatment was a mastectomy. The audit of these patient files showed that five of them should not have received the PtDA because breast conserving therapy was not indicated or because the patient had been diagnosed with Ductal Carcinoma In Situ, for which the PtDA is not suitable. For the other three patients, no clear reason for non-concordance was found.

Seven patients with a preference for a mastectomy underwent BCT: three of them had stated a preference for mastectomy, but eventually they first underwent neo-adjuvant chemotherapy, and then decided to go for BCT. Three patients thought the complexity of the choices made it hard to make a decision and they all felt insecure about the impact of radiotherapy. Two of them were offered another consultation with the radiotherapist and one patient sought reassurance by talking to the nurse again. For one patient there was no clear reason for the nonconcordance.

The mean patient-reported outcome of the SDM process as measured by the CollaboRATE was 8.1 (SD .8) on a 0-9 scale. One quarter of the patients $(24.4 \%$ ) gave a top score (a score of 9 on all of the three topics), on a scale from $0-100$. The average experience regarding SDM was comparable between hospitals. 
Multivariate backward logistic regression model of the perceived process of SDM showed that whether the delivery of the PtDA had been recorded (OR 1.2; 95\%CI .67-16.33), or whether patients had logged in to the PtDA (OR -.86; 95\%CI .15 - 1.3) was not significantly related to the patients' perception of the process of SDM, as measured by CollaboRATE.

Table 5. Concordance between preference and final treatment

\begin{tabular}{|l|l|l|l|l|l|l|}
\hline \multicolumn{2}{|l|}{} & Hosp. 1 & Hosp. 2 & Hosp. 3 & Hosp. 4 & Hosp. 5 \\
\hline \multicolumn{2}{|l|}{ Non-concordance } & $\mathrm{N}=84$ & $\mathrm{~N}=31$ & $\mathrm{~N}=18$ & $\mathrm{~N}=25$ & $\mathrm{~N}=10$ \\
\hline$*$ & $15(17 \%)$ & $6(19 \%)$ & $2(11 \%)$ & $3(12 \%)$ & $4(40 \%)$ \\
\hline$*$ & $\begin{array}{l}\text { Preference for breast conserving therapy } \\
\text { Eventual mastectomy treatment }\end{array}$ & 8 & & & & \\
\hline Concordance & $\begin{array}{l}\text { Preference for mastectomy } \\
\text { Eventual breast conserving therapy }\end{array}$ & 7 & & & & \\
\hline No preference & $60(72 \%)$ & $22(71 \%)$ & $14(78 \%)$ & $19(76 \%)$ & $5(50 \%)$ \\
\hline Missing & $8(10 \%)$ & $3(10 \%)$ & $2(11 \%)$ & $2(8 \%)$ & $1(10 \%)$ \\
\hline
\end{tabular}

\section{Discussion}

In our motivated teams of breast cancer clinicians, who were aware of being observed, the adherence to specific implementation strategies was fairly modest. Although there is still a long road ahead, glimpses of actual SDM behaviour were present. Almost all the patients (93\%) reported to have been informed about two treatment options, and that as such a decision had to be made ( $88 \%)$. However, even in cases of clear equipoise, the tumour boards indicated one option only for nearly half $(41 \%)$ of the patients, and in two-thirds of the cases $(66 \%)$ they failed to set an indication for the PtDA. Nevertheless, almost all patients $(92 \%)$ reported having received the prescription pad sheet for the PtDA, and this was recorded in the patient file for nearly all patients (89\%). Above all a substantial proportion of patients (67\%) actually used the PtDA. One of the implementation strategies in this study was tailored advice on timely delivery of the PtDA to the patient (by whom, how, in a motivating way). Explaining the importance of using the PtDA and giving instructions on how to use it seems a strong predictor of its actual use.

The average item score on the CollaboRATE instrument was high, although only one in four patients gave a top score. Recording the delivery of the PtDA seems to enhance a patient's experience of SDM, although this finding did not reach statistical significance. Another nonsignificant finding, is that the proportion of patients logging in to the PtDA seemed negatively related to their rating of top scores for the SDM experience. 
This might suggest that patients who actually use the PtDA not only gain information but also develop rather high expectations of the SDM process in the subsequent consultation. There may be a pitfall of the tumour board 'simply' indicating a preference-sensitive decision, leading to assumptions that a PtDA is in itself sufficient to guarantee SDM. Interestingly, overuse of the PtDA did occur, as 5 patients were inappropriately informed about the treatment choice they had. This could raise false expectations for patients, because their preference is not available to them, resulting in confusion, disappointment, decisional conflict and dissatisfaction. It is important for clinicians to be aware that using a PtDA is not a purpose in itself, but only an instrument to support the process of SDM and to help patients think about the options, their preferences and the actual decision.

\section{Strengths and limitations}

The breast cancer teams were willing to invest financially in using the PtDA, which implies an intrinsic motivation to implement SDM. A strong aspect of this study was that the patient sample was representative of the Dutch breast cancer patient population with regard to educational level. The patients' age, educational level and perceived experience of SDM were comparable between the different hospitals, implying that this study did not suffer from large baseline differences between hospitals with regard to patient selection and SDM performance. Nevertheless, we need to be cautious in interpreting the results because of the small study size $(\mathrm{N}=84)$.

Another strong aspect was that one researcher interviewed all of the included patients personally, using a structured interview guide. The interviews were held soon after the consultation in which the clinician had presented the diagnoses, but before the final decision had to be made, and gave participants sufficient time to use the PtDA.

The most prominent limitation is that we could not check the use of the PtDA by analysing the server data of the company that hosted the PtDA, and had to rely on patients' self-reports. The subjective perceptions of the patients may suffer from recall bias to a certain extent, but we are confident that our findings are comparable with the server data, given the interview technique we used of asking the patient to substantiate their statements with concrete examples.

Another limitation is the possible selection bias: the hospitals may have included those patients for whom they felt to have been really successful in delivering the PtDA. It is also possible that especially these were patients who were already intrinsically motivated to use the PtDA, who remembered the clinician promoting its use. 
The relatively large number of low educated patients may call against this bias. We did not find other studies for comparison of our findings. If this selection has occurred it has probably led towards overestimating the level of implementation success.

In this study, we used the CollaboRATE instrument in the telephone interviews to measure the patients' perception of SDM. Some of the patients perceived the questions, in particular the last question, as difficult to answer, so additional explanation was necessary. The explanations given to these patients could have differed from each other, which might have caused some ambiguity.

\section{Conclusion and recommendations}

Despite the small sample size and the limitations, which may have resulted in under- or overestimation of the effects, we can conclude that, although not straightforward the uptake of implementations strategies for SDM in breast cancer care among breast cancer teams that are reasonably motivated to implement SDM is improving. Despite the high level of complexity of the decision making in breast cancer teams, they adopted the complete implementation strategy in a minority but relevant proportion of the patients, on the other hand, some selfcontained implementation strategies were adopted in a major proportion of the patients. This study suggests the importance for clinicians to personally urge patients to use the PtDA. At the same time this creates expectations among patients and obligations for clinicians. Although the uptake of the PtDA and the implementation strategies was not a $100 \%$, patients scored high on the SDM process. Still, clinicians have to take the opportunity to discuss decisional attributes after the patient has used the PtDA. This implies that in order to systematically implement SDM, breast cancer teams may have to redesign the entire pathway to correctly perform SDM.

We would recommend a clear and systematic recording of the multiple options for each patient in the tumour board reports. This might prevent patients erroneously receiving a PtDA In addition, it seems wise to also systematically take notes on the patient's considerations and decisional attributes. Together with the results from the value elicitation exercise in the PtDA, which the patients should preferably take along to the next consultation, this could be a robust starting point for a dialogue in a subsequent consultation. Implementing SDM in the existing pathway is complex and involves many different aspects that need to be considered. Data from this study should be used to design a larger implementation study to validate our findings. 


\section{References}

1. Fisher B, Anderson S, Bryant J, Margolese R, Deutsch M, Fisher E, Jeong J-H, Wolmark N.Twenty-Year Follow-up of a Randomized Trial Comparing Total Mastectomy, Lumpectomy, and Lumpectomy plus Irradiation for the Treatment of Invasive Breast Cancer. New England Journal of Medicine. 2002;347(16):1233-41.

2. Caldon LJM, Collins KA, Wilde DJ, Ahmedzai SH, Noble TW, Stotter A, Sibbering DM, Holt S. Reed MWR. Why do hospital mastectomy rates vary? Differences in the decision-making experiences of women with breast cancer. Br J Cancer. 2011;104(10):1551-7.

3. Hershman DL, Buono D, Jacobson JS, McBride RB, Tsai WY, Joseph KA, Neugut AI. Surgeon characteristics and use of breast conservation surgery in women with early stage breast cancer. Annals of surgery. 2009;249(5):10.1097/SLA.0b013e3181a38f6f.

4. Barry MJ, Edgman-Levitan S. Shared Decision Making; The Pinnacle of Patient-Centered Care. New England Journal of Medicine. 2012;366(9):780-1.

5. Stacey D, Bennett CL, Barry MJ, Col NF, Eden KB, Holmes-Rovner M, Llewellyn-Thomas H, Lyddiatt A, Legare F, Thomson, R. Decision aids for people facing health treatment or screening decisions. Cochrane Database Syst Rev. 2014;1:CD001431.

6. Coulter A. Patient information and shared decision-making in cancer care. British Journal of Cancer. 2003;89(Suppl 1):S15-S6.

7. Elwyn G, Scholl I, Tietbohl C, Mann M, Edwards AG, Clay C, Legare F, van der Weijden T. Lewis, CL, Wexler RM, Frosch DL. "Many miles to go ...": a systematic review of the implementation of patient decision support interventions into routine clinical practice. BMC medical informatics and decision making. 2013;13 Suppl 2:S14.

8. Gravel K, Légaré F, Graham ID. Barriers and facilitators to implementing shared decision-making in clinical practice: a systematic review of health professionals' perceptions. Implementation Science. 2006;1:16-.

9. Legare F, Stacey D, Turcotte S, Cossi MJ, Kryworuchko J, Graham ID, Graham L, Lyddiatt A, Politi MC, Thomson R, Elwyn G, DonnerBanzhoff $N$. Interventions for improving the adoption of shared decision making by healthcare professionals. The Cochrane database of systematic reviews. 2014(9):CD006732.

10. Feibelmann S, Yang TS, Uzogara EE, Sepucha K. What does it take to have sustained use of decision aids? A programme evaluation for the Breast Cancer Initiative. Health expectations : an international journal of public participation in health care and health policy. 2011;14 Suppl 1:85-95. 
11. Belkora JK, Loth MK, Volz S, Rugo HS. Implementing decision and communication aids to facilitate patient-centered care in breast cancer: a case study. Patient education and counseling. 2009;77(3):360-8.

12. Savelberg $W$, van der Weijden T, Boersma L, Smidt M, Willekens C, Moser A. Developing a patient decision aid for the treatment of women with early stage breast cancer: the struggle between simplicity and complexity. BMC Med Inform Decis Mak. 2017;17(1):112.

13. Joseph-Williams N, Lloyd A, Edwards A, Stobbart L, Tomson D, Macphail S, Dodd C, Brain K, Elwyn G, Thomson R. Implementing shared decision making in the NHS: lessons from the MAGIC programme. BMJ (Clinical research ed). 2017;357:j1744.

14. Nguyen F, Moumjid N, Charles C, Gafni A, Whelan T, Carrere MO. Treatment decision-making in the medical encounter: comparing the attitudes of French surgeons and their patients in breast cancer care. Patient education and counseling. 2014;94(2):230-7.

15. O'Brien MA, Charles C, Lovrics P, Wright FC, Whelan T, Simunovic M, Kennedy E, Grunfeld E. Enablers and barriers to using patient decision aids in early stage breast cancer consultations: a qualitative study of surgeons' views. Implement Sci. 2014;9:174.

16. Sivell S, Edwards A, Manstead AS, Reed MW, Caldon L, Collins $\mathrm{K}$, Clements A, Elwyn G. Increasing readiness to decide and strengthening behavioral intentions: evaluating the impact of a web-based patient decision aid for breast cancer treatment options (BresDex: www.bresdex.com). Patient Educ Couns. 2012;88(2):20917.

17. Ogrinc G, Davies L, Goodman D, Batalden P, Davidoff F, Stevens D. SQUIRE 2.0 (Standards for QUality Improvement Reporting Excellence): revised publication guidelines from a detailed consensus process. BMJ quality \& safety. 2016;25(12):986-92.

18. Winn K, Ozanne E, Sepucha K. Measuring patient-centered care: An updated systematic review of how studies define and report concordance between patients' preferences and medical treatments. Patient education and counseling. 2015;98(7):811-21.

19. Elwyn G, Barr PJ, Grande SW, Thompson R, Walsh T, Ozanne EM. Developing CollaboRATE: a fast and frugal patient-reported measure of shared decision making in clinical encounters. Patient education and counseling. 2013;93(1):102-7.

20. Stubenrouch FE, Pieterse $A H$, Falkenberg $R$, Santema TK, Stiggelbout AM, van der Weijden T, Aarts JA, Ubbink DT. OPTION(5) versus OPTION(12) instruments to appreciate the extent to which healthcare providers involve patients in decision-making. Patient education and counseling. 2016;99(6):1062-8. 
21. Barr PJ, Thompson R, Walsh T, Grande SW, Ozanne EM, Elwyn G. The Psychometric Properties of CollaboRATE: A Fast and Frugal PatientReported Measure of the Shared Decision-Making Process. Journal of medical Internet research. 2014;16(1):e2. 


\section{Appendix 1 \\ Prescription pad sheet}

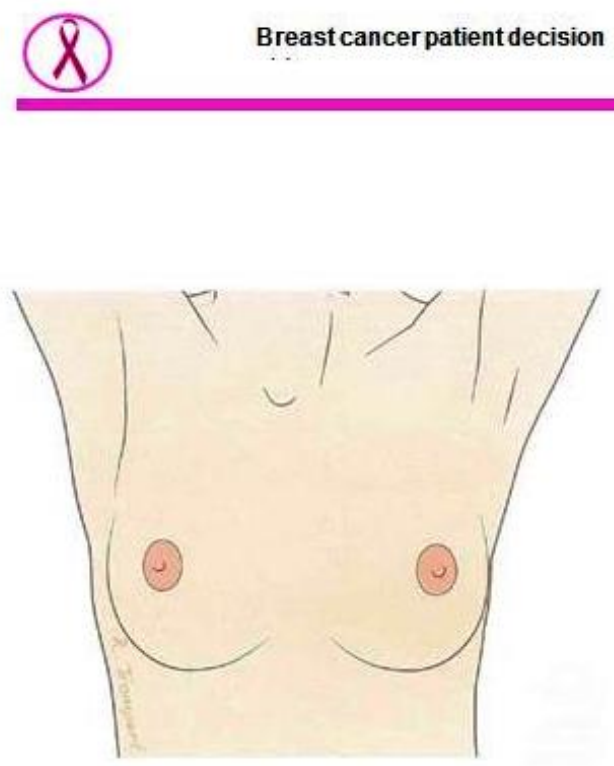

Your Surgeon is:

a Dr.S. Angel

a Dr.E. Header

a Dr.K. Keyfinder

a Dr.M.Jones

ournurse practitioner is:

a M. Grouse

a C. Mons

a

Yournurse is:
a J.Crain
E. Younger
a C. Goose

Your treatment options are:

Breast conserving therapy(tickone option)

a Is possible without neo-adjuvant therapy

- Is a better option after neo-adjuvant therapy

- Is only possible after successful chemotherapy

Mastectomy (tickall the possible options)

ㅁ Without reconstruction

a With an immediate reconstruction

a With a delayed reconstruction

Use the on line PtDA

1. Go to https://breastcancer.ptda.com Username:pat12345 password: ph49

2. Read more about your o ptions and register what is important to you.

3. Print and bring thesummaryto your next consultation 


\section{Appendix 2 Extraction sheet audit of patient file}

Variables:

1. Which treatment option(s) is/are recorded in the multidisciplinary tumour board report?

2. Are there any records in the tumour board report of the deliberation and/or dialogue about treatment options during the tumour board meeting

3. Is the indication for the Patient Decision Aid registered in the multidisciplinary tumour board report?

4. Are there any records in the patient file of the deliberation and/or dialogue about treatment options during the consultation?

5. Is the presentation of the Patient Decision Aid recorded in the patient file?

6. What was the final treatment? 


\section{Appendix 3 \\ Patient questionnaire}

General questions

1. Did your doctor tell you there were different options for treating your breast cancer?

2. Did your doctor make it clear that a decision needed to be made?

3. Which treatment do you prefer at this moment? Please choose one of the following answers:

- I definitely opt for a breast-conserving treatment

- I have a strong preference for a breast-conserving treatment

- I tend towards a breast-conserving treatment

- I am not sure which option I prefer

- I tend towards breast-removal surgery

- I have a strong preference for breast-removal surgery

- I definitely opt for breast-removal surgery

CollaboRATE

Thinking about the appointment you have recently had with your clinicians, please tell me how you feel, by choosing a number from 0 to 9

1. How much effort was made to help you understand your health issues?

2. How much effort was made to listen to the things that matter most to you about your health issues?

3. How much effort was made to include what matters most to you in choosing what to do next? 
The following questions are about the patient decision aid and its use. You may answer yes, no, or I don't know.

1. Did you receive a prescription pad sheet from your doctor or nurse with a log in code for the Patient Decision Aid?

2. Did the doctor/nurse tick the treatment options that are relevant for you?

3a. Did the doctor/nurse explain why it is important and/or how to use the Patient Decision Aid?

4a. Did you log in to the website of the Patient decision Aid

- If yes, continue to question 5

- If no, answer question 4b

4b. Can you indicate why you did not log in to the website of the Patient Decision Aid?

5. Did you select the treatment options in the Patient Decision Aid that your doctor/nurse had ticked on the prescription pad?

6a. Did you have any help when using the Patient Decision aid? If so, who helped you?

6b. Did somebody join you in using the Patient Decision Aid? If so, who joined you?

7a. The Patient Decision Aid includes value elicitation statements that could help you to decide about the best treatment for you.

Have you read these statements?

- If no or I don't know, continue to question 8

7b. Did you find it useful to read these statements?

8. Did you print the summary of the statements and take it along to your next appointment with your doctor/nurse?

- If no or I don't know, continue to question 10

9. Have you discussed this summary with your doctor/nurse? 
10 In general, how satisfied are you with the use of the Patient Decision Aid?

Please give a number between 0 and 10 , where 0 means that you are not satisfied at all and 10 means you are very satisfied.

11. Would you recommend the use of this decision aid to other women with breast cancer who also have multiple treatment options?

Please give a number between 0 and 10 , where 0 means that you would not recommend the Patient Decision Aid at all and 10 means you would very much recommend the Patient Decision Aid.

12. Do you have any further comments or suggestions with regard to shared decision making or the Patient Decision Aid?

13. What is the highest level of education you have completed?

- Primary School

- lower vocational education

- Intermediate secondary education

- Intermediate vocational education

- Higher secondary education

- Higher vocational education

- University degree

- I don't know/I don't want to tell you 
There is progress in sharing decisions with patients, although the second half of the shared decision-making process needs attention

Wilma Savelberg

Liesbeth Boersma

Marjolein Smidt

Trudy van der Weijden

Submitted BMC Health Services Research 


\section{Abstract}

\section{Introduction}

The implementation of shared decision making (SDM) for women facing early stage breast cancer still seems to be limited, despite all the efforts made. The use of a patient decision aid (PtDA), with an advice for professionals on how, when and why to use it, could enhance the involvement of patients in the treatment decision. This study aims to improve SDM implementation strategies by gaining an insight into patients' experiences with the SDM process.

\section{Method}

This qualitative study was part of a pilot study aiming to implement SDM in early adopter breast cancer teams. Patients were given access to a personalised PtDA. Breast cancer teams were instructed on how and when to deliver the PtDA. We interviewed patients on their experience with SDM and the PtDA.

\section{Result}

We interviewed 20 patients. Most patients experienced SDM, though to a certain extent. In contrast to choice talk and option talk, the elicitation of preferences and decision talk were hardly experienced. The PtDA was used by the majority of patients $(\mathrm{N}=13)$, all indicating that it was useful, especially to recall all the information given. Patients appreciated the contribution of breast cancer nurses in the clinical pathway. They considered them as true case managers, easy approachable and supportive.

\section{Conclusion}

Although patients felt well informed and satisfied with regard to the process of decision making and the decision made, the actual elicitation of preferences appeared very limited to non-existent. We recommend that breast cancer teams divide tasks in the process of shared decision making and reallocate the elicitation of preferences to the nurses in a well-defined clinical pathway. 


\section{Introduction}

A large number of women with early stage breast cancer are faced with the choice between a breast conserving or breast removing treatment. This is a preference sensitive decision, as both options have identical prognoses with regard to surviving rates, while each patient may value the advantages and disadvantages of both therapies differently. Therefore, the patient's preferences and values play an important role in the decision making process (1). In practice, however, treatment choices appear to be determined largely by local medical opinion (2). Variation in hospital mastectomy rates is associated with differences in the consultation and decision-making experiences of breast cancer patients. Patients' decisions are affected by the treatment option they were offered, the content and style of the information provided by their clinicians, the level of patient autonomy, and the time provided for decision making (3).

Shared decision making (SDM) is increasingly seen as a promising model to involve patients in deciding about treatment when there is more than one treatment option available. SDM is a process in which health care professionals and patients discuss treatment options, based on clinical evidence and the preferences of informed patients. First, the professional informs the patient that a decision is to be made and that the patient's opinion is important (choice talk), then the professional provides evidencebased, neutrally framed information about options, treatment burden, benefits and side effects (option talk). Finally, clinicians support the patient to deliberate about the options, which involves exploring and considering preferences (preference talk) and deciding what fits the patient best (decision talk) $(4,5)$.

Despite clinicians reporting positive attitudes, it appears that the actual application of SDM during clinical encounters is limited (6). Barriers for the implementation of SDM are found on the side of both clinicians as well as patients. Although the majority of patients prefer the SDM model, a minority of patients may not be prepared to be involved in the decision making process $(7,8)$. Moreover, some patients feel a lack of capacity or knowledge to be involved in the decision making process (9-11). Emotional distress could also prevent patients from engaging in the SDM process as well as taking the time needed to get involved (12). However, given the significant positive correlation between active involvement in the decision making and satisfaction with the final decision, patients' involvement in the decisionmaking process should be stimulated (13-15). If SDM is applied correctly and carefully, this can lead to a decision that fits the patient, which not only results in more knowledge about options, increased satisfaction and less decisional conflict, but also in a better doctor-patient relationship, fewer repeat visits and fewer second opinions (16-18). 
To implement SDM, we developed multifaceted strategies to enable breast cancer care teams to perform according to best practice, which included a web-based PtDA, a motivational five-minute video for patients, a ten-minute educational video for professionals and tailored advice on when and how to indicate and disseminate the PtDA (19). This study aimed to further improve these SDM implementation strategies by gaining an insight into: 1 ) the experiences and satisfaction with regard to SDM of patients who were exposed to best practice; 2) the support patients experience with regard to the PtDA.

\section{Methods}

This study was part of a larger study on the implementation of SDM using a PtDA for the surgical treatment of women with early-stage breast cancer (20). The study lasted for two years, from July 2015 until June 2017.

\section{Design}

We conducted qualitative interviews to assess subjective experiences from patients exposed to the implementation strategies to enhance SDM in breast cancer care. We used quantitative data on patient's experiences with regard to the process of SDM and the support they experienced regarding the PtDA to underpin the interview guide.

\section{Setting and population}

Data collection took place in dedicated breast cancer teams in four Dutch hospitals and one specialist breast cancer hospital between 1 April 2015 and 31 December 2015. We asked each hospital to include 10 patients (mother sample) by purposeful sampling (21). Patients had to be newly diagnosed with early-stage breast cancer (stage I or II), eligible for breast-conserving therapy or mastectomy and had been offered the PtDA. Eligible patients should be able to speak and understand Dutch and were identified at the tumour board meetings. The patients were asked to fill in a few quantitative questionnaires. Breast cancer nurses were instructed to invite each included patient from the mother sample for an interview, until a minimum of four patients per hospital were included. We aimed to include patients until saturation was reached, which in a study like this usually occurs after approximately 15 interviews (22). 


\section{Intervention}

All the members of the breast cancer teams were invited to attend a meeting, which took place within their own hospital. The meeting was prepared by the research team, with the first author (WS) having contacted key members of the team in advance. During the meeting, the research team clarified the principles of SDM and the PtDA, if necessary, and explained the implementation strategies. The strategies existed of recommendations (tailored to the specific needs of the team and to the hospital's specific workflow) on: 1 . a procedure on when and how to present the PtDA to the patient; 2 . minor adjustments to the pathway, such as planning a follow-up contact after patients used the PtDA; 3. watching both a ten-minute educational lecture and a fiveminute motivational video on SDM (role modelling). The strategies were built around a personalised web-based PtDA for patients. Participating patients were given access to the PtDA by means of a 'prescription pad'. This prescription pad contained the website address and a unique login code and, if prescribed correctly, enabled patients to personalise the PtDA. The breast cancer nurses were to provide additional information on why and how to use the PtDA $(23,19)$. Breast cancer nurses also informed patients about the present study and provided written information about the aim and procedure of the study, an informed consent form, three questionnaires and a prepaid envelope.

\section{Ethics}

The Maastricht University Medical Centre (MUMC+) ethics committee declares that this study does not fall under the scope of the Medical Research Involving Human Subjects Act (METC 14-5-042). Handling of personal data was in accordance with the Dutch Personal Data Protection Act and Medical Research (Human Subjects) Act. All participants provided written informed consent and all data were processed confidentially and anonymously.

\section{Data collection}

All included patients were invited to participate in a semi-structured face-to-face interview. If a patient gave permission to be approached, the researcher (WS) contacted them by telephone within two months after diagnosis, and made an appointment at a time of their convenience at their home or in the hospital. The interviews systematically addressed the following subjects: 1 ) experienced SDM and satisfaction with the process of SDM; 2) the usefulness and the degree of support provided by the PtDA. The interviews were conducted by a trained fifth-year medical student or the researcher (WS) and were audio-recorded. An interview guide was used. The interviewer took field notes. 
Prior to the interviews, we collected quantitative data about the mother sample. We collected demographic data such as age and level of education (low, intermediate or high) and asked patients about their current or past occupation. We also measured knowledge, decisional conflict and the process of SDM as perceived by patients.

These patient-reported experiences and outcomes and how these related to scores in existing literature (Appendix 1 ) were used to enrich the interview guide (Appendix 2). We used an adapted breast cancer information test to measure knowledge one week after the encounter (24). Patients' experience of the process of SDM was also measured at that time. We used the nine-item Shared Decision-Making Questionnaire (SDM-Q9) with a six-point scale from 0 (completely disagree) to 5 (completely agree), which is a standardised brief patient report instrument (25) used in clinical encounters, and the CollaboRATE which contains three brief questions with a 10-point anchored scale ( 0 = no effort was made, $9=$ every effort was made) (26). To further characterise the patients, we also measured decisional conflict three months after their diagnosis. The patients received a posted questionnaire containing the Decisional Conflict Scale (DCS), a16-item scale capturing to which extent patients feel uncertain, feel uninformed, feel supported and are unclear about personal values. Each of these items is scored on a five-point Likert scale from 1 (strongly agree) to 5 (strongly disagree) and summed to a total score of 1-100, with higher scores corresponding to more decisional conflict (27).

\section{Data analysis}

For the qualitative data, the interviews were transcribed verbatim and independently coded by the first author and a trained fifth-year medical student, using NVivo software to organise the data. The qualitative content analysis was performed using direct content analysis (28). We identified key themes that appeared throughout all interviews by grouping the codes into larger themes: 1) perceived SDM and SDM steps (choice talk, option talk and decision talk, including elicitation of preferences) during the clinical encounters; 2) delivery of the PtDA (by whom, how and when the PtDA was presented to the patient); 3 ) perceived usefulness of the PtDA. Differences in opinion were solved by discussion until agreement was reached.

The quantitative data were entered into a SPSS database, checked for completeness and errors by randomly controlling $15 \%$ of the data, and analysed using descriptive statistics (frequencies and percentages). 


\section{Results}

\section{Study population}

We gathered data from 41 patients, of whom 20 agreed to be interviewed (see Table 1). We interviewed these patients within three months of the diagnosis; the median time from diagnosis until the interview was 10 weeks (range 8-13 weeks). As regards these 20 patients, quantitative data were available for 17 patients. For different reasons, e.g. no eligible patients, no time or protection of patients already too much called upon for research, patient inclusion for the mother sample was difficult resulting in scattered and missing data (see Table 1). Nevertheless, the data made us aware of overarching potential issues, such as a perceived feeling of being well informed and problems with some of the steps of SDM. This resulted in the interview guide directing to dig deeper into the memory of patients especially with regard to preference and decision talk.

Table 1 Data collection of in total 41 included patients in five hospitals

\begin{tabular}{|c|c|c|c|c|c|c|}
\hline & \multicolumn{6}{|c|}{ Hospitals: } \\
\hline & Total & 1 & 2 & 3 & 4 & 5 \\
\hline Qualitative interviews & 20 & 6 & 4 & 1 & 5 & 4 \\
\hline \multicolumn{7}{|l|}{ Quantitative data } \\
\hline \multicolumn{7}{|c|}{ Process data Perceived by patients } \\
\hline$\checkmark$ SDM-Q9 & 30 & 8 & 10 & 2 & 3 & 7 \\
\hline$\checkmark$ CollaboRATE & 30 & 8 & 10 & 2 & 3 & 7 \\
\hline \multicolumn{7}{|l|}{ Patient outcome data } \\
\hline$\checkmark$ Knowledge & 30 & 8 & 10 & 2 & 3 & 7 \\
\hline$\checkmark$ Decisional conflict & 21 & 10 & 3 & - & 5 & 3 \\
\hline
\end{tabular}

All of the 41 patients included in the mother sample were asked permission to be contacted by the researcher (WS) to participate in an interview. The 20 interviewed patients were between 44 and 68 years of age with an average of 53 years, which did not differ from the patients in the mother sample. The interviews lasted between 11 and 67 minutes, with an average of 37 minutes. Of the 20 interviews, 14 were conducted face to face and six by phone. Table 2 describes the patient characteristics. 
With regard to the interviews, we found that patients with a higher level of education reflected more extensively on the conversation with their clinicians. They remembered with a greater attention to detail what their clinician told them and which profound questions they asked the clinician, like what the impact of the treatment would be on their job.

This was in contrast to patients with an intermediate or low level of education, who reported more general or practical essentials, like what the clinician told them about the procedure from that point on until the treatment, without getting into too much detail. This resulted in interviews that varied in richness and length between patients with a high level of education and patients with an intermediate or low level of education.

Table 2 patient characteristics.

\begin{tabular}{|c|c|c|c|c|c|c|c|}
\hline Patients & Hospital & Surgical treatment* & Age & Education & Logged in & \multicolumn{2}{|c|}{ Interview ${ }^{* *} \mathrm{DCS}^{* * *}$} \\
\hline Patient 1 & 1 & Mastectomy & 44 & High & Yes & 32 & 10.9 \\
\hline Patient 2 & 2 & Lumpectomy & 58 & Intermediate & No & 31 & 28.1 \\
\hline Patient 3 & 2 & Lumpectomy & 50 & Low & Yes & 54 & $* * * *$ \\
\hline Patient 4 & 1 & Lumpectomy & 55 & High & Yes & 41 & 31.3 \\
\hline Patient 5 & 1 & Depending on chemo & 48 & Intermediate & No & 34 & $* * * *$ \\
\hline Patient 6 & 1 & Mastectomy & 56 & Intermediate & No & 47 & 29.7 \\
\hline Patient 7 & 1 & Lumpectomy & 59 & High & Yes & 46 & $* * * *$ \\
\hline Patient 8 & 3 & Lumpectomy & 44 & Intermediate & No & 46 & 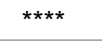 \\
\hline Patient 9 & 2 & Lumpectomy & 44 & Intermediate & Yes & 11 & 26.6 \\
\hline Patient 10 & 2 & Lumpectomy & 61 & High & Yes & 29 & 12.5 \\
\hline Patient 11 & 1 & Lumpectomy & 51 & Low & No & 32 & 26.6 \\
\hline Patient 12 & 5 & Mastectomy & 46 & Intermediate & Yes & 13 & $* * * *$ \\
\hline Patient 13 & 5 & Mastectomy & 61 & High & Yes & 53 & $* * \star *$ \\
\hline Patient 14 & 4 & Lumpectomy & 66 & Low & No & 11 & 15.6 \\
\hline Patient 15 & 5 & Lumpectomy & 51 & Low & No & 16 & 32.8 \\
\hline Patient 16 & 5 & Lumpectomy & 68 & High & Yes & 35 & $* * * *$ \\
\hline Patient 17 & 4 & Lumpectomy & 51 & High & Yes & 45 & 9.8 \\
\hline Patient 18 & 4 & Lumpectomy & 51 & High & Yes & 27 & 45.3 \\
\hline Patient 19 & 4 & Lumpectomy & 50 & Intermediate & Yes & 57 & 26.6 \\
\hline Patient 20 & 4 & Lumpectomy & 53 & High & Yes & 28 & 26.6 \\
\hline
\end{tabular}

${ }^{*}$ Preference at time of interview ${ }^{* *}$ Length in minutes ${ }^{* * *}$ Total score 1-100 ${ }^{* * * *}$ Missing 


\section{1) Experienced SDM steps and satisfaction with the SDM process}

In general, patients reported to have experienced SDM and were positive with regard to this experience of patient-centeredness. Most patients were positive about the process, the information they received, the way the clinicians supported and guided them and their accessibility. Some patients experienced patient-centeredness when health care professionals showed a true personal interest in them.

Most patients said they received a lot of information. Some patients found this somewhat overwhelming and stated that they forgot most of the information. Nevertheless, they generally felt well informed and well taken care of.

The effort of the breast cancer nurses was especially appreciated.

'They record the things that you are concerned with, and then they return to these topics themselves.' ... 'Those are the sorts of little things that make it so pleasant.' Patient 1

'You receive tremendous amounts of information, and I truly believe they really tell you everything, but obviously you don't absorb it all.' Patient 6

'I could always give her a call and turn to her with any questions I had or if I was feeling really lost.' Patient 3

\section{Choice talk}

Although some patients experienced a more paternalistic decision process, most patients reported that the clinicians, mostly the surgeon, made them aware about two relevant options for treatment during the clinical encounter. Most of the women remembered that their clinician specifically mentioned that both treatment options were equal with regard to survival rates and recurrence.

'Within five minutes, I was told that it was breast cancer and that there were two options: breast-conserving therapy or breast amputation.' Patient 17 


\section{Option talk}

Most of the patients reported the surgeon giving a comprehensive explanation of the tumour (size, location, risk of metastasis) and also describing the treatment options in general terms. Some patients referred to the surgeon also pointing out the pros and cons of both options. Occasionally a patient actively remembered how one of the clinicians summarised the options. Some patients received additional information from the breast cancer nurse in a second consultation.

'And then he just began telling what the pros and cons were of the various treatment options.' Patient 5

'Although they said that the survival chances were equal with breast-conserving or ... for me total amputation really felt strongly like, well ... with breast conserving-therapy, you never know what you leave behind.' Patient 12

\section{Preference talk}

A few patients indicated that they were asked about their preference for one of the options, after the clinician informed them about these options. In most cases, patients did not experience a discussion on preferences or any prompting for value clarification. A few patients expressed their concerns and fear that they lacked the knowledge to make such an important decision, which resulted in the clinician helping them to eliminate these concerns or increase their knowledge by arranging an appointment with another professional, e.g. a radiation or medical oncologist. Some patients reported that they had a firm intuitive preference from the beginning, which did not change throughout the process.

'That I would have to face the consequences of the radiation therapy really bothered me, and I really didn't feel that I had to keep my breast at all costs. To make sure that I was well informed anyway, the surgeon made an appointment with the radiation therapist, so I could consult with her as well to help me make my decision.' Patient 7 


\section{Decision talk}

Although most patients did not report any explicit decision talk and some patients reported a more paternalistic style of decision talk, patients felt that, eventually, they made their own decision. The majority of the patients felt no pressure and were given time to think and talk to relatives about the options. A few days later, they were given a follow-up appointment, often with a breast cancer nurse to reconsider or confirm their first intuition on treatment. Four patients stated they did not make the decision, either because they felt they had no choice or felt they had no preference, nor the knowledge to make such an important decision.

'Well, his first choice was breast-conserving therapy, and ... which woman wouldn't want that, I guess, but then he did add that I also had the choice of breast amputation. He said I had a choice, but that in principle it wasn't necessary.' Patient 13

'I simply don't have the knowledge. I just have to assume - and want to assume - that they have my best interests at heart.' Patient 2

\section{2) Perceived support of the PtDA}

At the time of the interview, $13(65 \%)$ of the patients had been using the PtDA. The non-users were all educated at an intermediate or low level. The patients who used the PtDA thought the information was clear and useful. Most of them remembered what and how they had read. Some patients had scrolled through the website reading bits and pieces they found interesting, while others had only read the screens that applied to them. Most of the patients indicated that it had been useful to read all the information again. They recognised most of the information they had already received verbally, but reading this again encouraged them to rely on their first intuitive preference or to feel confirmed in their deliberation about the treatment decision. One patient used the PtDA and decided to request a new appointment with her surgeon, after which she changed her treatment decision.

Half of the patients who used the PtDA stated they had read and completed the value elicitation part of the PtDA. A majority of the patients who had completed the value elicitation exercise had printed the summary of the answers they had given with the aim of presenting it during the follow-up consultation with the breast cancer nurse. Only one breast cancer nurse asked to look at and talk about it. 
Patients who had printed the summary and taken it to the next consultation were disappointed because the clinician did not inquire after their preferences. Two patients found completing the value elicitation statements emotionally distressing.

None of the patients viewed the PtDA as the primary resource for their treatment decision, although it had helped them become better informed. Patients regarded their surgeon and family as their most important decision-making resources. Most patients did not particularly use the PtDA to prepare the decision talk with their clinician.

'Well, I did make a printout and took it along, but we didn't discuss it specifically.' Patient 18

'So that was clear. Fine. Although I think that at that point I had more or less decided, I did appreciate the opportunity to read it all again.' Patient 16

'I did complete the decision aid and it had me thinking: well, they can depict it like that, and I'm seeing it all on screen, but I prefer to hear it from someone. Matters were pretty clear and when I completed the decision aid I did think: well, I'll go for breast-conserving therapy, that's what I'll do. But I still wanted to discuss it with the doctor ... and that's what really decided matters in the end.' Patient 9

\section{Discussion}

\section{Summary of main findings}

With regard to the SDM process, patients felt that clinicians made an effort to inform and involve them, which resulted in patients being satisfied with the process and having experienced SDM. Choice talk and option talk was occasionally somewhat evocative and did not completely refrain from the clinician's implicit opinion, but patients felt well informed and felt they had explicitly decided on the treatment option. Elicitation of preferences was very limited, both during the first and the follow-up consultation, after patients had been exposed to the PtDA. Apparently, a clear structure in the second half of the SDM process was lacking. Most patients did not remember any explicit value clarification or decision talk. 
In general, breast cancer nurses delivered and explained the PtDA to patients. A majority of the patients, mostly patients with a high level of education used, appreciated the PtDA and thought it was useful especially to recall all information given, but patients used the PtDA in various ways. Some patients read all the available information, completed the value elicitation exercise and read and printed the summary, while other patients just read one chapter and only briefly looked at the value elicitation questions. Patients that took the summery to the successive consultation were sometimes disappointment or surprised that the breast cancer nurse never asked to discuss it.

\section{Strengths and limitations}

The qualitative design of this study enabled us to learn about the experiences of patients with regard to SDM and the usefulness of the PtDA. The sample size of this study $(\mathrm{N}=20)$ was sufficient to reach data saturation. No new themes emerged from the data after 17 interviews. Although we urged the breast cancer nurses to recruit all the patients who were offered a PtDA, selection bias might have occurred with regard to patients who were most willing to use the PtDA. Such bias seems limited, as we succeeded in including patients with varying levels of education, with a reasonable balance between patients with high and low education levels. Originally, we planned a pre- and postimplementation study measuring objective and subjective results on outcome and process. Due to a difficult inclusion of patients, the quantitative data were too scattered to use as evidence (20). However, the data were meaningful to use as a source to enrich the qualitative work, helping us to get to the core questions and dig deeper in the memory of patients. The number of patients included in the interviews per participating hospital was not evenly distributed. One hospital supplied only one patient for this study, while another hospital supplied six patients.

\section{Comparison of the results with the current literature}

In general, patients were positive about the perceived level of SDM and felt well informed, which is reflected in the results of SDM-Q9 and CollaboRATE. True patient-centeredness was experienced especially when health care professionals showed themselves to be knowledgeable about personal details. This finding is consistent with conclusions from other studies, in which it became clear that the degree of trust in their clinician contributes to patients' feeling of being well informed $(29,30)$. The finding of patients lacking any experience of preference elicitation or value clarification during the medical encounters was in line with objective data we gathered.

Although the efforts of breast cancer nurses, who were viewed as easily approachable case managers, were highly appreciated by patients, their role varied considerably between hospitals and patients. 
In some hospitals they played a major part in the consultation, in others their role was limited, apart from coordinating the care process; they were deployed to educate and counsel patients. This was also consistent with findings in other studies (31). Nurses often also performed the last consultation before the patient had surgery. We recommend that breast cancer teams review their roles in the pathway, define them, and give nurses a clear responsibility in SDM, especially with regard to eliciting preferences.

Patients were overwhelmed by the amount of both verbal and written information they received during the encounters, especially the first one. The information they received did not only concern their own diagnoses but also information on hospital regulations, follow-up appointments, specific support and research projects most of the breast cancer units are involved in. We recommend that all the information given to patients is reviewed. Some of the written materials may not be applicable right after diagnosis and could be handed over during the second consultation, after the patient has had time to use the PtDA.

Concerning the PtDA, there was some variation in use and satisfaction. The percentage of patients using the PtDA corresponded to results from other studies (32). Patients that used the PtDA thought it was useful, especially in recalling the information they received from the clinician. Reading the information again strengthened them in underpinning their deliberation about the treatment.

\section{Conclusion}

In this study, we explored patients' experiences on SDM and a recently developed PtDA. It seems obvious that the process of SDM is taking small steps forward. We found a suitable level of perceived SDM. Patients felt well informed, reported being involved in the decision making process and were satisfied with the process and the decision made. Nevertheless, the perceived level of SDM was largely based on whether the first two steps of SDM, choice talk and option talk, were performed satisfactorily. Decision talk, in which preferences should be explored, remained limited, implying that more focus is needed on the second half of the process in the implementation of SDM. We will have to make it clear to clinicians that SDM means not only transmitting information, but also engaging in a dialogue in which patients' preferences are discussed and not guessed. Together with clinicians, we should define who performs this dialogue and when it should take place. A clear explanation on how to use the PtDA, including the value clarification, and motivating patients to use the PtDA as intended is necessary to persuade more patients to use the PtDA. 


\section{References}

1. Waljee JF, Rogers MAM, Alderman AK. Decision Aids and Breast Cancer: Do They Influence Choice for Surgery and Knowledge of Treatment Options? Journal of Clinical Oncology. 2007;25(9):106773.

2. Wennberg JE, Fisher ES, Skinner JS. Geography and the debate over Medicare reform. Health affairs. 2002; Suppl Web Exclusives:W96-114.

3. Caldon LJ, Collins KA, Wilde DJ, Ahmedzai SH, Noble TW, Stotter A, Sibbering DM, Holt S. Reed MWR. Why do hospital mastectomy rates vary? Differences in the decision-making experiences of women with breast cancer. Br J Cancer. 2011;104(10):1551-7.

4. Sivell S, Edwards A, Manstead AS, Reed MW, Caldon L, Collins $\mathrm{K}$, Clements A, Elwyn G. Increasing readiness to decide and strengthening behavioral intentions: evaluating the impact of a web-based patient decision aid for breast cancer treatment options (BresDex: www.bresdex.com). Patient education and counseling. 2012;88(2):209-17.

5. Stiggelbout AM, Pieterse AH, De Haes JCJM. Shared decision making: Concepts, evidence, and practice. Patient education and counseling. 2015;98(10):1172-9.

6. Elwyn G, Scholl I, Tietbohl C, Mann M, Edwards AG, Clay C, Legare F, van der Weijden T. Lewis, CL, Wexler RM, Frosch DL."Many miles to go ...": a systematic review of the implementation of patient decision support interventions into routine clinical practice. BMC medical informatics and decision making. 2013;13 Suppl 2:S14.

7. Moreau A, Carol L, Dedianne MC, Dupraz C, Perdrix C, Laine X, Souweine $G$. What perceptions do patients have of decision making (DM)? Toward an integrative patient-centered care model. A qualitative study using focus-group interviews. Patient education and counseling. 2012;87(2):206-11.

8. O'Brien MA, Charles C, Lovrics P, Wright FC, Whelan T, Simunovic M, Kennedy E, Grunfeld E. Enablers and barriers to using patient decision aids in early stage breast cancer consultations: a qualitative study of surgeons' views. Implement Sci. 2014;9:174.

9. Lee CN, Chang Y, Adimorah N, Belkora JK, Moy B, Partridge AH, Ollila DW. Sepucha KR. Decision making about surgery for earlystage breast cancer. Journal of the American College of Surgeons. 2012;214(1):1-10.

10. Salloch S, Ritter P, Wascher S, Vollmann J, Schildmann J. Medical expertise and patient involvement: a multiperspective qualitative observation study of the patient's role in oncological decision making. Oncologist. 2014;19(6):654-60. 
11. Pieterse AH, Baas-Thijssen MC, Marijnen CA, Stiggelbout AM. Clinician and cancer patient views on patient participation in treatment decision-making: a quantitative and qualitative exploration. British journal of cancer. 2008;99(6):875-82.

12. O'Brien MA, Whelan TJ, Charles C, Ellis PM, Gafni A, Lovrics P, Hasler A. Dimitry S. Women's perceptions of their treatment decisionmaking about breast cancer treatment. Patient education and counseling. 2008;73(3):431-6.

13. Janz NK, Wren PA, Copeland LA, Lowery JC, Goldfarb SL, Wilkins EG. Patient-physician concordance: preferences, perceptions, and factors influencing the breast cancer surgical decision. J Clin Oncol. 2004;22(15):3091-8.

14. Lam WW, Kwok M, Chan M, Hung WK, Ying M, Or A, Kwong A, Suen $D$, Yoon S, Fielding R. Does the use of shared decisionmaking consultation behaviors increase treatment decision-making satisfaction among Chinese women facing decision for breast cancer surgery? Patient education and counseling. 2014;94(2):243-9.

15. Brown R, Butow P, Wilson-Genderson M, Bernhard J, Ribi K, Juraskova I. Meeting the decision-making preferences of patients with breast cancer in oncology consultations: impact on decisionrelated outcomes. Journal of clinical oncology : official journal of the American Society of Clinical Oncology. 2012;30(8):857-62.

16. Stiggelbout AM, Pieterse AH, De Haes JC. Shared decision making: Concepts, evidence, and practice. Patient education and counseling. 2015;98(10):1172-9.

17. Legare F, Stacey D, Turcotte S, Cossi MJ, Kryworuchko J, Graham ID, Graham L, Lyddiatt A, Politi MC, Thomson R, Elwyn G, DonnerBanzhoff $\mathrm{N}$. Interventions for improving the adoption of shared decision making by healthcare professionals. Cochrane Database Syst Rev. 2014;9:CD006732.

18. Stacey D, Kryworuchko J, Belkora J, Davison BJ, Durand MA, Eden KB, Hoffman S.Koerner M, Légaré F, Loiselle MC, Street RL. Coaching and guidance with patient decision aids: A review of theoretical and empirical evidence. BMC medical informatics and decision making. 2013;13 Suppl 2:S11.

19. Savelberg W, Boersma L, Smidt M, Goossens M, Hermans R, Weijden $T$. Does lack of deeper understanding explain the suboptimal performance on crucial parts of shared decision making?Accepted. European Journal of Nursing Oncology 2018.

20. Savelberg W, Moser A, Smidt M, Boersma L, Haekens C, van der Weijden T. Protocol for a pre-implementation and postimplementation study on shared decision-making in the surgical treatment of women with early-stage breast cancer. BMJ open. 2015;5(3):e007698. 
21. Palinkas LA, Horwitz SM, Green CA, Wisdom JP, Duan N, Hoagwood K. Purposeful Sampling for Qualitative Data Collection and Analysis in Mixed Method Implementation Research. Administration and Policy in Mental Health and Mental Health Services Research. 2015;42(5):533-44.

22. Morse JM. Determining Sample Size. Qualitative Health Research. $2000 ; 10(1): 3-5$.

23. Savelberg W. Implementation of shared decision making in a clinical setting; how to make it fit in the daily workflow? 2014.

24. Sawka CA, Goel V, Mahut CA, Taylor GA, Thiel EC, O'Connor AM, Ackerman I, Burt JH, Gort EH. Development of a patient decision aid for choice of surgical treatment for breast cancer. Health Expect. $1998 ; 1(1): 23-36$.

25. Kriston L, Scholl I, Holzel L, Simon D, Loh A, Harter M. The 9-item Shared Decision Making Questionnaire (SDM-Q-9). Development and psychometric properties in a primary care sample. Patient Educ Couns. 2010;80(1):94-9.

26. Elwyn G, Barr PJ, Grande SW, Thompson R, Walsh T, Ozanne EM. Developing CollaboRATE: a fast and frugal patient-reported measure of shared decision making in clinical encounters. Patient Educ Couns. 2013;93(1):102-7.

27. O'Connor A. User manual - Decisional Conflict Scale 2010 [Available from: http://www.ohri.ca/decisionaid/.

28. Hsieh HF, Shannon SE. Three approaches to qualitative content analysis. Qual Health Res. 2005;15(9):1277-88.

29. Sepucha KR, Fagerlin A, Couper MP, Levin CA, Singer E, ZikmundFisher BJ. How Does Feeling Informed Relate to Being Informed? The DECISIONS Survey. Medical Decision Making. 2010;30(5_ suppl):77-84.

30. Wunderlich T, Cooper G, Divine G, Flocke S, Oja-Tebbe N, Stange $\mathrm{K}$, Lafata $\mathrm{JE}$, Inconsistencies in patient perceptions and observer ratings of shared decision making: The case of colorectal cancer screening. Patient education and counseling. 2010;80(3):358-63.

31. Berger-Höger B, Liethmann K, Mühlhauser I, Steckelberg A. Implementation of shared decision-making in oncology: development and pilot study of a nurse-led decision-coaching programme for women with ductal carcinoma in situ. BMC Med Inform Decis Mak. 2017;17.

32. Miller KM, Brenner A, Griffith JM, Pignone MP, Lewis CL. Promoting Decision Aid Use in Primary Care Using a Staff Member for Delivery. Patient Education and Counseling. 2012;86(2):189-94.

33. Körner M, Wirtz MA. Development and psychometric properties of a scale for measuring internal participation from a patient and health care professional perspective. BMC health services research. $2013 ; 13(1): 374$. 
34. Elwyn G, Barr PJ, Grande SW, Thompson R, Walsh T, Ozanne EM. Developing CollaboRATE: A fast and frugal patient-reported measure of shared decision making in clinical encounters. Patient education and counseling. 2013;93(1):102-7.

35. O'Connor A, '. User manual - Decisional conflict scale http://www. ohri.ca/decisionaid/2010 [

36. Härter M, Buchholz A, Nicolai J, Reuter K, Komarahadi F, Kriston L, Kallinowski B, Eich W, Bieber C. Shared Decision Making and the Use of Decision Aids: A Cluster-Randomized Study on the Efficacy of a Training in an Oncology Setting. Deutsches Ärzteblatt International. 2015;112(40):672-9.

37. Sepucha K, Ozanne E, Silvia K, Partridge A, Mulley AG. An approach to measuring the quality of breast cancer decisions. Patient education and counseling. 2007;65(2):261-9.

38. Osaka W, Nakayama K. Effect of a decision aid with patient narratives in reducing decisional conflict in choice for surgery among early-stage breast cancer patients: A three-arm randomized controlled trial. Patient education and counseling. 2017;100(3):55062.

39. Forcino RC, Barr PJ, O'Malley AJ, Arend R, Castaldo MG, Ozanne EM, Percac-Lima S, Stults CD, Tai-Seale M, Thompson R, Elwyn G. Using CollaboRATE, a brief patient-reported measure of shared decision making: Results from three clinical settings in the United States. Health expectations : an international journal of public participation in health care and health policy. 2018;21(1):82-9. 


\section{Appendix 1 \\ Patient-reported experiences and outcomes}

\begin{tabular}{|c|c|c|c|c|c|c|c|}
\hline Variable & Total & $\begin{array}{c}\text { Hospital } \\
1\end{array}$ & $\begin{array}{l}\text { Hospital } \\
2\end{array}$ & $\begin{array}{c}\text { Hospital } \\
3\end{array}$ & $\begin{array}{c}\text { Hospital } \\
4\end{array}$ & $\begin{array}{c}\text { Hospital } \\
5\end{array}$ & $\begin{array}{c}\text { Comparative } \\
\text { studies }\end{array}$ \\
\hline \multicolumn{8}{|l|}{ Process data } \\
\hline & $N=30$ & $\mathrm{~N}=8$ & $\mathrm{~N}=10$ & $\mathrm{~N}=2$ & $N=3$ & $\mathrm{~N}=7$ & * \\
\hline \multirow[t]{2}{*}{$\checkmark$ SDM-Q9 } & 86.3 & 87.5 & 80.2 & 90 & 88.9 & 93.9 & $72.7(20.6)$ \\
\hline & $N=30$ & $\mathrm{~N}=8$ & $\mathrm{~N}=10$ & $\mathrm{~N}=2$ & & $\mathrm{~N}=7$ & 1) \\
\hline$\checkmark$ CollaboRATE & 8.3 & $8.4(6.3)$ & $8.1(0.6)$ & $8.7(0.5)$ & $8.3(0.6)$ & $8.4(0.5)$ & \\
\hline \multicolumn{8}{|l|}{ Outcome data } \\
\hline & $N=30$ & $\mathrm{~N}=8$ & $\mathrm{~N}=10$ & $\mathrm{~N}=2$ & & $N=7$ & ** \\
\hline \multirow[t]{2}{*}{ Correct answers to } & $61 \%$ & $57 \%$ & $60 \%$ & $65 \%$ & $90 \%$ & $58 \%$ & $48.2(15.4)$ \\
\hline & $\mathrm{N}=20$ & $\mathrm{~N}=10$ & $N=4$ & $\mathrm{~N}=0$ & & $N=3$ & *** \\
\hline Overall score & 28.1 & 31.2 & 22.7 & - & 30.8 & 24.6 & $44.6(15.1)$ \\
\hline \multicolumn{8}{|l|}{ Subscores } \\
\hline Uncertainty & 29.2 & 32.5 & 20.8 & - & 29.7 & 29.1 & $56.7(22.7)$ \\
\hline Informed & 39.2 & 39.2 & 31.2 & - & 23.6 & 44.4 & $36.2(15.1)$ \\
\hline Value clarity & 25.0 & 27.5 & $25(6.8)$ & - & 30.1 & 20.8 & $49.7(21.0)$ \\
\hline Support subscore & 30.0 & 34.2 & $25(11.8)$ & - & 31.4 & 26.4 & $35.7(19.1)$ \\
\hline Effective decision & 20 & 25.0 & 14.1 & - & 27.4 & 15.6 & $53.5(9.7)$ \\
\hline
\end{tabular}

SDM-Q9: range 0-100, whereby 0 indicates the lowest possible level of SDM and 100 indicates the highest possible level of SDM. (33)

CollaboRATE: Top score = percentage of the patients responding 9 to all three items.

Higher scores represent more shared decision-making. (34)

Knowledge test: percentage of correct answers.

Decisional conflict: range 1-100. Higher score represents more decisional conflict. (35)

*Results from Härter, $M$ et al.(36) **Results from Sepucha, $K$ et al (37)

***Results from Osaka, W et al (38)

1) The only comparative study we found was Forcino, A et al (39), which used the top scoring method to analyse. This method has not been validated in the Netherlands. 


\section{Appendix 2 Interview guide}

Thank you for taking the time to speak to me today. You have agreed to be interviewed for this study about shared decision-making in clinical practice. With your permission, the interview is being recorded because we need to transcribe it. As agreed, everything that is discussed today will be processed anonymously and your name will not be mentioned in the report.

I would like to ask you some questions about your experiences with shared decision-making and the patient decision aid. Do not hesitate to tell me if you do not understand something. There are no good or bad opinions, you can say whatever you like. The results of this interview will be used to learn more about the implementation of shared decisionmaking and the usefulness of a patient decision aid.

\section{In general}

1. Could you describe the consultation during which you received the diagnosis and the treatment options/treatment plan?

2. How did you experience the conversation with your surgeon and/or your nurse/nurse practitioner in general?

3. Please describe how you and your surgeon determined a treatment plan. How did you decide on a mastectomy/breast-conserving therapy?

4. How did you experience the decision-making process?

- What information did you receive?

- What did you think of the information you received?

- At that time, did you understand the information?

- Were you able to contribute to the conversation? If so, what was your contribution?

- Were you able to express your preferences? If so, how did you express your preferences and how did the surgeon respond?

- How was the decision made? (you, your surgeon, together)

5. What could have been done better? 


\section{Patient decision aid (PtDA)}

6. Did you use the PtDA? If no, why not?

If yes:

7. How did you appreciate the PtDA in general?

8. How did you appreciate the information you read in the PtDA?

- Did you find the information you read useful?

- Did you find the information in the PtDA neutral?

- Did you find the information complete?

- What was your opinion with respect to the amount of information?

- Did you read all the information? If not, which parts did you read?

9. Did you read the value clarification statements? If yes, did you use them according to the explanation? Did you print the summary? Did you take the summary to your next consultation?

10. Did you find the PtDA feasible?

\section{Patient decision aid - implementation}

11. What is your opinion with regard to the timing of the delivery of the PtDA? How and by whom was the PtDA delivered? What did you appreciate in this process?

12. Would you rather have another clinician delivering the PtDA or done at another time?

13. Did the PtDA influence the knowledge you had about breast cancer and the treatment?

14. Did the PtDA influence your treatment decision?

15. How do you feel about the treatment you chose?

Those were my questions. If there is anything you would like to add to this interview, now is the time to do so. If not, I would like to thank you for your time and the openness that you have shown me. We will send you a report of this interview. You can read it and see whether you agree or not. If you do not agree or have remarks, you can email me. If you do not respond within three weeks, I assume you agree with how our conversation has been represented. 


\section{Does lack of deeper}

understanding explain the suboptimal performance on crucial parts of shared decision
making?

Wilma Savelberg

Liesbeth Boersma

Marjolein Smidt

Medi Goossens

Raoul Hermanns

Trudy van der Weijden

European journal of oncology nursing February 2019 Volume 38, Pages 92-97 oi.org/10.1016/j.

ejon.2018.12.004 


\section{Abstract}

\section{Purpose}

Although most of the clinicians in breast cancer care seem to approve of shared decision making (SDM), actual implementation is limited. The aim of this study was to explore the experiences, issues and concerns of early-adopter professionals with regard to shared decision making.

\section{Methods}

This qualitative interview study was part of a pilot study aimed at implementing SDM in breast cancer teams. We interviewed 27 clinicians, 9 breast cancer surgeons, 11 nurse practitioners and 7 breast cancer nurses. The teams were exposed to a multifaceted implementation programme, among others: a patient decision aid (PtDA), a procedure to disseminate the PtDA and advice on redesigning the clinical pathway.

\section{Results}

They considered SDM, including the delivery of the PtDA, to be a team effort, in which every professional should take responsibility. Most clinicians primarily focused on the first steps of SDM ignoring preference and decision talk. The remaining steps, like the uptake of the PtDA in the clinical pathway, were regarded as challenging, with surgeons, intentionally or unconsciously, delegating this responsibility to nurses. One barrier to successfully implementing SDM seems to lie in the fact that clinicians were unaware of their lack of competency regarding SDM.

\section{Conclusions}

A deeper understanding seems needed among clinicians of what SDM actually is and how a PtDA contributes to this process. Nurses play an important role in the delivery of the PtDA, but their role is not clearly defined. Teams should consider a clear realignment of tasks between surgeons and nurses, which implies redesign of the clinical pathway. 


\section{Introduction}

Women diagnosed with early stage breast cancer often can be given the choice between breast conserving therapy (BCT) or mastectomy. Both options have identical prognosis with regard to survival, but each patient may value the advantages and disadvantages of these therapies differently (1), indicating that the patient's preference may determine the decision. Patients vary in their personal preferences, influenced by issues such as level of fear and anxiety, body image values and attitudes towards radiotherapy (2-4).

Several studies have shown that involving patients in the decisionmaking process improves their knowledge about treatment risks and benefits, and their satisfaction with the decision made (5). There is also increasing evidence that most patients want to take an active part in treatment decisions (6). Shared decision making (SDM) is the process in which clinician and patient discuss treatment options, to determine the treatment option that best fits the individual patient. First, the clinician needs to invite the patient to work together as a team to make a decision between two relevant options (choice talk). This is followed by information on the pros and cons of the options (option talk), and, once the patient has digested the information, elaborating with the patient to elicit the preference (preference talk), and finally, to make the treatment decision (decision talk) with the patient $(7,8)$.

Tools to support SDM, like a patient decision aid (PtDA), seem to improve the process of patients' involvement in the decision making process, with patients showing more knowledge about the options and more accurate risk perceptions, and decisions being more consistent with patients' values (9-11).

Although support for the wide-scale adoption of SDM and the development of PtDAs is growing, actual implementation is slow and faces many challenges. Implementation of SDM is suffering from lack of knowledge and self-efficacy, and negative attitudes among clinicians towards SDM in general or to the content of PtDAs. Although interventions to implement SDM adjusted to clinical schedules, including the use of PtDAs in a time-saving manner, evoke less resistance, the best timing and procedures for integrating a PtDA in the clinical pathway are still unknown (12-15).

To close the gap between the principles of SDM and the actual implementation, we developed a SDM implementation programme for breast cancer care teams, including a PtDA, a motivational five-minute video for patients, a ten-minute educational video for professionals and tailored advice on when and how to indicate and disseminate the PtDA. 
The objective of this study was to explore the experiences, issues and concerns of professionals in teams that were exposed to the implementation programme, and the specific lessons on the implementation of a PtDA within an oncological clinical pathway. Various studies abroad have generated insights into relevant barriers and facilitators for the implementation of $\operatorname{SDM}(13,14,16,17)$. We seek to validate these findings for the situation in the Netherlands. We believe we add to the existing body of knowledge as we conducted our research with early-adopter teams that were already dedicated to implementing SDM. We considered these teams as early-adopters because they showed special interest in SDM and the use of the PtDA. They showed this by volunteering for participation in this study as early as during the development of the PtDA. We exposed them to an implementation programme we developed. We assumed this would provide more knowledge on successful implementation strategies, which can help scale up the use of PtDAs among breast cancer teams also willing to adopt SDM.

\section{Method}

\section{General design}

The study focused implementing a PtDA in daily clinical practice.

This was a qualitative study, part of a pilot study aimed at the implementation of SDM in the surgical treatment process of early stage breast cancer. The study lasted two years, from July 2015 until June 2017.

\section{Population and setting}

Dedicated breast cancer teams, known for their positive attitude towards SDM and willingness to improve the process of SDM, from eight hospitals in the west and south of the Netherlands were invited to participate in this study. Seven teams decided to participate. The teams gained free access to a web-based PtDA, for which they had to pay a subscription fee if they decided to continue to use it after the pilot. All team members were invited to join an introduction meeting to explain the implementation programme. To generate meaningful input for the interviews, the clinicians were asked to audiotape some patient contacts during the course of the implementation period. The audiotaped consultations ( $\mathrm{N}=33$ from 13 different clinicians) were rated with Observer Option 5 and the scores were compared with earlier research results $(8,18)$. From each participating hospital a minimum of two clinicians, at least one breast cancer nurse and one breast cancer surgeon, were purposefully included in this study. Participating clinicians had to be fully exposed to the programme. 


\section{Ethical considerations}

The Maastricht University Medical Centre (MUMC+) ethics committee declared that this study does not fall under the scope of the Medical Research Involving Human Subjects Act (METC 14-5-042). Handling of personal data was in accordance with the Dutch Personal Data Protection Act and Medical Research (Human Subjects) Act.

\section{Implementation programme}

The research team organised a meeting in each hospital for the breast cancer team to explain the implementation programme and discuss the tailored advise on when and how to indicate and disseminate the PtDA. The programme consisted of offering recommendations (tailored to the specific needs of the team and to the hospital's specific workflow) on: 1. a procedure on how to present the PtDA to the patient, 2. minor adjustments in the pathway, 3 . watching both a ten-minute educational lecture and a five-minute motivational video on SDM (role modelling). The programme was built around a personalised PtDA for patients. The preferred procedure for presenting and using the PtDA was described as follows:

The personal login code is printed on a paper prescription pad, which is available on the clinician's desk in the consultation room. Each sheet contains the various treatment choices to remind the professional about presenting the PtDA, and a unique personal login code; see Figure 1. The clinician hands out the prescription pad sheet with the personal login code to 'prescribe' the PtDA. The clinician personalises the sheet by ticking the treatment options that are relevant for the patient in addition to breast conserving treatment and mastectomy, such as adjuvant or neo-adjuvant chemotherapy, and/or reconstructive surgery during or after the curative surgery.

The web-based PtDA can be read at home, when the patient logs in. After first reading the general information, the patient is invited to tick the options that had been marked on the prescription pad sheet, so only the treatment options that are available to the individual patient are shown on the screen. Thus, each patient can personalise the PtDA to prevent an overload of information.

The PtDA includes a five-minute video, aimed at both patients and professionals, in which a clinician and a patient talk about the importance of SDM and how the PtDA can be used to support this process. The purpose is to raise the team's awareness regarding the SDM process and the positive impact of SDM. 


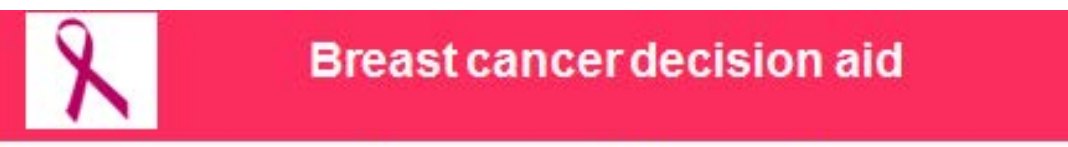

Your options:

Breast conserving treatment
Please mark one option
- Is possible without chemotherapy
Is better after chemotherapy
Is only possible after successful
chemotherapy
Mastectomy
Multiple options
Without a reconstruction
With an immediate reconstruction
- With a delayed reconstruction

Your login details:

You can read more information about breast cancer and the treatments on https://breastcancer decisionaid.com. You will be supported to align your considerations. You will find your considerations in the summary.

Please print the summary and take it to your next consultation. If you do not have a printer, please take this login code. We will go through the summary.

Username:

Password:

Maastricht UMC+

$\mathbf{0}_{\text {axm }}^{2} \overline{\bar{M}}-\mid \nabla$ Mastricht Uaiversity

This patient decision aids is developed by Maastricht UMC+ and zorgkeuzelab

\section{Data collection}

A total of 34 clinicians consisting of surgeons, nurses and nurse practitioners from seven hospitals were invited to participate in a semi-structured face-to-face interview. The interview systematically addressed the following topics: 1 . their attitude and behaviour with respect to SDM, 2. their knowledge about SDM and the PtDA, 3. the use of the PtDA within the process of SDM. The interviews were recorded on audiotape, the interviewer also took field notes. See Appendix 1 for the interview guide. 
Many clinicians feel they involve patients in a correct way in decision making, but seem to lack knowledge on what SDM is really about (19-21). Additionally, in general, human beings seem to have the tendency to overestimate their abilities in many social and intellectual areas (22). Therefore, after the clinicians were exposed to the main questions, approximately halfway through the course of the interview, the researcher showed Elwyn's model of SDM as it was used in the educational video, thus making the clinicians aware of the different steps in the process (23). The clinicians also received a brief feedback on 1 . the process data of the pilot study, 2 . the actual uptake of the PtDA, 3. the results of the Observer Option ${ }^{5}$ on previously made audio tapes in the consultation room. Observer OPTION 5 aims to measure to what extent the patient is involved in the decision about the treatment. The instrument consists of a set of competences, including problem definition, explaining legitimate choices, portraying options and communicating risk, and conducting the decision process. The measurement level is ordinal with scores of 0 to 4 . Two members of the research team assessed these recordings independently using the Observer Option ${ }^{5}$ instrument (24).

The scores were compared and differences were discussed until consensus was reached. The overall inter-rater reliability, measured by Cohen's Kappa, was substantial (0.71). Showing Elwyn's model and the data we helped professionals to compare their own perceived performance with what SDM actually consist of and the objective results.

\section{Data analysis}

The interviews were transcribed verbatim and processed anonymously. Each interview was independently coded by two authors applying thematic content analysis, using NVivo software to organise the data. Differences in opinion between the coders were solved by discussion until agreement was reached. We identified key themes by grouping the codes into larger themes, which were further explored, restructured, refined and reduced in number (25).

\section{Results}

\section{Study population}

Of the 34 invited, 27 professionals from 7 different breast cancer teams were willing to participate. Most of these professionals, (male: $\mathrm{N}=4$ ) were female $(\mathrm{n}=23), 9$ were breast cancer surgeons, 11 nurse practitioners and 7 breast cancer nurses (see Table 1 ). The average duration of the interviews was 23 minutes (SD 6.5, range 14-43 minutes). 
Table 1: Study population

\begin{tabular}{|l|l|c|l|l|l|l|l|l|l|}
\hline & Total & Hosp. 1 & Hosp. 2 & Hosp. 3 & Hosp. 4 & Hosp. 5 & Hosp. 6 & Hosp.7 & \\
\hline Professionals & & & & & & & & & $\begin{array}{l}\text { Average } \\
\text { duration } \\
\text { (SD) }\end{array}$ \\
\hline $\begin{array}{l}\text { Breast cancer } \\
\text { surgeon }\end{array}$ & 9 & 3 & 0 & 1 & 2 & 1 & 1 & 1 & $\begin{array}{l}19 \\
\min (2)\end{array}$ \\
\hline $\begin{array}{l}\text { Nurse } \\
\text { practitioner }\end{array}$ & 11 & 2 & 2 & 1 & 3 & 1 & 1 & 1 & $\begin{array}{l}23 \\
\min (6)\end{array}$ \\
\hline Nurse & 7 & 3 & 1 & 0 & 0 & 1 & 1 & 1 & $\begin{array}{l}31 \\
\min (5)\end{array}$ \\
\hline $\begin{array}{l}\text { Nr. of } \\
\text { interviews }\end{array}$ & 27 & 8 & 3 & 2 & 5 & 3 & 3 & 3 & \\
\hline
\end{tabular}

The main themes that emerged from the data analyses were: 1 ) Diverging attitudes of clinicians towards SDM and the PtDA. 2) A more or less successful delivery of the PtDA. 3) Specific barriers in the implementation of SDM behaviour.

\section{1) Diverging attitudes among clinicians towards SDM and the PtDA}

Team effort

The attitudes of individual clinicians towards SDM and the PtDA seemed to depend on there being a shared vision within the breast cancer team regarding SDM, working experience, and age. Especially older clinicians seemed to experience more difficulties in altering their routine workflow to implement SDM and the PtDA. However, most clinicians felt positive towards SDM and considered SDM to be a team process in which every professional has a responsibility to achieve appropriate implementation. In this process the nurses were often considered to be the case manager, with an important contribution in low-key communication with the patient and the execution of several steps in the SDM process. As nurses, in general, see or talk to the patients after they had time to use the PtDA and to discuss the options with their family, they play an important role in the preference and decision talk steps.

Although clinicians indicated they understand the SDM model, elicitation of preferences was not common and patients' decisions seemed somewhat influenced by the preferences of the clinician. 
'Uhm. You know, I think that the nurse is a very important person. We, surgeons, don't have the time to extensively explain the PtDA, talk about psychosocial aspects of a treatment. So, that is when the nurses take over, they support the patients to make a decision, they guide them through the whole process, explain the PtDA.' (Surgeon0203)

\section{Critical attitudes}

Some clinicians reported (not speaking for themselves) a rather critical attitude in their teams towards SDM and the PtDA. It was felt to be too disruptive with regard to the prevailing routines. In their opinion, the best possible treatment was already chosen in the Multi-disciplinary Tumour board (MDT), and involving the patient might lead to inferior medical treatment. Other clinicians doubted the applicability of SDM as it might increase the complexity of care and confuse patients.

'Sometimes there are patients who really have a very small tumour, less than 8 millimetres. We discuss this in the MDT, because if the patient really wants to have a mastectomy, the extensive surgery does more harm to the body than the radiotherapy, according to de radiotherapist. Then of course patients will be offered the choice, but we are inclined to say; "Gosh, this could very easily be a breast conserving therapy, why would you chose such a heavy intervention?' (Nurse partitioner0201)

'That's one of those new things they introduce, and if you're already close to your retirement, and then you suddenly have to go about your diagnostic interviews in an entirely new way, that ... uhm ... takes some getting used to.' (Surgeon0206)

'Out of the entire department? Yes, you'll find quite a number of surgeons who think it's all nonsense' (Surgeon0107) 


\section{2) A more or less successful delivery of the PtDA}

\section{Delivering the PtDA}

Clinicians were positive about the PtDA, as it provides easily accessible information, facilitates more conscious treatment choices and more active patient participation. Many clinicians struggled to establish an appropriate method for indicating the PtDA and to determine the best timing in the routine clinical pathway to deliver the PtDA to the patient. However, it was believed by some that in the course of our project this clearly improved, as it became part of the normal work routine. This was indeed illustrated by increased distribution rates in some hospitals. According to the clinicians, this was mostly due to the breast cancer nurses, who acted as an important link in the delivery of the PtDA and promoting its use to patients. However, breast cancer nurses often felt that they were the only ones who made an effort to deliver the PtDA. Despite improved distribution rates, the quality of integration and the use of the PtDA varied between hospitals.

\section{Clinician experiences with regard to the PtDA}

Clinicians who used the PtDA correctly were enthusiastic and reported they experienced its benefits. Yet, many clinicians lacked knowledge on the content of the PtDA, and why or how they should use it. This led to inaccurate expectations regarding the PtDA, incorrect or limited use and limited implementation of SDM. Some clinicians regarded the PtDA as a purpose in itself, instead as a means to support SDM, which seems to have resulted in the limitation of the SDM process to choice talk and option talk only. These clinicians erroneously believed that announcing that a choice was going to be made, the invitation to the patient to be involved and just providing the PtDA to the patient was sufficient and thus to have fully complied with the principles of SDM. These clinicians erroneously believed that the PtDA provided sufficient information and thus to have fully complied with the principles of SDM.

Most of the clinicians who actually delivered the PtDA to patients had high expectations about the eagerness with which patients would use it, and were disappointed about the rather moderate uptake. These clinicians reflected on the huge amount of information patients often receive, such as written materials on treatments, patient associations and study invitations. 
'I ... uhm ... uhm ..., I think that I had expected more enthusiasm. I had expected people to say: "Oh, it's great and it was very clear what my choices were", and ... something like that. And, in practice, I think ... uhm ... whether this is down to patients or not, I don't know, it's disappointing how we, how much the patient is using it.' (Surgeon0101)

\section{Costs with regard to the PtDA}

Finally, some clinicians reported that the actual implementation of a PtDA would generate extra costs, without creating more income. Patient associations and authorities like insurance companies are more or less forcing hospitals to use several of these PtDAs, in order to preserve their quality certificates. The costs, after the implementation period, to gain access to the patient decision aids are equal for each hospital without consideration of the size of the patient group.

This worries clinicians of low-volume breast cancer sites, as this price tag could create a serious barrier.

'Uhm ... no. No, you see ... uhm ... the health insurance provider more or less requires us to use decision aids. And if this price is just as expensive as for standard, for big hospitals, then this really is a serious problem for us. So, the question is; more and more is being added, costs are on the increase and the budgets that hospitals have aren't getting any bigger. You can only spend what you've got once, so that's got to be an ... uhm ... issue that needs to be addressed.' (Surgeon0104)

\section{3) Barriers in the implementation of SDM behaviour in breast cancer care}

SDM performance

While most clinicians perceived SDM as being well implemented in their daily workflow, the actual behaviour as assessed through the audiotapes ranged from above average to very limited or non-existent. A minority of the clinicians appeared to have an adequate view on how to perform SDM. They reported they actively explore patients' preferences, context and specific characteristics during the consultation. These clinicians were aware of the different values patients find important. However, most clinicians only used a limited part of the SDM process, primarily focusing on the explanation of the treatment choice (choice talk), and options in general (option talk). 
The elicitation of preferences, concerns or values were not spontaneously considered to be important by these clinicians. This also applied to the last step in the SDM process, as there seems to be too little room for considering and discussing the final decision (decision talk). In some hospitals, patients were given a PtDA without planning a face-to-face follow-up appointment for the decision talk, thus failing to make it self-evident to patients that they can express their considerations and preferences. In addition, most of the clinicians stated that the treatment decision is still influenced by the opinion of individual clinicians and the advice of the tumour board, especially if the tumour board recommends one treatment option only.

Some of the clinicians questioned the applicability of SDM, because decision making in cancer care is of such high complexity. Clinicians also considered their patients to be vulnerable, e.g. patients with low intellectual skills or frail elderly patients, and felt the inclination to protect them. They noticed they were consciously more paternalistic in consultations with such vulnerable patients, urging patients towards a certain treatment, instead of exercising SDM.

Confronted with feedback on the actual process of SDM, the results on Observer Option ${ }^{5}$ (see Table 2), some clinicians acknowledged they were unconsciously incompetent, and reported a lack of a deeper understanding of what SDM actually is. To improve their understanding of SDM clinicians mentioned a need for coaching, training or face-to-face 'on the job' instructions. 
Table 2 Observer OPTION 5 Topics and Mean Scores (SD) for the breast cancer teams $(N=33)$, compared to performance of other clinicians $(N=101)$ in a comparable setting of implementation

\begin{tabular}{|l|l|l|}
\hline & Breast cancer & Chest pain* \\
\hline Option 5 & & \\
Mean (SD) & $42.0(10.8)$ & $44.9(10.8)$ \\
Median (range) & $41.3(20-60)$ & $42.5(17.5-72.5)$ \\
\hline Item 1 & & \\
Alternate Options & & \\
Mean (SD) & $2.5(0.7)$ & $2.2(0.4)$ \\
Median (range) & $2.3(1-3.5)$ & $2(0-3)$ \\
\hline Item 2 & & $1.0(0.6)$ \\
Support deliberation / forming a partnership & $1.3(0.7)$ & $1(0-3)$ \\
Mean (SD) & $1(0-3)$ & $1.99(0.53)$ \\
Median (range) & & $2(1-3)$ \\
\hline Item 3 & & $2(1-4)$ \\
Information about options & $2.0(0.7)$ & $1.9(0.6)$ \\
Mean (SD) & $2(0-3)$ & $2(0-4)$ \\
Median (range) & & \\
\hline Item 4 & & \\
Eliciting preferences & $(0-4)$ & \\
Mean (SD) & & \\
Median (range) & & \\
\hline Item 5 & & \\
Integrating preferences in decision & & \\
Mean (SD) & & \\
Median (range) & & \\
\hline
\end{tabular}

Scores on each item ranged from 0 "No effort" to 4 "exemplary effort." Overall scores are recalculated to a 0 to 100 point scale.

* Results Barr, $P$ et all. (18) (at the time of writing there were no breast cancer studys using Observer option ${ }^{5}$ available)

\section{Conflicting interests}

In addition, clinicians mentioned the conflict of the consequences of SDM with the quality requirements of the National Breast Cancer Audit (NBCA). According to these quality requirements, patients diagnosed with breast cancer should start treatment within five weeks, thus limiting the time for deliberation and planning extra consultation to achieve a well-considered decision. 
'Uhm ... is the MDT meeting decisive? I think it is, yes. There are just very few patients who ... uhm ... if a whole team of professionals presents them with a certain policy, there are very few patients who will actually say: "Nope; I'm not doing that. For me, this is my preferred choice." I think that, yes, most people will then go along with the MDT.'

'In fact, I'm actually pretty sure that they will.' (Nurse practitioner0201)

The advantages and disadvantages will then be outlined, very briefly, and the patient will then be given the decision aid. And then ... uhm ... ultimately, the patient will receive a phone call, two or three days later. The truth is that treatment will then already have been set in motion from a medical point of view, so the treatment proposal will already have been set in motion. But the patient can always ... uhm ... we will always check which choice a patient wants to make in a telephone call. Something like; "well, did you use the decision aid, and ... uhm ... are you happy with the proposal and can we now go ahead with your treatment?" Like that really ... uhm.'(Nurse0206)

'I sometimes sense that the various choices, yes ... uhm ... how would you say that, actually confuse the patient even more. If that happens, I explain that they have these choices and then I say; "This would be my preferred choice." I give them a little push in that direction.' (surgeon0101)

\section{Discussion}

\section{Summary of main findings}

Most of the interviewed clinicians were well aware of the relevance of SDM, but also consider SDM, including the provision of the PtDA, to be a challenging team effort, while some of them feel some reluctance due to fear of disrupting routine care. Within the team every professional is expected to take responsibility, with an important role for breast cancer nurses. Doctors delegated the uptake of the PtDA in the clinical pathway, intentionally or unconsciously, to nurses. The results also show that these breast cancer teams indeed proved to be early-adopters as glimpses of true SDM behaviour could be rated on audiotaped consultations with an objectified scale. Nevertheless, even in such best practice examples, misconceptions, paternalism and scepticism, as well as a limited implementation of SDM appeared. 
Most clinicians seemed to lack a deeper understanding of what SDM is actually about, as they primarily focused on the first steps of SDM, the team/choice talk and option talk, neglecting preference and decision talk. Some of the clinicians questioned the limits of the types of decisions that patients are able to be involved in, due to cognitive and organisational barriers. Other important barriers mentioned were the rather fixed treatment recommendations set by the tumour board, even in case of preference-sensitive decisions, and the conflict between the time that is needed for the SDM process and the benchmarks for timely treatment required for quality of care indicators from the National Breast Cancer Audit.

\section{Strength and limitations}

The qualitative design of this study allowed us to learn about the experiences and concerns of dedicated clinicians who recently started to implement SDM in daily clinical practice, as well as about the barriers and facilitators they encountered. The interviews were held with the clinicians who were still trying to implement SDM; therefore, recall bias was minimised. The sample size of this study $(N=27)$ was sufficient to reach data saturation; no new themes emerged from the data after 23 interviews. We interviewed early-adopters who favour SDM. This conscious selection bias strengthens the relevance of the findings that are most likely underestimating the critical attitudes and barriers and complexity among the total group of breast cancer clinicians. The process of SDM is increasingly considered to be a team effort. Our sample consisted of individual surgeons, nurse practitioners and nurses. Therefore, the results do not represent the opinion of the whole breast cancer teams. Although the surgeons and nurses are viewed as the primary partners in SDM for breast cancer, a limitation is that we did not involve radiotherapists and medical oncologists.

\section{Comparison of the results with the current literature}

In line with earlier research, the results of this study show that most clinicians are apparently unaware of the substantial deviance of their actual behaviour from the SDM process (26-28). In particular, the preference and decision talk is often neglected or incorrect, apparently caused by a lack of understanding on how patients construct preferences with regard to certain treatments $(29,30)$. 
What this study contributes is the finding that the attitude towards SDM among clinicians also often depends on the attitude of their teams. Earlier studies regarding the implementation of SDM primarily focused on the isolated patient-professional interaction. In the current study, clinicians reported that implementation of SDM depends on the team's understanding of SDM within the limits set by the organisation of the local clinical pathways. Teams willing to explore the role of each team member and motivated to alternate tasks could improve the SDM process. As almost every clinician mentioned that the breast cancer nurses are crucial for the delivery of the PtDA and the SDM process as a whole, it is evident that they should obtain more and perhaps different responsibilities in this process. Earlier research suggests that the engagement of nurses, when well positioned and provided with the necessary expertise, could lead to important quality improvements in $\operatorname{SDM}(31)$.

Our results suggest that even if patients have the required knowledge it is difficult to decide against an advice formulated by multiple clinicians during the tumour board. Therefore, the treatment advice given by the tumour board, especially when clinicians communicate the preference of the MDT during the clinical encounter, seems to contribute to maintaining an uneven power balance between professionals and patients where the patient's preference gets easily overruled (32). This imbalance may be an important factor of which clinicians should be aware, and which they should try to minimise.

Some clinicians felt frustrated in their expectations of the use of the PtDA and enthusiasm of patients, which could partially be caused by a lack of awareness and understanding with regard to the use of the PtDA (4). The results also reveal the difficulties encountered in altering routine workflow in order to implement the PtDA as a part of SDM (33). Clinicians need more support on the use and delivery of a PtDA, and need to be made aware that implementing a PtDA is not the same as implementing SDM.

Some clinicians questioned the limits to implementing SDM, given the vulnerability of patients, a barrier that is also found in other countries (34). For them, SDM does not seem suitable for every patient in every situation, depending on the patient's intellectual capacity, older age or lack of motivation for SDM. This means that even in early-adopter breast cancer teams willing to invest in SDM, we found there is a prejudice about what patients want rather than asking them about their preferred level of involvement $(32,35)$. This prejudice seems persistent and will not simply be solved by introducing a PtDA. 
Clinicians were also concerned that too many tools and too much information will lead to an information overkill, which limits the use of the PtDA among patients (36).

Finally, the more or less forced implementation of PtDAs by patient associations and health insurance companies may also lead to extra costs. The prospect of implementing several of these PtDAs in the future is worrisome for the clinicians in smaller hospitals. The price tags could create serious limitations in the future.

\section{Conclusion}

In our early-adopter teams, the clinicians were generally willing to implement SDM and the PtDA. Actual implementation in clinical practice, however, was still limited. The implementation of essential parts of the SDM process, preference and decision talk, seemed inadequate, which could partially be explained by a lack of deeper understanding of SDM among clinicians. We need to convince clinicians that using a PtDA in the clinical pathway will not indisputably lead to more awareness and higher performance in SDM. Breast cancer teams that want to apply SDM should not only focus on the patient-doctor communication during clinical encounters but should also consider the role of the breast cancer nurse, a task reallocation and the reorganisation of the clinical pathway, in order to create an environment where SDM is seen as the usual care. Additionally, we suggest that the tumour board in its current form is a potential barrier to implementing SDM, as quite often, despite the preference-sensitive decisions, only one treatment option was recommended. 


\section{References}

1. Fisher B, Anderson S, Bryant J, Margolese RG, Deutsch M, Fisher ER, Jeong JH, Wolmark N. Twenty-year follow-up of a randomized trial comparing total mastectomy, lumpectomy, and lumpectomy plus irradiation for the treatment of invasive breast cancer. The New England journal of medicine. 2002;347(16):1233-41.

2. Legare F, Briere N, Stacey D, Lacroix G, Desroches S, Dumont S, Fraser KD, Rivest LP, Durand J, Turcotte S, Taljaard M, Bourassa $H$, Roy L, Gainchaud Guerard G. Implementing shared decisionmaking in interprofessional home care teams (the IPSDM-SW study): protocol for a stepped wedge cluster randomised trial. BMJ open. 2016;6(11):e014023.

3. Hershman DL, Buono D, Jacobson JS, McBride RB, Tsai WY, Joseph $K A$, Neugut A. Surgeon characteristics and use of breast conservation surgery in women with early stage breast cancer. Annals of surgery. 2009;249(5):10.1097/SLA.0b013e3181a38f6f.

4. Caldon LJ, Collins KA, Reed MW, Sivell S, Austoker J, Clements AM, Patnick J, Elwyn G, BresDex Group. Clinicians' concerns about decision support interventions for patients facing breast cancer surgery options: understanding the challenge of implementing shared decision-making. Health expectations : an international journal of public participation in health care and health policy. 2011;14(2):133-46.

5. Barry MJ, Edgman-Levitan S. Shared decision making--pinnacle of patient-centered care. The New England journal of medicine. 2012;366(9):780-1.

6. Coulter A. Patient information and shared decision-making in cancer care. British Journal of Cancer. 2003;89(Suppl 1):S15-S6.

7. Elwyn G, Durand MA, Song J, Aarts J, Barr PJ, Berger Z, Cochran N, Frosch D, Galasinski D, Gulbrandsen P, Han PKJ, Carter M, Kinnersley P, Lloyd A, Mishra M, Perestelo-Perez L, Scholl I, Tomori K, Trevena L, Witteman HO, Van der Weijden T. A three-talk model for shared decision making: multistage consultation process. BMJ (Clinical research ed). 2017;359:j4891.

8. Elwyn G, Tsulukidze M, Edwards A, Légaré F, Newcombe R. Using a 'talk' model of shared decision making to propose an observationbased measure: Observer OPTION 5 Item Patient education and counseling. 2013;93(2):265-71.

9. Stacey $D$, Legare $F$, Col NF, Bennett $C L$, Barry MJ, Eden KB, Holmes-Rovner M, Llewellyn-Thomas H, Lyddiatt A, Legare $F$, Thomson, R.Decision aids for people facing health treatment or screening decisions. The Cochrane database of systematic reviews. 2014(1):CD001431. 
10. Sivell S, Edwards A, Manstead AS, Reed MW, Caldon L, Collins $\mathrm{K}$, Clements A, Elwyn $\mathrm{G}$. Increasing readiness to decide and strengthening behavioral intentions: evaluating the impact of a web-based patient decision aid for breast cancer treatment options (BresDex: www.bresdex.com). Patient Educ Couns. 2012;88(2):20917.

11. Livaudais JC, Franco R, Fei K, Bickell NA. Breast cancer treatment decision-making: are we asking too much of patients? Journal of general internal medicine. 2013;28(5):630-6.

12. Legare F, Stacey D, Turcotte S, Cossi MJ, Kryworuchko J, Graham ID, Graham L, Lyddiatt A, Politi MC, Thomson R, Elwyn G, DonnerBanzhoff $\mathrm{N}$. Interventions for improving the adoption of shared decision making by healthcare professionals. The Cochrane database of systematic reviews. 2014(9):CD006732.

13. Feibelmann S, Yang TS, Uzogara EE, Sepucha K. What does it take to have sustained use of decision aids? A programme evaluation for the Breast Cancer Initiative. Health expectations : an international journal of public participation in health care and health policy. 2011;14 Suppl 1:85-95.

14. Elwyn G, Scholl I, Tietbohl C, Mann M, Edwards AG, Clay C, Legare $F$, van der Weijden T. Lewis, CL, Wexler RM, Frosch D. "Many miles to go ...": a systematic review of the implementation of patient decision support interventions into routine clinical practice. BMC medical informatics and decision making. 2013;13 Suppl 2:S14.

15. Belkora JK, Loth MK, Volz S, Rugo HS. Implementing decision and communication aids to facilitate patient-centered care in breast cancer: a case study. Patient education and counseling. 2009;77(3):360-8.

16. Legare F, Ratte S, Gravel K, Graham ID. Barriers and facilitators to implementing shared decision-making in clinical practice: update of a systematic review of health professionals' perceptions. Patient education and counseling. 2008;73(3):526-35.

17. Legare F, Witteman HO. Shared decision making: examining key elements and barriers to adoption into routine clinical practice. Health Aff (Millwood). 2013;32(2):276-84.

18. Barr PJ, O'Malley AJ, Tsulukidze M, Gionfriddo MR, Montori V, Elwyn G.The psychometric properties of Observer OPTION(5), an observer measure of shared decision making. Patient Educ Couns. 2015;98(8):970-6.

19. Dunning D, Johnson K, Ehrlinger J, Kruger J. Why People Fail to Recognize Their Own Incompetence. Current Directions in Psychological Science. 2003;12(3):83-7.

20. Gulbrandsen P, Dalby AML, Ofstad EH, Gerwing J. Confusion in and about shared decision making in hospital outpatient encounters. Patient education and counseling. 2014;96(3):287-94. 
21. Joseph-Williams N, Lloyd A, Edwards A, Stobbart L, Tomson D, Macphail S, et al. Implementing shared decision making in the NHS: lessons from the MAGIC programme. BMJ (Clinical research ed). 2017;357:j1744.

22. Mangla M, Cha TD, Dorrwachter JM, Freiberg AA, Leavitt LJ, Rubash $\mathrm{HE}$, et al. Increasing the use of patient decision aids in orthopaedic care: results of a quality improvement project. BMJ quality \& safety. 2018;27(5):347-54.

23. Elwyn G, Frosch D, Thomson R, Joseph-Williams N, Lloyd A, Kinnersley P, Cording E,Tomson DD, Rollnick S, Edwards A, Barry M. Shared decision making: a model for clinical practice. Journal of general internal medicine. 2012;27(10):1361-7.

24. Stubenrouch FE, Pieterse $A H$, Falkenberg $R$, Santema TK, Stiggelbout AM, van der Weijden T, T, Aarts JA, Ubbink DT. OPTION(5) versus OPTION(12) instruments to appreciate the extent to which healthcare providers involve patients in decision-making. Patient education and counseling. 2016;99(6):1062-8.

25. Vaismoradi $M$, Turunen $\mathrm{H}$, Bondas $\mathrm{T}$. Content analysis and thematic analysis: Implications for conducting a qualitative descriptive study. Nursing \& Health Sciences. 2013;15(3):398-405.

26. Stiggelbout AM, Van der Weijden T, De Wit MP, Frosch D, Legare F, Montori VM, Trevena L, Elwyn G.Shared decision making: really putting patients at the centre of healthcare. BMJ. 2012;344:e256.

27. Pass M, Volz S, Teng A, Esserman L, Belkora J. Physician behaviors surrounding the implementation of decision and communication AIDS in a breast cancer clinic: a qualitative analysis of staff intern perceptions. Journal of cancer education : the official journal of the American Association for Cancer Education. 2012;27(4):764-9.

28. Hoffmann TC, Legare F, Simmons MB, McNamara K, McCaffery K, Trevena LJ, Hudson B, Glasziou PP, Del Mar CB. Shared decision making: what do clinicians need to know and why should they bother? The Medical journal of Australia. 2014;201(1):35-9.

29. Blair $L$, Legare F. Is Shared Decision Making a Utopian Dream or an Achievable Goal? Patient. 2015;8(6):471-6.

30. Sevdalis N, Harvey N. Predicting preferences: a neglected aspect of shared decision-making. Health expectations : an international journal of public participation in health care and health policy. 2006;9(3):245-51.

31. Stacey D, Murray MA, Legare F, Sandy D, Menard P, O'Connor A. Decision coaching to support shared decision making: a framework, evidence, and implications for nursing practice, education, and policy. Worldviews on evidence-based nursing. 2008;5(1):25-35. 
32. Joseph-Williams N, Elwyn G, Edwards A. Knowledge is not power for patients: A systematic review and thematic synthesis of patientreported barriers and facilitators to shared decision making. Patient education and counseling. 2014;94(3):291-309.

33. Elwyn G, Frosch DL, Kobrin S. Implementing shared decisionmaking: consider all the consequences. Implement Sci. 2016;11:114.

34. Lloyd A, Joseph-Williams N, Edwards A, Rix A, Elwyn G. Patchy 'coherence': using normalization process theory to evaluate a multifaceted shared decision making implementation program (MAGIC). Implementation Science. 2013;8(102).

35. Joseph-Williams N, Lloyd A, Edwards A, Stobbart L, Tomson D, Macphail S, Dodd C, Brain K, Elwyn G, Thomson R. Implementing shared decision making in the NHS: lessons from the MAGIC programme. BMJ (Clinical research ed). 2017;357:j1744.

36. Lin GA, Halley M, Rendle KA, Tietbohl C, May SG, Trujillo L, Frosch DLI. An effort to spread decision aids in five California primary care practices yielded low distribution, highlighting hurdles. Health Aff (Millwood). 2013;32(2):311-20. 


\section{Appendix \\ Interview guide}

Before we started this study, you had the opportunity to get acquainted with the process of shared decision making and the interventions to improve this process. Could you please tell me what you know about these interventions?

1. Are you familiar with the Patient Decision Aid (PtDA)?

2. Did you watch the video lecture on Shared Decision Making (SDM)?

3. Did you watch the introduction film on Youtube concerning the use of the PtDA?

4. Can you identify the changes we proposed in the clinical pathway?

- In your opinion, what are the advantages and disadvantages in using a PtDA?

- To how many patients did you hand out the PtDA? In what way do you hand out the PtDA? At which point in the clinical pathway do you hand out the PtDA? If not you yourself, who hands out the PtDA?

- Do you register the delivery of the PtDA?

- Do you know how many patients actually used the PtDA?

- How did using the PtDA influence your patient education?

- Do you discuss the use of the PtDA with the patient in the sequel consultation? Do you discuss the summary of the value elicitation with the patient in a next consultation?

- Did your preparation of the consultations change now that you are using a PtDA? If so, how did they change? 
- Does the use of the PtDA meet your expectations? If yes, in what way; if no, why not?

- With the implementation of the PtDA we also realized some minor changes in the pathway. What do you think of these changes?

- Which barriers do you experience in the implementation of the PtDA?

- What do you need to ensure that using the PtDA becomes standard care?

- Would you recommend the use of the PtDA to other breast cancer teams?

- What do you think Shared Decision Making means and what does it propose? Why do you consider SDM to be important?

- At this point we show the model.

- Do you recognize these steps? Do you use all the steps? Could you please tell me how you apply these steps?

- How do you explore patients' preferences and how do you integrate these in the decision making process?

- Did you ever apply Shared Decision Making? Give feedback on the result of previous audiotaped consultation and the scores on the option 5.

- What is the influence of the treatment advice which is formulated by the clinicians in the tumour board meeting?

- What is the general opinion on SDM and the PtDA in your breast cancer team?

- What are the strengths in your breast cancer team with regard to SDM? What could be improved?

Finally, do you want to make any comment on SDM or the PtDA?

Thank you for your time.

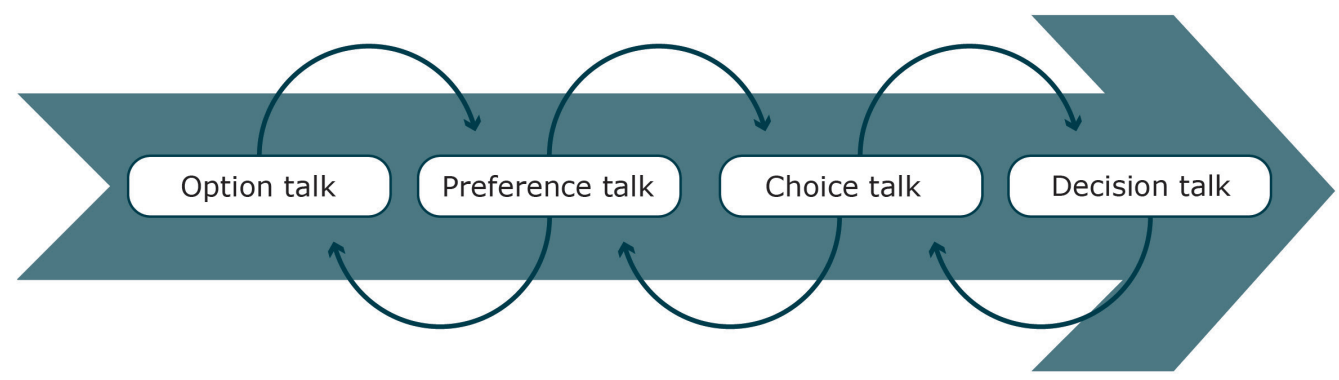

Elwyn G et al. J Gen Int Med 2012

Elwyn G et al. Pat Educ Couns 2013 


\section{General discussion}




\section{Outline}

This chapter first repeats the aims and research questions, and provides a short overview of the studies we conducted and the results we found. The overview is followed by a reflection on the main strengths and limitations of this thesis. The second part of the chapter consists of a reflection on our findings compared to current literature. Subsequently the conclusions on the status of SDM in breast cancer care and recommendations for practice and research are presented.

Despite being promoted by government, the Dutch Patient Federation and health policymakers, shared decision-making (SDM) is still poorly implemented in clinical practice $(1,2)$. During the last decade, a lot of effort has been put in the development of patient decision aids (PtDA) and measuring its effectiveness, training professionals and empowering patients. As it concerns complex behaviour, it is not easy to achieve sustainable implementation (3). In this thesis we aimed to increase patient centeredness in breast cancer care by raising awareness among professionals on the positive influence of patient involvement in the decision making process. We not only tried to gain insight in the barriers and facilitators to execute SDM, we also developed an implementation strategy, tailored to the needs of each participating hospital.

The research questions were:

- How to develop, improve and alpha test a PtDA for surgical treatment of early stage breast cancer and how to ensure that usability, comprehensibility and acceptability of the tool itself meets the standards and requirements of professionals and patients?

- What is the uptake of the SDM implementation strategies in breast cancer care by professionals and the perceived uptake and use of a PtDA by breast cancer patients?

- What are the experiences of patients with regard to the SDM process in breast cancer and the usefulness of the PtDA?

- What are the experiences and perceived barriers and facilitators of professionals with regard to the SDM process in breast cancer care? 


\section{Summary of main results}

The development of the PtDA was a challenging process in which the stakeholders, involved in the alpha test, did not always agree on the content (chapter 2). Differences of opinion between professionals and patients were mostly about whether or not to use narratives (personal stories from patients). The main controversy among professionals concerned risk and outcome data. We succeeded in solving these differences but the process was much more extensive and complex than had been planned beforehand. However, it contributed to the PtDA being accepted by and presented as best practice on the website of the Dutch Breast Cancer Association and already being used in 12 hospitals in the Netherlands at this moment (4). To further investigate implementation challenges regarding SDM, we provided highly motivated breast cancer teams with a multifaceted strategy, including the PtDA and how to integrate it in the clinical pathway (chapter 4). We also advised the teams to register the multiple treatment options instead of a treatment plan with one single treatment, in the MDT report. The adherence of the implementation strategies was fairly modest. The full implementation strategy was followed in a minority, but relevant proportion of the patients. A satisfactory delivery of the PtDA and concordance between stated preference and the actual treatment decision was achieved. Most patients reported to have experienced SDM, though to a certain extent (chapter 5). In contrast to choice talk and option talk, the elicitation of preferences and decision talk were hardly experienced. The PtDA was used by the majority ( $65 \%)$ of patients, all indicating that it was useful, especially to recall all the information given. Patients highly appreciated the contribution of breast cancer nurses in the clinical pathway. They considered them as true case managers, easy approachable and supportive. Clinicians were well aware of the relevance of SDM, but they seemed to lack deeper understanding of what SDM is actually about, as they primarily focused on the first steps of SDM, the team/choice talk and option talk, neglecting preference and decision talk (chapter 6). They also consider SDM to be a challenging team effort in which every professional is expected to take responsibility. Nurses play an important role in the delivery of the PtDA, but their role is not clearly defined. 


\section{Strengths and limitations}

In this section six issues will be discussed: the involvement of various stakeholders in the development and implementation of the PtDA; the study design applying mixed methods; the recruitment of patients; the discrepancy between the original protocol and the actual conducted study; a reflection on missing data; and finally the problem of limited health literacy.

\section{Stakeholder involvement}

In each phase of the research we involved various stakeholders, all directly involved in SDM. Both professionals and patients participated in the development of the PtDA, as well as during the pilot test to implement the PtDA, and during the process evaluation. In addition, with regard to the professionals, we did not only involve doctors, but also nurses. This proved to be important, as all professionals agreed that nurses play a pivotal role in the decision making process. Involving nurses provided us with significant insight in various issues like how to design the procedures that were part of the implementation strategy. Including participants with various backgrounds like doctors from different disciplines and from different hospitals not only gave us a broad understanding on how SDM is being applied in daily practice, but also increases the validity of this study. Another strength was the double role of the researcher (WS) in this thesis, being the researcher and being a staff member with a focus on patient education and patient involvement of the oncology center at that time. An additional strength is that we safeguarded the content of the PtDA with the Dutch breast cancer care guideline. Some of the professionals involved in the development of the PtDA are also involved in the up-date of the national breast cancer guideline as full member of the guideline committee.

\section{Mixed methods}

The predominantly qualitative approach, we have chosen for this study, ensured that we were able to do a deep exploration of experiences, opinions, attitudes, with regard to SDM and the use of a PtDA, from patients as well as professionals. This goes beyond the information that can be collected by using a structured and often closed-end quantitative survey. In each phase of the study we used profound and different methods to collect the data, we were able to compare results we found in professionals with the finding from patients, and with findings from literature. We were also able to use the quantitative results that we gathered to construct our interview guide and the data extraction form for the process evaluation. Consequently, the study results are based on a multitude of perspectives and experiences on what is needed and which strategy seem useful to promote SDM. Using a combination of methods increases the validity of the study. 


\section{Recruiting Patients}

Except for the quantitative pilot data to measure effects in the pre- and post-implementation phase of this study, the sample size in each phase was large enough to conveniently reach data saturation for the process evaluation and the qualitative studies. We urged breast cancer nurses to recruit all the patients who were offered the PtDA, but there is no guarantee that inclusion was biased to patients with an extra interest in SDM or a PtDA. Still, that having said, we succeeded to include patients of all ages, reflecting the target group and with a reasonable balance between high and low levels of education.

The in-depth interviews with patients to assess experiences and the usefulness of the PtDA were planned to be executed within a reasonable timeframe. We saw to it, that the interviews were not planned too soon after the diagnosis. This prevented that patients were still in an emotional aroused state or experiencing too much stress because of the diagnoses. The otherwise relatively short timeframe was important to prevent that patients did not remember what was said or what they experienced. In general, the interviews were conducted face by face, and took place at a location of the patients' convenience, often at the patient's home. Home interviews are often preferred, not only because the interviewer can observe participants' natural environment, but it also helps participants to feel at ease to open up to the researcher (5).

\section{Failed quasi-experimental study}

We planned to perform a pre- and post-implementation pilot study, to collect outcome and process data from patients and objective outcomes with regard to professional performance on involving patients. Firstly, we intended to measure the patients' experience of SDM, and the impact on the patients' knowledge and decisional conflict. Secondly, we wanted to measure the extent to which the PtDA and the SDM produced changes in the intended (i.e. preferences) and final treatment decisions by clinicians and patients. Both measurements were intended to support the design of a large-scale effect study to evaluate the final implementation strategy. These data were meant to be used to further investigate performance of professionals on SDM and implementation issues. We planned to collect data from four breast cancer teams from three hospitals and one specialised breast cancer clinic, with each team including 10 patients in the pre-implementation period and 10 patients in the post-implementation period. 
Before we started data collection for the pre-implementation period, one hospital withdrew from the study because of fear of interference with one of their own research projects. The specialised breast cancer hospital was, due to lack of time and motivation, not able to include patients in the pre-implementation period, while inclusion in the other two hospitals was not easy as well. We included 14 patients instead of the 40 patients we aimed at. Before we started the post-implementation period, two other breast cancer teams from other hospitals signed up to participate in the study. This resulted in more, but scattered data, not equally divided among hospitals and with quite a few missing data. This meant we could not use the data as planned and had to deviate from the original protocol. We were not able to conduct a multicentre cluster RCT to test the implementation of SDM and a PtDA. Nevertheless, the gathered data did provide useful insights in the clinical practice of breast cancer care and important input to compile a multi-faceted implementation strategy.

\section{Missing objective user data}

Another limitation is that we were unable to collect objective user data regarding the use of the PtDA by patients from the hosting company of the web based PtDA. All of our patient data are based on patients and clinicians self-report, and from limited audio recordings of consultations, and audit of patient files. Although, during the process evaluation, we interviewed patients within two weeks after their diagnoses, the subjective perceptions of patients might have suffered from recall bias. Given our structured interview technique, and asking to support some of their answers with concrete examples, we are confident that our findings are valid.

With regard to the professionals, we interviewed them on attitudes, knowledge on SDM and the PtDA. Objective data to explore the up-take of the implementation strategy were obtained by auditing patient files and MDT reports, and the limited audio recordings of consultations. Nevertheless we lack objective data on the actual number of patients who received the PtDA during the data collection. Another potential limitation concerns the rather small sample of patients included in the process evaluation. We found a positive relation between some of our implementation strategies and the uptake of the PtDA, but given the sample size of $n=84$, we have to be cautious interpreting these results.

\section{Limited attention to health literacy}

In this study we did not explicitly take health literacy into account. Although we managed to also include patients with a low level of education, we did not specifically focus on this theme. Even though SDM has a positive effect, patients with lower health literacy seem to be less engaged in the process and in health care overall (6). 
It is not unthinkable that patients with low health literacy cannot understand what clinicians are telling them during SDM consultations, moreover, there often is a mismatch between patients' skills and competencies and the complexity of written health information materials $(7,8)$. There also seems to be a relation between patient's skills and confidence to find the right health information and the extent of being involved in decision making (9). In this study we found that from the patients we interviewed during the pilot, especially the patients with a low educational level did not use the PtDA. These patients mentioned the following reasons for not using the PtDA: too much information, too busy, forgot all about it, lack of computer skills and lack of need to get more information. We should have more clearly ask them whether they understood why and how to use the PtDA and the written information they received. It could well be, they never logged in because the prescription pad was already too difficult to understand. In our implementation strategies in the further study we did not take this finding into account.

\section{Overcoming challenges to implement SDM}

This section provides a somewhat deeper reflection on the main issues we encountered, as well as comparisons with the current literature. These issues relate to the development of the PtDA and the implementation strategies to improve SDM in clinical practice.

\section{Involving patients in the development of a PtDA}

The International Patient Decision Aid Standards (IPDAS) Collaboration aims to enhance the quality and effectiveness of PtDAs by setting criteria for improving the content, development, implementation, and evaluation of PtDAs. Although IPDAS emphasizes the importance of patients' involvement in the development of PtDAs, the most recent Cochrane review in PtDAs for people facing health treatment or screening decisions shows that only half of the included studies on PtDAs reported to have involved patients in the development phase of the PtDA $(10,11)$. Patients bring their own perspective, are end users and involving them helps to ensure that the PtDA reflects what patients find important (12). However, the different needs with regard to the PtDA contents between patients and professionals described in this thesis, show the struggle in which developers need to meet patients and professionals requirements. Compromising between both stakeholder groups embodies an important challenge in the development of PtDAs and raises questions in how and when to involve patients and who should have the final say $(13,14)$. Until now there is little evidence of the best method to involve patients $(15,16)$. 
Whether or not to use narratives

During the development of the PtDA it became clear that some of the differences of opinion between professionals and patients could not be solved. Although not supported by scientific evidence, patients felt strongly that health problems after radiation, especially in the longer term, were more frequent than indicated in the PtDA. They based their opinion on their own experience and subjective stories, narratives from other patients. However, lack of scientific evidence did not support a misconception of facts and figures in the PtDA, still in all of the test rounds this issue was mentioned and heavily discussed between patients and professionals. At a certain point, patients proposed to use narratives to endorse the severity of side effects experienced by patients. In absence of scientific evidence we chose not to do so. In current literature, lack of evidence on narratives still is an issue, as PtDAs using narratives, do not prove to be more effective as PtDAs without narratives (17). There is also the tone of voice of the narratives that can cause discussion and confusion among patients (18). Moreover, a recent review shows that using narratives could reduce the quality of decision making (19).

\section{Including psychosocial issues in a PtDA}

Another difference of opinion between professionals and patients was the fact that in the PtDA, there could have been more room for the psychosocial aspects of a cancer treatment. As some patients pointed out that there is more to the description of breast reconstruction with own tissue, from the abdomen, back or legs, than a purely medical story. The impact of such a major surgery is of great influence, not only on physical but also on mental and social functioning. For instance, patients would have liked to know how long it takes to recover completely, or what the impact of this major surgery is, emotionally and socially. Professionals argued that, as this is different for each patient, it is not possible to give an average time or impact indication that would be applicable to individual patients. Clearly, a PtDA should provide unbiased, neutrally framed, evidence based information. The information presented in the PtDA by narratives or otherwise could be confusing for patients because scientific results do not always match individual patient experiences $(10,20,21)$. However, in another study with regard to a PtDA for breast reconstruction, the developers used patient testimonials, which were highly appreciated; patients were very positive towards providing emotional information and coping strategies next to surgical information $(22,23)$. 
Professionals' attitudes toward SDM

Implementing a PtDA in a sustainable way in which it really supports the process of SDM, is a challenge. Although most clinicians were aware of the relevance of SDM, we found some reluctance in performing it. Some surgeons felt that using a PtDA was enough to support the process without considering the complexity of SDM. However, the use of a PtDA in itself cannot guarantee SDM in the clinical encounter (24). We also found that professionals are convinced about their attitude towards SDM being clearly positive. Digging a bit deeper learned this often appeared to be true to a certain degree only. This is in line with current literature as changing attitudes seems to be a key challenge in implementing SDM (25-28).

Care pathways do not meet conditions to implement SDM In our study, we first tested the PtDA in real life in clinical practice to learn about perceived gaps or problems. The implementation of a PtDA is considered to be a complex intervention in a complicated field of interactions between professionals and patients. This should be taken into account, with regard to the implementation strategy (3). We found that some of the pathways in specific hospitals did not meet the requirements to implement SDM or even the dissemination of the PtDA. We also found that doctors intentionally or unconsciously delegated some parts of SDM to the breast cancer nurses, without really making clear agreements on tasks and recording this. During the delivering of the diagnosis, explanation of the options was done by the surgeon. Offering the PtDA was more often done by the breast cancer nurses, as was the successive consultation in which patients could reflect on what they read, talked or thought about at home. This means that both clinicians, doctor and nurse, need to be aware of what each of them is telling to the patient, to make sure that the information given is not confusing. Using a team approach at system level could facilitate SDM if done correctly. However, this means that each team member should have its own role in the process (29-32).

In our multifaceted implementation strategy, in which we did not only address the process during the clinical encounters, we advised systematic reporting during the tumour board discussions on offering the PtDA, discussing preferences, and deliberations on values in MDT reports and patient files which would lead to a more effective and more meaningful sequences of consultations. Taking into account the organizational and system level to implement SDM and to assess barriers is increasingly recognized as a model that could support SDM, but only if executed well $(1,32,33)$. 
Tumour boards, a source of quality in decision making but complex barrier for SDM

During our pilot we learned that in breast cancer treatment, even in the early-adopter teams involved in our study, recommendations in multidisciplinary tumour boards (MDT) were often poorly tailored to the individual patient's needs. Communicated treatment options were predominantly determined in provider-only MDTs, which are the cornerstone of medical decision making. The MDT is almost exclusively medically oriented with little opportunity to appoint and include nonmedical information such as the patients' social wellbeing, interests, values and goals. In current literature we find that disagreements between members of the MDTs is common and there is no obvious agreement on how to report this. In all cases, Meanwhile if there is more than one treatment option advised in the MDT, this should be discussed with the patient $(34,35)$.

Once we recommended on setting the indication to offer a PtDA and reporting points of discussion among clinicians during the MDT, we felt that the MDT could be seen as a barrier or a facilitator to implement SDM. We advised teams to record both treatment options in the MDT report as a reminder to discuss these options with the individual patient in an equipoise manner. In current literature we found that, although the non-medical contribution had an essential impact on the course of the decision making procedure, non-medical information is scarce in MDT discussions and patients' preferences are rarely taking into account $(36,37)$. If in MDTs more than one option was discussed, often still a single option was written down in the recommendation and often even one single option was discussed with the patient. This seems to be in line with literature that finds that in case of disagreement in the MDT, the clinician who had to inform the patient about the treatment choice, framed this in such a way that it suited to what the clinician him or herself thought was the best option $(36,38)$.

During the course of our process evaluation we saw that reporting two options increased and eventually we found two or more options in more than half of the MDT reports. In even slightly more patient files we found two options reported as being discussed with the patient.

True SDM behaviour or being empathetic

We were able to compare patients' perceived level of SDM with the clinicians' reported performance on SDM and the objective outcomes of performed SDM, measured by the Observed OPTION5.. Patients scored high on the perceived level of SDM. 
These high scores seem to be prompted not only by real SDM performance but also by friendlyness and the demonstration of true attention for the patient as a person by clinicians. The same phenomenon was found in other studies which conclude that patients may feel to want to give socially desirable answers. In addition, it may be possible that patients cannot fully understand or identify shared decision making if they have not experienced it before (39). As an example; Patients experienced true patient centeredness and satisfaction with the proces once their clinician remembered a personal detail about the patient's private life. If we compare patient's subjective expierence with the objective results on Observer OPTION5, we see some discrepancies. Although patients felt very much involved in the process of decision making, we could not confirm these experiences by objective data. Especially the steps supporting deliberation, eliciting preferences and integrating them in the decision did not score particularly high. These low scores correspond with the results from other studies (40-42). Digging deeper in patients memory, to establish what was said, taught us that professionals were open and communication did not seem to be completely refrained from the professional's implicit preferences. Interestingly, during our interviews we found that most professionals were convinced of their own neutral display of options. This is an issue that is well-known in current literature. Many clinicians feel they involve patients in a correct way in decision making, but seem to lack knowledge on what SDM is really about $(25,43,44)$. Human beings in general seem to have the tendency to overestimate their abilities in many social and intellectual areas. People do not always have the skills spotting the limits of their knowledge and expertise, which refers to not being able to evaluate own performance (45).

\section{The nurses' role is indispensable}

In our study we found that nurses play a pivotal role in SDM, as they are easy approachable and easy to talk to, and they are highly appreciated by patients. Moreover, surgeons as well als nurses themselves were in the opinion that implementing SDM without nurses is almost imposible. They were convinced that conducting SDM should be a team effort and not an individual action. The importance of involving the entire team to implement SDM is also found in other studies (46-48). At the same time, the breast cancer teams failed to define the roles of both the doctor and the nurse, they did not agree on a division of tasks, nor impose responsibilities for each discipline (49).

In current literature we find an increasing interest in decision coaching by specialist and trained nurses. Although a promising idea, change of roles is complex and only training will not do the trick $(29,50,51)$. 


\section{SDM: Are we getting there?}

In this section we will summarise the main lessons learned. Although we had a different idea on how to conduct this study when we wrote our protocol, the setback we encountered made us creative. The subsequently chosen approach ensured that we gained a lot of insight in issues that only recently seem to be recognised as obstructing the process of SDM. The current thesis contributes to the exploration of implementing SDM. The research presented in this thesis was original with respect to the process evaluation we conducted: systematically observing a process in early-adopter breast cancer teams to view the performance on SDM and how implementation strategies were adapted and executed in daily clinical practice.

So far, research on SDM seems to mainly focus on the development and effectiveness of PtDAs, and barriers and facilitators for uptake of PtDAs $(18,26)$. We were able to learn from patient files, which gave us an objective illustration on factors that could support the SDM process and performance, we had the opportunity to observe SDM performance, and to talk to many stakeholders, which gave us an overview on the progress of SDM in participating hospitals. We investigated the breast cancer care pathway and all the organizational factors surrounding the clinical practice, several practical issues and fitting SDM in this pathway.

Because we could work so close in clinical practice together with clinicians, who actually initiated the development of the PtDA in order to implement SDM, we gained insight in several phenomena. Clinicians believed that developing a PtDA and then, as a team, agreeing that this PtDA is being offered to patients, was sufficient to implement the PtDA and to achieve SDM. However, the pilot implementation showed us that some of the used pathways, were actually not very suitable to implement SDM as there was no follow-up consultation after patients received the PtDA.

We also found that offering the PtDA was not always accompanied by an explanation about the purpose of the PtDA, or an explanation on how to use it. We also noticed that offering the PtDA was often forgotten. These observations stimulated us to build an implementation strategy also focussing on the point where breast cancer teams set the diagnosis. We tailored parts of the implementation strategy to the convenience of each hospital because tailoring implementation strategies is well known to have the best results (52). In some of the hospitals we stimulated the clinicians to report more details of the deliberation with the patient in the patient file, while in another hospital we considered and implemented an extra follow up with clinicians. 
As we learned from professionals, the MDT is the place where not only the diagnosis is determined, but also the place were a treatment plan is discussed and agreed upon by professionals. Our hypothesis was that every part of the clinical pathway, with decision making starting in the MDT, should facilitate SDM to really promote the implementation of SDM. The MDT could be a facilitator to implement SDM, but only if it would be more patient centred, with more attention to objective nonmedical information.

Promising practises like skills training for professionals or including SDM in the curriculum of health professionals, developing high quality PtDAs and making them available to patient will give a boost to the uptake of SDM. However, such implementation strategies seem to suffer from an often overlooked blind spot $(28,53)$. For the future we should also be focussing on implementation strategies tailored to the organizational and system level.

\section{Conclusion}

We saw promising examples of progress in SDM during our study, as awareness in clinicians has grown rapidly. Our study shows that in early stage breast cancer care almost all patients know they have more than one treatment option and they are invited to choose the treatment that fits them best. We also experienced willingness in professionals to change their attitude and work processes, their way of reporting in patient' files and MDT reports. Still, there is a gap between the widely interest to adopt SDM and the actual performance. Clinicians are convinced that they actually involve patients in the decision making process, just as patients have the impression to have clearly decided for themselves on the treatment plan. However, we observed that there is a world to win with regard to the second half of the SDM process as preference talk and decision talk seems hardly ever performed.

\section{Recommendations for practice}

The results of this thesis may contribute to a better insight into barriers and facilitators in the entire organisation of oncology care and not only in professionals and patients. This section refers to three themes that could make a difference with regard to SDM in clinical practice. 
The first recommendation concerns the design of the clinical pathway. The results of this thesis represent a valuable perspective on future action to improve the performance of SDM. Hospitals willing to implement SDM should critically assess the clinical pathway with regard to relevant barriers and facilitators for SDM. This might lead to a redesign of the pathway in which SDM is addressed and facilitated. In the redesign of the pathway, teams should also reconsider tasks of individual team members. As patients have multiple, consecutive clinical encounters, with different team members (surgeon oncologist, nurse, radiation oncologist or medical oncologist), they should determine who disseminates the PtDA, and who communicates, what communication goals. It is likely that this increases efficiency and that the steps of SDM will be discussed more predominantly. Figure 1 shows an example on how to refine the clinical pathway in which SDM is supported in every decision node, using the SDM model that distinguishes four steps: choice talk, option talk, preference talk and decision talk (40). In our model the indication for SDM, and subsequently for providing a PtDA, is already set in the multi-disciplinary team (MDT). We propose to allocate choice and option talk to the surgeon and preference and decision talk to the breast cancer nurse (practitioner). We also advocate to use tools in every decision node to support SDM. If additional consultations are required with other clinicians, for instance if neo adjuvant chemotherapy is an option or the patient feels the need for extra consultations, we propose that involved clinicians again deliberate on preferences taking all new information into account.

The second theme that should be addressed concerns the MDT, being a crucial panel of experts in the clinical pathway. These tumour boards have achieved much to improve the care of patients with cancer, now it is time to take the next step. The MDT is a merely medical oriented meeting, with little room to talk about values and preferences of patients, if at all known by one of the attending clinicians. It is evident that in the light of preference-sensitive decisions, which often occurs in oncology, this lack of involving the patient perspective is slowly becoming out-dated. Should we then offer patients the possibility to attend the MDT, to represent themselves? Considering the limited time, the way the current MDT is organised, logistics and the expected reluctance in clinicians and feeling of intimidation by patients this does not seem to be feasible. 
However, a more patient centred approach, e.g. with nurses as patient advocates, presenting patients not only as merely a medical case but as a human being with a social context, could make the difference. Therefore, in the near future, clinicians should find strategies to increase patient centeredness in the MDT.

Figure 1 SDM in the clinical pathway of breast cancer care

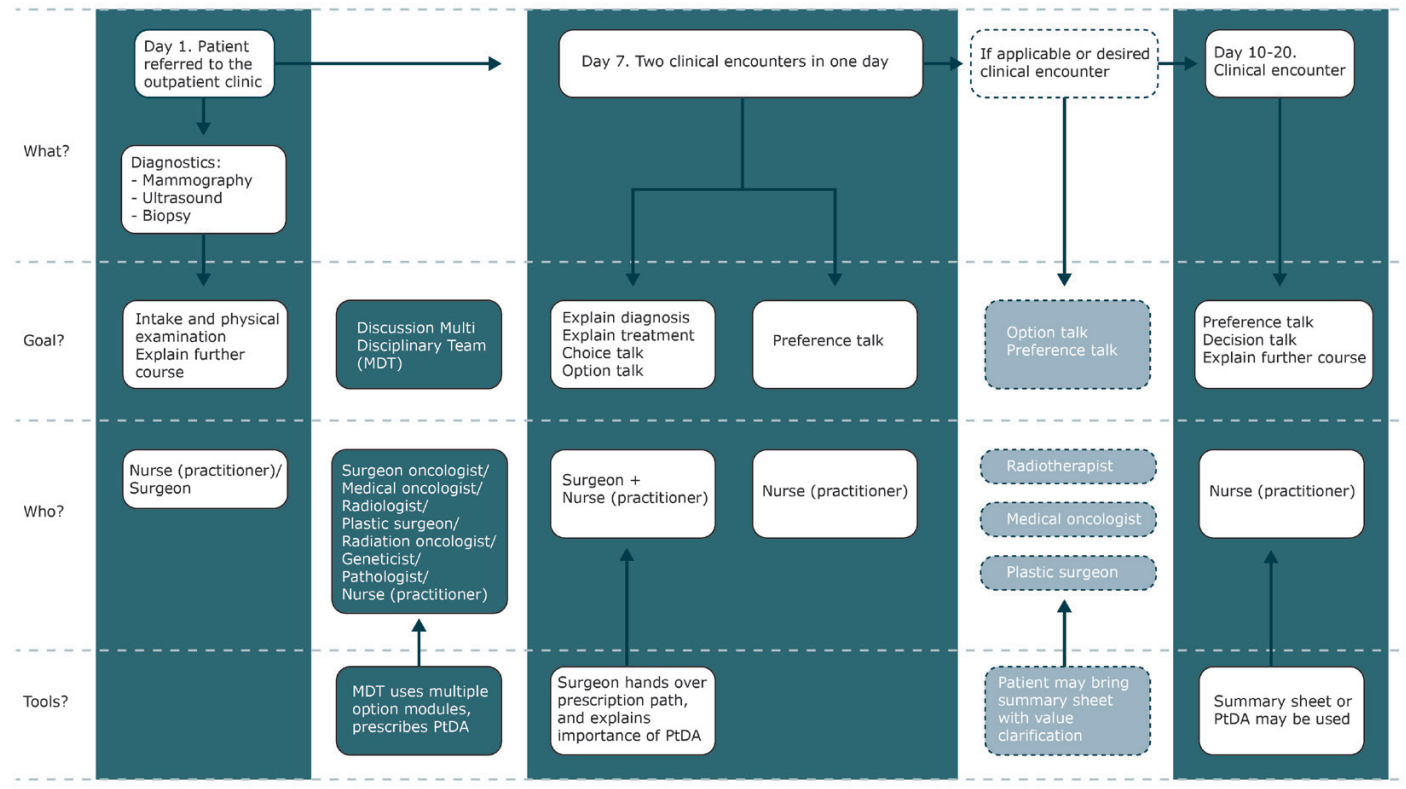

A third theme lies in the presentation of the PtDA. In our process evaluation we found that clear explanation and encouragement on how and why to use the PtDA seemed to promote an increased uptake and use by patients. However, we also had the idea that the expectations of patients with regard to the PtDA, and the content of the subsequent consultations were high. Patients with a high level of education, who used the PtDA more often than patients with a low level of education, were sometimes disappointed about the way the preferences and values and ultimate decision was discussed. So, if PtDAs are distributed, clinicians need to be clear to patients on what can be expected in the consultation to come. As nurses often are the clinicians that hand out the PtDA I would recommend nurses to pay careful attention to what is communicated with patients in this regard. Training nurses in SDM and communication skills seems to be important in this respect. 
Finally, in our research we found that the development and use of a web based PtDA may be expensive for hospitals, as some PtDA developers ask an implementation support fee and license fee. At the same time, we are confronted with the fact that, at least in the Netherlands, hospitals and insurance companies want to use more and more PtDAs, preferably web based. Clinicians should carefully evaluate the efficiency of these PtDAs against the financial costs. Stakeholders should critically consider patient's and professional's capacity, the size of the target group and weigh all the possibilities and perhaps consider simpler alternatives on decision support materials before deciding to develop one after another complex web based PtDA. Currently there seems to be a change, first, recently a guideline has been developed, with a set of minimum criteria for the development process, content and governance of patient directed knowledge tools (54). Second, patient associations together with the federation for medical specialists started to develop more option grid like decision support materials.

\section{Recommendations for research}

Several research themes emerged from the outcomes of this study. The following topics will be briefly described: the MDT, implementation strategies, and SDM for patients with low health literacy. Subsequently some recommendations with regard to the costs of SDM are made.

First, we need a better understanding on how to restructure the MDT and the impact this has on the quality of the dialogue between patients and clinicians in the consultation room with regard to SDM. We must shine our light on what is decided in the MDT and whether or not the members follow the guidelines or also take the individual patient into account. We than have to observe whether there are discrepancies between what is decided in the MDT and what is discussed with the patient. Do clinicians deviate from the MDT recommendation, that usually are based on guidelines, when confronted with the unique patient? We could also consider to make the guidelines less strict, and describe treatments as options with pros and cons instead of an advice. If well defined in the MDT this could make it easier for doctors to apply SDM. 
We need to gain knowledge on how to engage patients with low health literacy in SDM. Health literacy is important to enable the process of SDM and the use of PtDAs, however to what extent is not known yet. There are uncertainties on how to apply SDM and a PtDA to patients with different levels of health literacy (55). Patients with low health literacy have less positive experiences with SDM, they also lack the ability to find, understand and use health information (56). We should also explore what competencies, support and adaptations are needed in clinicians, patients, PtDAs to address the different levels of health literacy.

Although my research did not focus on costs of SDM in particular, we found that this could become an issue. Professionals mentioned among others, the costs of the development and hosting of PtDAs, which could become a problem. Although professionals did not always recognised the challenge, we found that some hospitals needed to adjust their pathway to ensure that it enabled the process of SDM. In our research this was just a small adjustment and a small extension of nurses' tasks. However, in the long run this could lead to extra costs. Therefore we should study actual costs and gains of SDM.

\section{About Hannah and Mary}

In the introduction of this thesis, I referred to Hanna and Mary, both having a very explicit opinion on what the best treatment was for them. Hannah had a strong preference for a mastectomy, while Mary preferred a breast conserving therapy. They both had the opportunity to be able to express their preference. Their clinicians listened and supported them. Both women felt they had an important say in the decision and were ultimately happy with the choice they made. They have taken up their lives after a very difficult period in which their spouses, friends and clinicians helped them to make an informed and well thought-through decision. Hannah even stated there has never been one minute she regretted this decision. Together with their clinicians, they choose a treatment that reflected their values, which led to a positive attitude toward the process and the decision they made. 


\section{References}

1. Scholl I, LaRussa A, Hahlweg P, Kobrin S, Elwyn G. Organizationaland system-level characteristics that influence implementation of shared decision-making and strategies to address them - a scoping review. Implement Sci. 2018;13(1):40.

2. Nederland P. Theme shared decision making https://www. patientenfederatie.nl/themas/samen-beslissen/ [

3. Herrmann A, Mansfield E, Hall AE, Sanson-Fisher R, Zdenkowski $N$. Wilfully out of sight? A literature review on the effectiveness of cancer-related decision aids and implementation strategies. BMC medical informatics and decision making. 2016;16:36.

4. BVN. Keuzehulp borstkanker Zorgkeuzelab https://borstkanker. $\mathrm{nl} / \mathrm{nl} /$ keuzehulp/operatie/zorgkeuzelab-keuzehulp-borstkanker: Borstkanker Vereniging Nederland; [updated April 2018.

5. Warren S, Vincent C. "This won't take long...": Interviewing, ethics and diversity. International Journal of Qualitative Studies in Education. 2001;14(1):39-53.

6. Ishikawa $\mathrm{H}$, Yano E. Patient health literacy and participation in the health-care process. Health expectations : an international journal of public participation in health care and health policy. 2008;11(2):11322.

7. McAllister M. Shared decision making, health literacy, and patient empowerment. In: Elwijn G, Edwards A, Thompson R, editors. Shared decision making in health care2016. p. 234 -8.

8. Rowlands G, Protheroe J, Winkley J, Richardson M, Seed PT, Rudd R. A mismatch between population health literacy and the complexity of health information: an observational study. British Journal of General Practice. 2015;65(635):e379-e86.

9. Wigfall LT, Tanner AH. Health Literacy and Health-Care Engagement as Predictors of Shared Decision-Making Among Adult Information Seekers in the USA: a Secondary Data Analysis of the Health Information National Trends Survey. Journal of Cancer Education. 2018;33(1):67-73.

10. Stacey D, Legare F, Col NF, Bennett CL, Barry MJ, Eden KB, Holmes-Rovner M, Llewellyn-Thomas $H$, Lyddiatt A, Legare $F$, Thomson, R.Decision aids for people facing health treatment or screening decisions. The Cochrane database of systematic reviews. 2014(1):CD001431.

11. Coulter A, Stilwell D, Kryworuchko J, Mullen PD, $\mathrm{Ng} \mathrm{CJ}$, van der Weijden T. A systematic development process for patient decision aids. BMC medical informatics and decision making. 2013;13(2):S2. 
12. Dugas M, Trottier M-È, Chipenda Dansokho S, Vaisson G, Provencher T, Colquhoun H, Dogba Maman J, Dupéré S, Fagerlin Angela, Giguere AMC, Haslett L, Hoffman A, Ivers NM, Légaré F, Légaré J, Levin CA, Menear M, Renaud JS, Stacey D, Volk RJ, Witteman HO.Involving members of vulnerable populations in the development of patient decision aids: a mixed methods sequential explanatory study. BMC medical informatics and decision making. 2017;17(1):12.

13. Plaisance A, Witteman HO, LeBlanc A, Kryworuchko J, Heyland DK, Ebell MH, Blair L, Tapp D, Dupuis A, Lavoie-Bérard CA, McGinn $C A$, Légaré $F$, Archambault PM. Development of a decision aid for cardiopulmonary resuscitation and invasive mechanical ventilation in the intensive care unit employing user-centered design and a wiki platform for rapid prototyping. PLOS ONE. 2018;13(2):e0191844.

14. Garvelink MM, Emond J, Menear M, Brière N, Freitas A, Boland L, Perez MMB, Blair L, Stacey D, Légaré F. Development of a decision guide to support the elderly in decision making about location of care: an iterative, user-centered design. Research Involvement and Engagement. 2016;2(1):26.

15. McNeil H, Elliott J, Ashbourne J, Heckman G, Walker J, Stolee P. Engaging older adults in healthcare research and planning: a realist synthesis. Research Involvement and Engagement. 2016;2.

16. Witteman HO, Dansokho SC, Colquhoun H, Coulter A, Dugas M, Fagerlin A, Giguere A, Glouberman S, Haslett L, Hoffman A, Ivers $\mathrm{N}$, Légaré $\mathrm{F}$, Légaré $\mathrm{J}$, Levin $\mathrm{C}$, Lopez $\mathrm{K}$, Montori $\mathrm{V}$, Provencher $\mathrm{T}$, Renaud JS, Sparling K, Stacey D, Vaisson G, Volk RJ, Witteman W. User-centered design and the development of patient decision aids: protocol for a systematic review. Systematic Reviews. 2015;4(1):11.

17. Osaka W, Nakayama K. Effect of a decision aid with patient narratives in reducing decisional conflict in choice for surgery among early-stage breast cancer patients: A three-arm randomized controlled trial. Patient education and counseling. 2017;100(3):55062.

18. Austin C, Mohottige D, Sudore RL, Smith AK, Hanson LC. Tools to promote shared decision making in serious illness: A systematic review. JAMA Internal Medicine. 2015;175(7):1213-21.

19. Syrowatka A, Krömker D, Meguerditchian AN, Tamblyn R. Features of Computer-Based Decision Aids: Systematic Review, Thematic Synthesis, and Meta-Analyses. Journal of Medical Internet Research. 2016;18(1):e20.

20. Durand MA, Witt J, Joseph-Williams N, Newcombe RG, Politi MC, Sivell S, Elwyn G. Minimum standards for the certification of patient decision support interventions: feasibility and application. Patient education and counseling. 2015;98(4):462-8. 
21. Stacey $D$, Bennett $C L$, Barry MJ, Col NF, Eden KB, HolmesRovner M, Llewellyn-Thomas $H$, Lyddiatt A, Legare $F$, Thomson, R. Decision aids for people facing health treatment or screening decisions. The Cochrane database of systematic reviews. Syst Rev. 2014;1:CD001431..

22. Sherman KA, Shaw LK, Jørgensen L, Harcourt D, Cameron L, Boyages J, Elder E, Kirk J, Tucker K.Qualitatively understanding patients' and health professionals' experiences of the BRECONDA breast reconstruction decision aid. Psycho-Oncology. 2017;26(10):1618-24.

23. Sherman KA, Harcourt DM, Lam T, Shaw LK, Boyages J, BRECONDA: Development and acceptability of an interactive decisional support tool for women considering breast reconstruction. Psycho-Oncology. 2014;23(7):835-8.

24. Agoritsas T, Heen AF, Brandt $L$, Alonso-Coello P, Kristiansen A, Akl EA, Neumann I, Tikkinen KAO, van der Weijden T. Elwyn G, Montori VM, Guyatt GH, Vandvik PO. Decision aids that really promote shared decision making: the pace quickens. BMJ : British Medical Journal. $2015 ; 350$.

25. Joseph-Williams N, Lloyd A, Edwards A, Stobbart L, Tomson D, Macphail S, Dodd C, Brain K, Elwyn G, Thomson R. Implementing shared decision making in the NHS: lessons from the MAGIC programme. BMJ (Clinical research ed). 2017;357:j1744.

26. Elwyn G, Frosch DL, Kobrin S. Implementing shared decisionmaking: consider all the consequences. Implement Sci. 2016;11:114.

27. Muller E, Hahlweg P, Scholl I. What do stakeholders need to implement shared decision making in routine cancer care? A qualitative needs assessment. Acta Oncol. 2016;55(12):1484-91.

28. van Veenendaal $H$, van der Weijden $T$, Ubbink DT, Stiggelbout AM, van Mierlo LA, Hilders CGJM. Accelerating implementation of shared decision-making in the Netherlands: An exploratory investigation. Patient education and counseling. 2018.

29. Berger-Hoger B, Liethmann K, Muhlhauser I, Steckelberg A. Implementation of shared decision-making in oncology: development and pilot study of a nurse-led decision-coaching programme for women with ductal carcinoma in situ. BMC medical informatics and decision making. 2017;17(1):160.

30. Elwyn G, Durand MA, Song J, Aarts J, Barr PJ, Berger Z, Cochran N, Frosch D, Galasinski D, Gulbrandsen P, Han PKJ, Carter M, Kinnersley P, Lloyd A, Mishra M, Perestelo-Perez L, Scholl I, Tomori K, Trevena L, Witteman HO, Van der Weijden T. A three-talk model for shared decision making: multistage consultation process. BMJ (Clinical research ed). 2017;359:j4891. 
31. Kane HL, Halpern MT, Squiers LB, Treiman KA, McCormack LA. Implementing and evaluating shared decision making in oncology practice. CA Cancer J Clin. 2014;64(6):377-88.

32. Joseph-Williams N, Elwyn G, Edwards A. Knowledge is not power for patients: A systematic review and thematic synthesis of patientreported barriers and facilitators to shared decision making. Patient education and counseling. 2014;94(3):291-309.

33. Squires JE, Sullivan K, Eccles MP, Worswick J, Grimshaw JM. Are multifaceted interventions more effective than single-component interventions in changing health-care professionals' behaviours? An overview of systematic reviews. Implementation Science. 2014;9(1):152.

34. Lamb BW, Taylor C, Lamb JN, Strickland SL, Vincent C, Green JSA, Sevdalis N.. Facilitators and Barriers to Teamworking and Patient Centeredness in Multidisciplinary Cancer Teams: Findings of a National Study. Annals of Surgical Oncology. 2013;20(5):1408-16.

35. Taylor C, Brown K, Lamb B, Harris J, Sevdalis N, Green JSA. Developing and Testing TEAM (Team Evaluation and Assessment Measure), a Self-assessment Tool to Improve Cancer Multidisciplinary Teamwork. Annals of Surgical Oncology. 2012;19(13):4019-27.

36. Hamilton DW, Heaven B, Thomson RG, Wilson JA, Exley C. Multidisciplinary team decision-making in cancer and the absent patient: a qualitative study. BMJ open. 2016;6(7).

37. Restivo L, Apostolidis T, Bouhnik A-D, Garciaz S, Aurran T, JulianReynier C. Patients' Non-Medical Characteristics Contribute to Collective Medical Decision-Making at Multidisciplinary Oncological Team Meetings. PLOS ONE. 2016;11(5):e0154969.

38. Hahlweg P, Hoffmann J, Härter M, Frosch DL, Elwyn G, Scholl I. In Absentia: An Exploratory Study of How Patients Are Considered in Multidisciplinary Cancer Team Meetings. PLOS ONE. 2015;10(10):e0139921.

39. Barr PJ, Elwyn G. Measurement challenges in shared decision making: putting the 'patient' in patient-reported measures. Health expectations : an international journal of public participation in health care and health policy. 2016;19(5):993-1001.

40. Stiggelbout AM, Pieterse AH, De Haes JCJM. Shared decision making: Concepts, evidence, and practice. Patient education and counseling. 2015;98(10):1172-9.

41. Kunneman $M$, Pieterse AH, Stiggelbout AM, Nout RA, Kamps $M$, Lutgens LCHW, Paulissen J, Mattheussens OJA, Kruitwagen RFPM, Creutzberg CL. Treatment preferences and involvement in treatment decision making of patients with endometrial cancer and clinicians. British Journal Of Cancer. 2014;111:674. 
42. Kunneman M, Marijnen CAM, Rozema T, Ceha HM, Grootenboers DARH, Neelis KJ, Stiggelbout A, Pieterse A, Decision consultations on preoperative radiotherapy for rectal cancer: large variation in benefits and harms that are addressed. British Journal Of Cancer. 2014;112:39.

43. Pollard S, Bansback N, Bryan S. Physician attitudes toward shared decision making: A systematic review. Patient education and counseling. 2015;98(9):1046-57.

44. Gulbrandsen P, Dalby AML, Ofstad EH, Gerwing J. Confusion in and about shared decision making in hospital outpatient encounters.

Patient education and counseling. 2014;96(3):287-94.

45. Dunning D, Johnson K, Ehrlinger J, Kruger J. Why People Fail to Recognize Their Own Incompetence. Current Directions in Psychological Science. 2003;12(3):83-7.

46. Mangla M, Cha TD, Dorrwachter JM, Freiberg AA, Leavitt LJ, Rubash $\mathrm{HE}$, Simmons LH, Wendell EL, Sepucha KR. Increasing the use of patient decision aids in orthopaedic care: results of a quality improvement project. BMJ quality \& safety. 2018;27(5):347-54.

47. Sepucha KR, Simmons LH, Barry MJ, Edgman-Levitan S, Licurse AM, Chaguturu SK. Ten Years, Forty Decision Aids, And Thousands Of Patient Uses: Shared Decision Making At Massachusetts General Hospital. Health Aff (Millwood). 2016;35(4):630-6.

48. Stacey $D$, Legare F, Breire N. Engaging clinical teams in an interprofessional approach to shared decision making. In: Elwijn G, Edwards A, Thompson R, editors. Shared desicion making in health care2016. p. 64 - 9.

49. Sieck CJ, Johansen $M$, Stewart J. Inter-professional shared decision making - increasing the "shared" in shared decision making. International journal of healthcare. 2016;2(1).

50. Lenzen SA, Daniels R, van Bokhoven MA, van der Weijden T, Beurskens $A$. What makes it so difficult for nurses to coach patients in shared decision making? A process evaluation. International journal of nursing studies. 2018;80:1-11.

51. Stacey D, Kryworuchko J, Belkora J, Davison BJ, Durand M-A, Eden KB, Hoffman S. Koerner M, Légaré F, Loiselle MC, Street RL. Coaching and guidance with patient decision aids: A review of theoretical and empirical evidence. BMC medical informatics and decision making. 2013;13(2):S11.

52. de Visser SM, Woiski MD, Grol RP, Vandenbussche FPHA, Hulscher MEJL, Scheepers HCJ, Hermens RPMG. Development of a tailored strategy to improve postpartum hemorrhage guideline adherence. BMC Pregnancy and Childbirth. 2018;18(1):49.

53. Coulter A, Edwards A, Entwistle V, Kramer G, Nye A, Thomson $\mathrm{R}$, Walker E. Shared decision making in the UK: Moving towards wider uptake. Zeitschrift für Evidenz, Fortbildung und Qualität im Gesundheitswesen. 2017;123-124:99-103. 
54. Weijden Tvd, Dreesens $D$, Faber MJ, Bos N, Drenthen T, Maas I, Kersten, S., Malanda U, Scheur S, van der Post H, Knops A., Developing quality criteria for patient-centred knowledge tools related to clinical practice guidelines. A development and consensus study. Health expectations. 2018.

55. Malloy-Weir LJ, Charles C, Gafni A, Entwistle VA. Empirical relationships between health literacy and treatment decision making: A scoping review of the literature. Patient education and counseling. 2015;98(3):296-309.

56. Rademakers J, Heijmans M. Beyond Reading and Understanding: Health Literacy as the Capacity to Act. International Journal of Environmental Research and Public Health. 2018;15(8):1676. 
Summary 
Chapter 1 describes the background and objectives of this thesis. In current Dutch health care, shared decision making (SDM) is strongly promoted by the government, Dutch Patient Federation and health policy makers. Despite this, the actual implementation in clinical practice remains difficult. This thesis is focused on the challenge of implementation of shared decision making in early stage breast cancer care. In our project we developed a patient decision aid (PtDA) for women with early-stage breast cancer and exposed motivated breast cancer teams to a multi-faceted implementation strategy. The thesis is built around four research questions:

How to develop, improve and alpha test a PtDA for surgical treatment of early stage breast cancer and how to ensure that usability, comprehensibility and acceptability of the tool itself meets the standards and requirements of professionals and patients?

What is the uptake of the SDM implementation strategies in breast cancer care by professionals and the perceived uptake and use of a PtDA by breast cancer patients?

What are the experiences of patients with regard to the SDM process in breast cancer and the usefulness of the PtDA?

What are the experiences and perceived barriers and facilitators of professionals with regard to the SDM process in breast cancer care?

Chapter 2 reports the development of the patient decision aid and the results of five iterative test rounds in which we interviewed 26 patients and 26 professionals. We performed an alpha test during the development of the PtDA; this is an acceptance test, to identify all possible issues before releasing a product to everyday users. To ensure that the developed PtDA was considered usable, comprehensible and acceptable, and meeting the requirements of both professionals and patients, we saw to it that both groups of stakeholders had a significant influence on content, layout and structure. The aim of this qualitative study was to develop a generic early stage breast cancer PtDA, which could be used across the Netherlands. This was a challenging process, as some professionals preferable used the specific local hospital performance indicators in the PtDA. However, we used outcome estimates based on indicators from Dutch cancer organisations expressed in exact numbers, alternating with ranges in which professionals, not only from specific hospitals but throughout the Netherlands, could recognise their level of performance.

We engaged professionals from different hospitals in the alpha test, thus enabling them to contribute to the content. This decreased their resistance towards the idea of using a PtDA and increased their sense of ownership. 
It was a challenge to reach consensus between patients and professionals regarding some facts and figures of certain outcomes. The research team and developers decided, as there was no scientific evidence for patients' views, and after thorough literature search, not to adjust the facts and figures. Also some difference of opinion occurred between professionals. In these cases literature was reviewed and clinicians in relevant disciplines were asked for input. After thorough considerations the content was adjusted or not. While the research group opted for simplicity in the PtDA in the interest of implementation, the clinicians objected that the complexity of the decision could not be ignored. Given this complexity in early-stage breast cancer, we chose for a web based PtDA which could provide the comprehensive information required but with a functionality to personalise the PtDA to prevent information overload. Eventually, the development of the PtDA was a time consuming, prolonged and expensive process.

Chapter $\mathbf{3}$ describes the protocol of a pre-post implementation study to beta test the patient decision aid and the related implementation strategies. The objective was to pilot-test and optimise strategies for the implementation of SDM for patients with early-stage breast cancer in an actual clinical setting. We hypothesised that a multi-facetted strategy would enable us to implement SDM in a way that it met the needs of both professionals and patients, without disrupting daily practice. The protocol describes an implementation strategy consisting of a PtDA, instructions regarding SDM, and suggestions for integrating the patient decision aid in the clinical pathway. Accept for the PtDA, the intervention was tailored, with a certain degree of local adaptation allowed for each hospital and department. The protocol describes the methods to evaluate barriers, facilitators, needs and preferences of patients and professionals. Furthermore, it provides an overview regarding the methods to evaluate the effect of the final implementation strategy.

Chapter 4 describes the way we exposed early adopter breast cancer teams to the final multi-faceted implementation strategies with the aim to improve the process of SDM. The findings in this prospective process evaluation were based on interviewing 84 patients and auditing their patient files. The aim was to assess the uptake of the proposed strategies by professionals regarding the implementation of the PtDA. One of the proposed strategies was to use a standardized procedure to discuss and systematically report treatment options in the tumour board as well as setting and reporting the indication for using the PtDA. In the teams we observed a modest uptake of the implementation strategies. The blue print of the final implementation strategy was followed completely for $14 \%$ of the included patients; the most frequently missed step was setting the indication for the PtDA by the tumour board. 
In the tumour board report we found two treatment options recommended in $58 \%$ of the included patients, in addition we found the indication to offer the PtDA in $34 \%$ of the patients only.

Chapter $\mathbf{5}$ gives a comprehensive view on the patients' perceptions of the SDM process and the uptake and usefulness of the PtDA. The aim was to improve SDM implementation strategies by gaining insight into patients' experiences with the SDM process. The findings in this qualitative study were based on 20 interviews with patients. Most patients remembered that the clinician performed the first step of SDM, choice talk. They also remembered that they received a prescription pad sheet with a code to login to the PtDA. Of the included patients $65 \%$ actually logged in to the PtDA, of whom most personalized it and read the value clarifications. Two-third of the patients remembered they received instructions from the clinician on how and why to use the PtDA, which seems to be a strong predictor of its actual use.

With regard to the process of SDM patients felt that clinicians made an effort to inform and involve them, which resulted in patients being satisfied with the process and having experienced SDM. Choice talk and option talk was performed to the liking of patients. Patients felt well informed and it was clear to them, even when clinicians' phrasing contained some implicit opinion, instead of a neutrally framed advice, they had decided which treatment option would be the best for them. Elicitation of preferences was limited according to the patients, both during the first consultation as well as during the follow-up consultation, after patients used the PtDA. Patients who used the PtDA appreciated it and evaluated it as useful to recall all information given, but the way patients used the PtDA showed a wide variation on time spent reading the information and completing the value clarification.

Experiences and perceived barriers and facilitators of professionals with regard to the SDM process are described in chapter 6 . In this qualitative study we interviewed 27 clinicians, using a structured interview guide. Prior to the interviews we collected quantitative data by audiotaping consultations and analysing these with the Observer OPTION5. These objective data were used to enrich our interview guide. The study aimed to further improve implementation strategies for shared decision making. Although some clinicians were reluctant to use SDM and a PtDA, in general, clinicians were aware of its relevance. Within the breast cancer teams every professional was expected to take responsibility, with an important role for breast cancer nurses. Doctors delegated the uptake of the PtDA in the clinical pathway, intentionally or unconsciously, to nurses. In these early adopter breast cancer teams we found glimpses of true SDM behaviour. 
Still, misconceptions, paternalism and scepticism, as well as a limited implementation of SDM appeared, even in best practice examples. Most clinicians seemed to lack a deeper understanding of what SDM is actually about, as they primarily focused on the first steps of SDM, the team/choice talk and option talk, neglecting preference and decision talk. Important barriers mentioned were the rather fixed treatment recommendations set by the tumour board, even in case of preferencesensitive decisions, and the conflict between the time that is needed for the SDM process and the benchmarks for timely treatment required for quality of care indicators from the National Breast Cancer Audit.

Chapter 7 provides a short overview of the main findings of this thesis followed by $s$ reflection on methodological strengths and limitations. Subsequently the chapter presents some of the main issues we encountered and how this thesis contributed to development of a PtDA and the implementation of SDM in breast cancer care. The findings presented in this thesis illustrate the main challenges we need to face if we want to close the gap between the desirable and actual level of SDM. One of this challenges is to convince professionals we need more than PtDAs and training. We need to encourage them, to review their own SDM performance and to reassess care pathways, including the MDT in a manner that it facilitates SDM. In practice we would like to recommend professionals to remain critical with regard to the development of comprehensive PtDAs and carefully evaluate the efficiency of these PtDAs against the financial costs. 


\section{Nederlanse samenvating}


Samen beslissen binnen de Nederlandse gezondheidszorg wordt door de overheid, de Nederlandse Patiëntenfederatie en nationale beleidmakers sterk aanbevolen. Desondanks blijkt de implementatie in de dagelijkse praktijk moeilijk. Deze thesis beschrijft implementatieonderzoek van samen beslissen binnen de zorg voor vrouwen met vroeg stadium borstkanker. Voor deze studie is een keuzehulp ontwikkeld, in samenwerking met de eindgebruikers, voor vrouwen met vroeg stadium borstkanker. In overleg met de borstkankerteams die werden beschouwd als voorlopers zijn implementatie strategieën gericht op de belangrijkste knelpunten en behoeften en opgebouwd uit meerdere facetten, ontwikkeld, onderzocht, en verder verbeterd.

Hoofdstuk 1, de introductie beschrijft de achtergrond en doelen van deze thesis. De vier onderzoeksvragen die geformuleerd waren, zijn: Hoe kan een keuzehulp worden ontwikkeld, voor de behandeling van vrouwen met vroeg stadium borstkanker, die voldoet aan de wensen en maatstaven van zorgprofessionals en patiënten met betrekking tot bruikbaarheid, begrijpelijkheid en acceptatie?

1. Hoe worden de implementatiestrategieën voor samen beslissen uitgevoerd en geaccepteerd door zorgprofessionals, en hoe ervaren en gebruiken patiënten met vroeg stadium borstkanker de keuzehulp?

2. Wat zijn de ervaringen van patiënten met vroeg stadium borstkanker met betrekking tot het proces van samen beslissen en de impact van de keuzehulp?

3. Wat zijn de ervaringen en waargenomen belemmerende en bevorderende factoren van zorgprofessionals ten aanzien van het proces van samen beslissen in de borstkanker zorg?

Hoofdstuk 2 beschrijft de ontwikkeling en de resultaten van vijf opeenvolgende test rondes van de keuzehulp. Tijdens de ontwikkeling van de keuzehulp, in samenwerking met Zorgkeuzelab $\AA$, werd een alpha test uitgevoerd door middel van interviews met 26 patiënten en 26 zorgprofessionals. Met een alpha test wordt software in een vroeg stadium getest om alle mogelijke problemen en gebruiksongemakken eruit te halen voordat het product wordt aangeboden voor daadwerkelijk gebruik door de eindgebruikers. Deze test werd in vijf verschillende rondes uitgevoerd, met steeds nieuwe patiënten en zorgprofessionals. Zorgprofessionals uit verschillende borstkankerteams in Nederland werden betrokken bij de alpha test om hen zodoende de gelegenheid te geven bij te dragen aan de inhoud van de keuzehulp. We verwachtten dat dit hun weerstand tegen het gebruik van een keuzehulp zou verminderen en hun gevoel van medeverantwoordelijkheid voor de keuzehulp zou verhogen. 
In de eerste ronde werden de meeste problemen onderkend, vervolgens werden in de volgende rondes de restproblemen gevonden. Om te zorgen dat de keuzehulp voor alle belanghebbenden voldeed aan de eisen van bruikbaarheid en begrijpelijkheid en men bereid was om de keuzehulp in de praktijk te gebruiken, kregen zowel de zorgprofessionals als ook de patiënten veel invloed op de inhoud, structuur en de layout van de keuzehulp. Het doel van deze kwalitatieve studie was om een generieke keuzehulp voor de behandeling van vroeg stadium borstkanker te maken, die door borstkanker teams in heel Nederland gebruikt zou kunnen worden.

Dit was om verschillende redenen een uitdagend proces. Zo wensten verschillende zorgprofessionals dat bij voorkeur de lokale ziekenhuis specifieke prestatie indicatoren in de keuzehulp werden gebruikt. In de keuzehulp werden uitkomstmaten gebruikt die gebaseerd waren op data van de Nederlandse Kankerregistratie en de NBCA (Nationaal Borstkanker Overleg Nederland Breast Cancer Audit). De uitkomstmaten werden weergegeven in gemiddelden met variaties waarin zorgprofessionals van alle ziekenhuizen hun eigen prestaties zouden kunnen herkennen.

Het was niet makkelijk om consensus tussen zorgprofessionals en patiënten te bereiken met betrekking tot feiten, grafieken en uitkomsten in de keuzehulp. Het onderzoeks- en ontwikkelteam besliste om feiten en figuren niet aan te passen aan wensen van patiënten bij gebrek aan wetenschappelijk bewijs. Ook de zorgprofessionals verschilden op een aantal aspecten onderling van mening. Deed zich dit voor, dan werd de literatuur opnieuw bekeken en andere professionals uit de betreffende disciplines geraadpleegd.

Vanaf het begin streefde de onderzoeksgroep omwille van implementatie overwegingen naar eenvoud in de keuzehulp. De zorgprofessionals gaven aan dat een eenvoudige keuzeondersteuning onvoldoende ondersteuning zou bieden gezien de complexiteit van de beslissing. Uiteindelijk is daarom een digitale keuzehulp met veel informatie ontwikkeld om recht te doen aan alle keuzemogelijkheden. Deze kan middels een receptenblaadje waarop de chirurg de keuzemogelijkheden voor elke individuele patiënt kan aankruisen, gepersonaliseerd worden om te voorkomen dat patiënten belast worden met irrelevante informatie. Al met al was de ontwikkeling van de keuzehulp een tijdrovend, twee jaar durend, een kostbaar maar uiteindelijk lonend proces. 
Hoofdstuk 3 beschrijft het protocol van de pre- en postimplementatiestudie om de keuzehulp en de aanverwante implementatiestrategieën in de praktijk te testen. Het doel was om een pilot te doen van alle strategieën om samen beslissen in de dagelijkse praktijk van de borstkankerzorg te implementeren en deze vervolgens daar waar nodig aan te passen. Onze hypothese was dat een strategie bestaande uit meerdere facetten, rekening houdend met de wensen van zorgprofessionals en patiënten, zou bijdragen aan een duurzame implementatie van samen beslissen, zonder de dagelijkse praktijk te verstoren. Het protocol beschrijft de volledige implementatiestrategieën bestaande uit: een keuzehulp, instructies over hoe samen beslissen in de praktijk wordt uitgevoerd, en suggesties over de integratie van de keuzehulp in het zorgpad. Op de keuzehulp na, die generiek is voor alle teams, werden de implementatiestrategieën voor ieder borstkankerteam op maat gemaakt, rekening houdend met bestaande processen en werkwijzen. Het protocol beschrijft het design van een prospectieve procesevaluatie en een pre-post effect evaluatie van de implementatiestrategieën.

Het doel van hoofdstuk 4 was te onderzoeken in hoeverre de teams van zorgprofessionals de voorgestelde strategieën om de keuzehulp te implementeren daadwerkelijk gebruikten. De teams kregen het advies om gestandaardiseerde procedures te gebruiken tijdens de multidisciplinaire patiënten bespreking (MDO): 1) bespreek opties en leg deze opties vast in het dossier in plaats van een vastomlijnd behandelplan met slechts één optie, 2) stel tijdens het MDO een indicatie voor het gebruik van de keuzehulp en leg dit eveneens vast. De resultaten zijn gebaseerd op gestructureerd dossieronderzoek bij 84 patiënten die voor meerdere behandelopties in aanmerking kwamen. Deze patiënten werden ook geïnterviewd met een gestructureerde vragenlijst.

De teams namen de volledige voorgestelde procedure beperkt over: slechts bij $14 \%$ van de geïncludeerde patiënten werd de voorgestelde procedure volledig gevolgd. Bij $58 \%$ van de geïncludeerde patiënten vonden we meerdere behandelopties die in het MDO waren vastgesteld en vastgelegd in het dossier. Het advies om de indicatie voor het gebruik van de keuzehulp te stellen tijdens het MDO en dit te registreren in het patiënt dossier werd het minst opgevolgd. In 34\% van de dossiers vonden we een indicatie voor het aanbieden van een keuzehulp. 
Hoofdstuk 5 beschrijft de ervaringen van patiënten met het proces van samen beslissen, de gebruikte procedure om te keuzehulp aan te bieden en de bruikbaarheid van de keuzehulp. Het doel was om de strategieën voor de implementatie van samen beslissen te verbeteren door inzicht te krijgen in de ervaringen van patiënten.

De resultaten van deze kwalitatieve studie zijn gebaseerd op kwalitatieve interviews met 20 patiënten. De meeste patiënten herinnerden zich dat de zorgprofessional de eerste stap van het samen beslissen proces ("er is iets te kiezen, en ik wil dat graag samen met u doen") had toegepast. De meeste patiënten benoemden ook dat ze een receptenblaadje hadden ontvangen met daarop de, voor deze patiënt beschikbare behandelopties, een inlogcode en het webadres voor de keuzehulp. Van de geïncludeerde patiënten had $65 \%$ daadwerkelijk ingelogd op de website van de keuzehulp. De meerderheid van de patiënten die inlogden hadden de keuzehulp gepersonaliseerd en de waarde verhelderende stellingen ingevuld. Twee derde van de geïncludeerde patiënten benoemden expliciete instructie door de zorgprofessional over waarom en hoe de keuzehulp te gebruiken. Deze instructie lijkt een relevante bijdrage te leveren aan het daadwerkelijke gebruik van de keuzehulp.

Patiënten hadden het gevoel dat de zorgprofessionals echt moeite deden om hen te informeren en betrekken bij de beslissing. Ze waren tevreden over het proces en vonden dat er sprake was geweest van gezamenlijke besluitvorming. Patiënten waren tevreden over de eerste twee stappen van samen beslissen (bespreken keuze en de opties) en voelden zich goed geïnformeerd. Zelfs als de zorgprofessional impliciet een eigen voorkeur formuleerde, hadden patiënten toch het gevoel dat zijzelf de beslissing namen over de behandeling die het beste bij hen paste. De derde stap van samen beslissen, het uitvragen van voorkeuren en de reden daarvan, bleef beperkt zowel tijdens het eerste consult als ook in de loop van het proces, nadat de patiënt de keuzehulp had gebruikt. Patiënten die de keuzehulp hadden gebruikt waren positief, vooral om de reeds mondeling ontvangen informatie nog een keer terug te kunnen lezen. De manier waarop patiënten de keuzehulp gebruikten varieerde met betrekking tot de leestijd, wat er gelezen werd en het wel of niet volledig invullen van de waarden verhelderende stellingen. 
Hoofdstuk 6 beschrijft de ervaren belemmerende en bevorderende factoren met betrekking tot samen beslissen bij zorgprofessionals. Het doel van deze studie was de strategieën om samen beslissen te implementeren verder te verbeteren. Voor deze kwalitatieve studie werden 27 zorgprofessionals uit zeven ziekenhuizen geïnterviewd. Voorafgaand aan de interviews werden een aantal kwantitatieve data verzameld, door consulten in de spreekkamer op te nemen en te analyseren met de Observer OPTION5 waarbij we in deze voorloper borstkankerteams een beperkte implementatie van samen beslissen zagen, meestal beperkt tot de eerste twee stappen in het proces van samen beslissen. De data werden gebruikt om de interviews te verrijken.

Hoewel enkele zorgprofessionals terughoudend waren in het toepassen van samen beslissen en het gebruiken van een keuzehulp, was men zich over het algemeen wel bewust van de relevantie van samen beslissen. Men ging binnen de borstkankerteams uit van individuele verantwoordelijkheid van ieder teamlid met betrekking tot de uitvoering van samen beslissen. De professionals zagen een belangrijke rol hierin weggelegd voor de verpleegkundigen en verpleegkundig specialisten. Artsen delegeren dan ook het aanbieden van de keuzehulp bewust of onbewust aan de verpleegkundigen of verpleegkundig specialisten. Veel zorgprofessionals ontbreekt het aan kennis over wat samen beslissen nu eigenlijk is. Met name de belangrijke laatste stappen, het uitvragen van voorkeuren en het daadwerkelijk beslissingsgesprek werden nauwelijks toegepast. Tot de belangrijke belemmeringen om samen te beslissen goed te implementeren, behoorden 1 ) het vastleggen van een min of meer vastomlijnd behandelplan met slechts één optie in het MDO, 2) het ontbreken van kennis over het model van samen beslissen, 3) het conflict tussen de tijd die nodig is om samen beslissen goed vorm te geven en voldoen aan de kwaliteitsindicatoren met betrekking tot de doorlooptijd van een behandeling. 
Hoofdstuk 7 bevat een samenvatting van de belangrijkste bevindingen uit de studies, een reflectie op de sterke en zwakke punten van de onderzoeksmethoden, gevolgd door discussie over belangrijke kwesties die zich voordeden tijdens het onderzoek, zoals: de verschillen van mening over de inhoud van de keuzehulp tussen patiënten en professionals; de plek van samen beslissen en de keuzehulp in het zorgpad en de rol van het MDO in het proces van samen beslissen. Deze thesis draagt bij aan de implementatie van samen beslissen binnen de borstkankerzorg doordat de resultaten en conclusies uit deze thesis belangrijke uitdagingen illustreren die ons te wachten staan als we de kloof tussen het gewenste niveau van samen beslissen en het daadwerkelijke niveau willen verkleinen.

Een van de grootste uitdagingen is, om zorgprofessionals te overtuigen dat we meer nodig hebben dan alleen trainingen en keuzehulpen om daadwerkelijk invulling te geven aan het proces van samen beslissen. We moeten hen aanmoedigen om hun eigen prestaties op het gebied van samen beslissen kritisch te beoordelen. Daarnaast is het zinvol om zorgpaden, inclusief het MDO, opnieuw te beoordelen en deze zodanig in te richten dat ze samen beslissen bevorderen. De thesis eindigt met aanbevelingen voor verder onderzoek, zoals: de structuur en inhoud van het MDO; meer inzicht krijgen in samen beslissen bij mensen met lage gezondheidsvaardigheden en de kostenaspecten die gemoeid zijn met samen beslissen. Tenslotte worden aanbevelingen voor de praktijk genoemd, zoals: een kritische houding ten aanzien van het ontwikkelen van omvangrijke keuzehulpen en zorgvuldige afweging van de baten en efficiency van digitale keuzehulpen tegen de kosten. 
Valorisation 
The process of disseminating scientific knowledge, and making it available for society, is called valorisation of knowledge. This chapter describes the valorisation potentials of this thesis. This thesis explored the implementation of shared decision making in breast cancer teams. The results described in this thesis can be relevant for patients, health care professionals, scientific community, insurance companies and patient associations.

\section{Patients}

Patient become more and more empowered, and are eager to learn about the consequences of treatment and therapies on their quality of life. At the same time, developments in health care are rapidly increasing. As more treatments become available, patients should get the opportunity to make a well-informed decision on which treatment option suits their situation best. Unfortunately, many patients are faced with a poorly executed process of SDM. Results of this study have been communicated with breast cancer care professionals in the Netherlands. Several breast cancer teams adopted the patient decision aid and some of the additional implementation strategies that were developed in this thesis, which might have led to an adjustment in their routines, and subsequently in improving the process of SDM. The patient association has also adapted the PtDA and made it available on their website. By doing this, the PtDA became accessible for patients in hospitals that do not use a PtDA in routine care.

\section{Health care professionals}

Health care professionals from various breast cancer teams in the Netherlands were involved in the development of the PtDA. The results of this thesis were presented to health care professionals at several national and international conferences and meetings aimed to improve communications between professionals and patients and to increase SDM. The insights of this thesis were useful to motivate professionals in various professional fields to critically review the organisation of their clinical care path and explore whether it met the requirements of SDM. The recommended implementation strategy with regard to reporting all treatment options in the Multi-Disciplinary Tumour board (MDT) has led to a critical view of this meeting. During the writing of this thesis we were asked to help re-evaluate the degree of patient centeredness and the extent to which the MDT contributes to SDM in five other clinical care pathways in head- and neck cancer, gynaecological cancer, prostate cancer, colon cancer and haematology in the MUMC+. Moreover, currently we are involved in a project to help redesign the MDT in other hospitals in the Netherlands, among which Maxima Medical Centre and University Medical Centre Utrecht, according to the Maastricht model for breast cancer. 


\section{Scientific community}

The results from this thesis contribute to current views on the development of a PtDA and the implementation of SDM. It shows the challenge to involve professionals and patients in a balanced manner in the development of a PtDA, and the compromises that are needed to get approval from both parties on the final product. The results and recommendation of this thesis were published in peer reviewed international journals and were presented at international scientific conferences. The insights generated in this thesis on the MDT structure, has led to a grant application in collaboration with several Dutch hospitals. This study aims to develop and evaluate an integrated oncological decision model that supports the formation of an individualized treatment plan.

\section{Health insurance companies}

Health insurance companies increasingly aim to influence the quality of health care for their clients in hospitals. One of their focuses is to increase SDM by promoting the use of PtDAs in hospitals. With the knowledge we gained in this thesis we participated in a national project in which health insurance companies were also involved. We presented our concerns with regard to the use of PtDAs without applying any other implementation strategies to increase SDM. The report on this project recommends health insurance companies to apply multiple strategies for implementation of SDM, as performing high quality of SDM does not only depend on the use of a PtDA. We also recommended health insurance companies to collaborate with the national SDM platform of which researchers, patient representatives, quality officials and healthcare professionals are members, to develop a set of clear components Indicators with which a hospital can demonstrate their effort to implement SDM. 


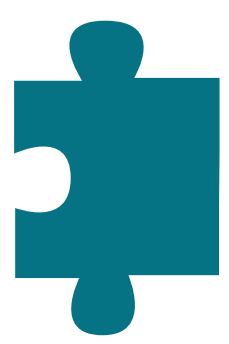

Dankwoord 
De motivatie om meer dan vijf jaar keihard te werken om een proefschrift af te krijgen breng je alleen maar op, als je heel veel lieve mensen om je heen hebt die je helpen. Ik ben dan ook blij dat ik nu eindelijk al die mensen uitgebreid mag gaan bedanken.

Prof. dr. van der Weijden, Trudy, enorm bedankt voor de mogelijkheid die je me hebt geboden. Wat heb ik geboft dat ik je leerde kennen, dat je me de gelegenheid gaf om onderzoek te gaan doen en dat je me ook nog liet promoveren. Jij gaf me kansen waarvan ik op afstand droomde, maar waarvan ik nooit had verwacht dat ze uit zouden komen. Ik kwam in een volledig nieuwe wereld terecht, jij spoorde me aan om na te denken. Je gaf me ruimte om mijn eigen weg te vinden en je was er voor me als ik het even niet meer wist. Wat een genot om met jou samen na te denken over samen beslissen in de praktijk. Je belangstelling voor mij als promovendus, maar ook als mens, als werknemer, als reiziger, voelde als een warm bad. Ik wens je heel veel succes met alle vervolg onderzoeken die er hopelijk gaan aankomen en ik hoop dat we nog in veel nieuwe ontwikkelingen samen mogen werken.

Prof. dr. Boersma, Liesbeth, ontzettend bedankt voor je altijd snelle en duidelijke reacties, je kritische maar altijd positieve kijk op alles wat ik je stuurde. Daar waar ik me al eens liet leiden door emotie zorgden jouw inzichten ervoor dat ik weer met beide benen op de grond kwam te staan. Met je heldere en uitgebreide feedback zette je me steeds weer op het goede spoor. Onze gesprekken vond ik inspirerend en ik heb dan ook voor jou als professional, maar ook als mens ontzettend veel bewondering. Ik wens je heel veel succes met alles waar je mee bezig bent, en hoop dat je in je streven naar de beste zorg voor mensen met kanker, al je ambities waar kunt maken.

Dr. Smidt, Marjolein, hartelijk dank voor alle levenslessen die je af en toe over me uitstrooide, maar ook voor je relativerende verhalen die me in een klap weer opbeurden als ik even er doorheen zat. Je krabbels in de kantlijn, nauwelijks leesbaar, zoals het voor een echte dokter hoort, waren altijd to the point, duidelijk en constructief. Je complimenten deden me goed, en kwamen vaak op een moment dat ik het kon gebruiken. Je heldere analyses hielpen me om de zaken op rij te krijgen. Ik ga onze gesprekken missen. Ik wens je heel veel succes met alles wat je doet. Ik hoop dat al je wensen en dromen uitkomen en dat je je ambities helemaal kunt waarmaken. 
Dr. Maessen, Jose, ook jou wil ik ontzettend bedanken. Jij was degene die me enthousiast maakte over samen beslissen en onderzoek doen. Jij was ook degene die me bij Trudy introduceerde, met dit prachtige proefschrift als gevolg. Nu zijn we collega's, samen op een kamer en in een onderwerp dat ons beiden aan het hart gaat. We vullen elkaar mooi aan, jij met je ongelooflijk doordachte kennis, en ik met mijn pragmatische blik. Samen vormen wij volgens mij een onverslaanbaar duo; kruisvaarders in hun tocht naar "alles beter voor de patiënt".

Dr. Moser, Albine, zonder jou had ik het volgens mij al in de eerste maanden opgegeven. Wat een worsteling om een protocol te schrijven. Elke paar weken zat je weer met mij samen om helder te krijgen wat we nu eigenlijk wilden gaan doen. Je schreef, je tekende, je maakte tabelletjes en overzichtjes om mij duidelijk te maken hoe onderzoek wordt gedaan. Je was mijn vraagbaak als het ging om kwalitatief onderzoek, en je hielp me met de worstelingen om een proces helder op papier te zetten. Mijn dank aan jou is groot en ik verheug me op verdere samenwerking.

Ook wil ik de leden van de leescommissie heel hartelijk bedanken voor het beoordelen van dit proefschrift.

Prof. dr. Kremer, Bernd, mijn dank, niet alleen voor het lezen en beoordelen van dit proefschrift, als voorzitter van deze leescommissie, maar ook voor je spontane reactie toen je gevraagd werd om deze taak op je te nemen. Jouw woorden van waardering zo nu en dan en onze inspirerende gesprekken zorgden er vaak voor dat ik mijn schouders er weer onder zette en doorging.

Prof. dr. Bos, Gerard, dank je wel voor alles wat jij in mijn 12 jarige carrière in het Maastricht UMC+ voor mij hebt betekend. Je altijd kritische houding heeft mij geleerd om niet zomaar iets voor waar aan te nemen, en als ik al met je in discussie moet, dan weet ik dat ik moet zorgen voor een goed onderbouwde mening. Dat je nu ook nog mijn proefschrift hebt gelezen en beoordeeld maakt dat het plaatje compleet is.

Ook de overige leden van de leescommissie, prof. dr. Vermeulen, dr. Engelen en dr. Jie: dank jullie wel omdat jullie je kostbare tijd hebben vrij gemaakt om deel uit te maken van deze leescommissie. 
Alle patiënten die ik in de loop van de jaren heb mogen interviewen, wil ik bedanken. Jullie lieten mij toe in jullie privé leven en deelden moeilijke en mooie herinneringen met mij. Als jullie er niet waren geweest, dan was dit proefschrift nooit tot stand gekomen. Ik hoop dat het jullie allemaal heel goed gaat.

Alle artsen, verpleegkundig specialisten en verpleegkundigen die mij te woord wilden staan, dank je. Jullie lieten mij een kijkje nemen in jullie keuken. Daarnaast rekruteerden jullie patiënten voor mij en zorgden jullie ervoor dat ik dit onderzoek kon uitvoeren. Jullie professionaliteit, integriteit, en jullie inzet voor patiënten zal ik nooit vergeten.

Mammateam Oncologiecentrum, jullie waren en zijn altijd mijn grote voorbeeld. Bij jullie leerde ik wat we goed en minder goed deden; bij jullie haalde ik op wat ik in andere ziekenhuizen weer kon gebruiken. Bedankt voor jullie bereidwilligheid om steeds met mij mee te denken en dank voor jullie belangstelling en steun al die jaren. In het bijzonder: Christel, Janine, Conny en Elly, ondanks alle drukte waren jullie toch altijd bereid om weer iets te doen voor mijn onderzoek. Ik kan jullie hiervoor niet genoeg bedanken.

Alle collega's in het Oncologiecentrum en op de afdeling Kwaliteit en Veiligheid, dank jullie voor alle belangstelling, voor jullie goede raad, voor de afleiding waar jullie voor zorgden en vooral voor jullie humor. Promoveren maakt dat je heel veel behoefte hebt aan goede grappen en gelukkig waren die er. Lieve Ingrid, dank je dat je a la minute weer even teksten voor me corrigeerde. Wat ben je toch een engel.

Drs. Fillekes, Fred, als ik in chronologische volgorde zou bedanken, dan stond jij bovenaan. Jij was degene die mij stimuleerde en motiveerde om weer te gaan studeren. Onze gesprekken over de manier waarop we in ons leven en werk stonden, zorgden ervoor dat ik besloot om je naar de universiteit te volgen. Ik wil je dan ook ontzettend bedanken dat je me overtuigde van het feit dat ik dat varkentje wel ging wassen, waarmee je uiteindelijk aan de basis van dit boekje staat. Ik hoop dat $j i j$, net als ik, voldoening vindt in alles wat je doet. 
Dit onderzoek is uitgevoerd binnen de vakgroep huisartsengeneeskunde. Ook al was ik een wat vreemde eend in de bijt, de medewerkers uit deze vakgroep hebben mij vanaf dag een welkom geheten. De collegae promovendi hadden aan een woord genoeg om te begrijpen waar ik tegenaan liep. Dat "lotgenoten contact" heeft me zo nu en dan over een dood punt geholpen. Alle lieve collega's waar ik zomaar kon binnenlopen om vragen te stellen over SPSS, NVivo of wat dan ook, mijn dank dat jullie altijd bereid waren om tijd voor mij vrij te maken en mij te woord te staan. Janine en Annemiek, mijn kamergenoten. Soms zagen we elkaar vaak, maar soms ook nauwelijks. Ieder bezig met onze eigen dingen, maar zelfs na weken van afwezigheid lukte het om de draad gewoon weer op te pikken. Ik kreeg de mogelijkheid om met jullie mijn lief en leed te delen, maar kon ook alle klaagzangen bij jullie kwijt over hoe dom ik me soms voelde, hoe zwaar het me soms viel. Jullie begrepen precies wat ik bedoelde en hielpen me door te delen dat jullie ditzelfde gevoel hadden (gehad).

Lieve DatDatMog'ers, jullie oprechte interesse en medeleven deed mij goed. Maar belangrijker nog was het feit dat ik op woensdagavond altijd even los kwam van dat proefschrift, waarvoor mijn welgemeende dank. Ik beloof niet dat ik meer ga oefenen nu de druk van mijn proefschrift achter de rug is, maar wellicht komt er eindelijk in mijn hoofd weer wat ruimte om te begrijpen waar dat hekje toe dient of waar dat kringeldingetje naartoe leidt. Mocht dat toch niet lukken, dan blijf ik gewoon die rijenvuller die blijkbaar ook erbij hoort.

Ruud, Joep en Clim, zonder jullie was dit fantastische boekje er niet geweest. Het schrijfwerk is van mij, maar de creativiteit is van jullie. Dank jullie wel voor jullie hulp bij het bedenken en ontwerpen van de layout en de omslag. Ik kon niet trotser zijn dan ik nu ben. 
Mijn lieve paranimfen, Elly en Manon. Manon, jij was degene die mij op mijn eerste dag Oncologiecentrum begroette, me onder je vleugels meesleepte naar MDO's, me wegwijs maakte in dat enorm grote ziekenhuis en me zo nu en dan liet razen als ik dat nodig had. Je was er altijd, zelfs toen je (tijdelijk) afwezig was. Wat hebben we de afgelopen jaren veel samen gelachen, gemopperd, en vooral heel hard gewerkt. Je bent een collega uit duizenden en daarom had ik geen betere paranimf kunnen kiezen. Elly, onze woensdagmiddag lunches waren jarenlang mijn rustpunt midden in de week. Even geen werk, maar wat babbelen over onze gezamenlijke interesses; koken en reizen. Je wist het niet, maar je reisde overal met mij mee naartoe. Als ik ergens een presentatie hield, een poster presenteerde, jij was er, want jouw foto was een vertrouwd plaatje in al mijn uitingen. Voor mij was dat zoiets als: "er kan niks misgaan want Elly is bij me". Meiden dank jullie dat jullie er voor me waren, dat jullie hebben bijgedragen aan mijn gevoel van thuis horen in het Oncologiecentrum en dat jullie er nu opnieuw weer voor me zijn.

Lieve familie Savelberg, als we bij elkaar zijn is het altijd gezellig. De keuvelavondjes had ik nodig om tussendoor te ontspannen. Daarom, dank jullie voor het natje en droogje en de gespreksstof die me hielpen om op te laden.

Jessie en Jean, Mia en Huub, Riny en Harrie, lieverds, wat heb ik veel steun aan jullie. Ik weet dat jullie regelmatig onderling verzuchtten: "waar gaat ze nu weer aan beginnen". Desondanks geloven jullie onvoorwaardelijk in mij en geniet ik van alle momenten die we samen zijn. Ik ervaar een gevoel voor humor dat ons bindt en dat me regelmatig door lastige momenten heen helpt. Dank jullie wel lieve schatten, omdat ik altijd jullie "kleine" zusje mag zijn. En Harrie, ik denk er nog vaak over na en ondanks dat ik heel veel heb geleerd weet het nog steeds niet: is jokeren zonder joker, nu eigenlijk jokeren? 
En dan last but not least. Leo, geen andere partner zou ja zeggen op mijn invallen voor weer een gek weekendje weg, geen andere partner zou meegaan in al mijn vreemde vakantie wensen, geen andere partner zou zonder na te denken, last minute samen met mij in de trein springen om ergens een kleine wens te laten uitkomen. En geen andere partner zou zo rustig blijven bij alle nieuwe kansen die ik krijg en neem. Vaak zelfs zonder met je te overleggen spring ik erin, boordevol energie, die jij dan gelukkig weer wat weet te doseren. Je steunt me op je eigen manier, je remt me af als je dat nodig vindt en je gunt me de kansen die ik door mijn nieuwsgierigheid steeds weer creëer. Lieverd, veel mensen zeggen vlak voor hun pensionering dat ze nu eindelijk kunnen gaan genieten van hun leven. Wij genieten al vanaf het moment dat we elkaar leerden kennen en ik weet zeker dat we dat blijven doen. Dank je voor alles wat je voor me betekent en voor me bent, nu en altijd. 


\section{About the author}




\section{Curriculum Vitae}

Wilma Savelberg-Pasmans was born on the 11th of June 1958 in Margraten, the Netherlands. After obtaining het nursing degree on the in-service education at St. Pauls and Op de Bies, she worked several years consecutively as a nurse, manager and project manager in a care taking service for mentally and physically disabled people. Here she developed an urge wanting to involve clients and their relatives to determine their living, support and activity preferences. Following her master degree in Health education and promotion at Maastricht University, she was appointed in mental health care as a program leader in a prevention program for children growing up in a family with a mentally ill or an alcohol addicted parent. She became involved in training programmes to strengthen the coping skills of children, to make them more resilient to deal with the difficult situations in their family. Thereafter, she worked in a home care organisation with the task to develop and evaluate self-management training programs to support people in coping with health issues that severely influence quality of life. In 2007 she started working as a health care scientist in the Oncology Centre in Maastricht University Medical Centre (Maastricht UMC+).

One of her tasks was to ensure that patients were properly informed about their treatment. In addition, she set up a meeting centre where patients could express all questions, uncertainties and concerns related to their illness and in which specialized professionals were available to help patients. She was also given the opportunity to regularly interview patients on experiences with the care they received, which eventually resulted in a patient panel for the Oncology Centre. She also became interested in involving patient in their treatment and how to deal with side effects of treatment. In 2013 she started her Ph.D. focussing on shared decision making (SDM) for women in early stage breast cancer. In 2017 she became involved in an implementation project to accelerate SDM in the Netherlands. Since 2018 Wilma is appointed as a staff member of the department of Quality and safety in the Maastricht UMC+ with a focus on patient participation within hospital care. 


\section{Publications}

Protocol for a pre-post implementation study on shared decision making in the surgical treatment of women with early stage breast cancer. W. Savelberg, A. Moser, M. Smidt, L Boersma, C. Haekens, T.van der Weijden BMJ Open 2015;5:e007698. doi: 10.1136/ bmjopen-2015-007698

Shared decision making in daily practice in early stage breast cancer care; how to make it work. W. Savelberg,L. Boersma, C. Haekens, M. Smidt, D. Ubbink,S. van der Mey, O. Guicherit, M. Bessems, A. Moser, T. van der Weijden European Journal of Cancer april 2016 57:S31 doi. org/10.1016/S0959-8049(16)31962-1

Developing a patient decision aid for the treatment of women with early stage breast cancer: the struggle between simplicity and complexity. W. Savelberg, T. van der Weijden, L. Boersma, M. Smidt, C. Willekens, A. Moser, BMC Medical Informatics and Decision Making BMC series - open, 2017 17:112 doi.org/10.1186/s12911-017-0505-6

Does lack of deeper understanding explain the suboptimal performance on crucial parts of shared decision making? An example from breast cancer care W. Savelberg, L. Boersma, M. Smidt, M. Goossens, R. Hermanns, T. van der Weijden European Journal of Oncology Nursing February 2019 Volume 38, Pages 92-97 doi.org/10.1016/j. ejon.2018.12.004

\section{Oral presentations international}

Implementing Shared Decision Making in early stage breast cancer. W. Savelberg, M. Smidt, L. Boersma, C. Haekens, D. Ubbink, S. van der Mey, O. Guicherit, M. Bessems, A. Moser, T. van der Weijden. International Conference on Communication in Health care (ICCH) Heidelberg, 2016 


\section{Poster presentations international}

Using a patient decision aid as part of the shared decision making process. W. Savelberg, M. Smidt, L. Boersma, C. Haekens, D. Ubbink, S. van der Mey, O. Guicherit, M. Bessems, A. Moser, T. van der Weijden. International Conference on Communication in Health care (ICCH) Heidelberg, 2016

Shared decision making in daily practice in early stage breast cancer care; how to make it work? W. Savelberg,L. Boersma, C. Haekens, M. Smidt, D. Ubbink,S. van der Mey, O. Guicherit, M. Bessems, A. Moser, T. van der Weijden. European Breast Cancer Conference, (EBCC) Amsterdam 2016

Large-scale implementation of shared decision making; action needed from tumor board to consultation room. W. Savelberg, L. Boersma, M. Smidt, T. van der Weijden. International Shared Decision Making (ISDM) conference Lyon, 2017 
